\title{
Study of Parameters Affecting the Strength of Yarns
}

\author{
Babak Farsi Dooraki \\ Department of Mechanical Engineering \\ McGill University \\ Montreal, Canada
}

February 2006

A thesis submitted to McGill University in partial fulfillment of the requirements of the degree of Master of Engineering

(C) Babak Farsi Dooraki, 2006 


$\begin{array}{ll}\begin{array}{l}\text { Library and } \\ \text { Archives Canada }\end{array} & \begin{array}{l}\text { Bibliothèque et } \\ \text { Archives Canada }\end{array} \\ \begin{array}{l}\text { Published Heritage } \\ \text { Branch }\end{array} & \begin{array}{l}\text { Direction du } \\ \text { Patrimoine de l'édition }\end{array} \\ \begin{array}{l}\text { 395 Wellington Street } \\ \text { Ottawa ON K1A 0N4 }\end{array} & \begin{array}{l}\text { 395, rue Wellington } \\ \text { Ottawa ON K1A ON4 } \\ \text { Canada }\end{array} \\ \end{array}$

Your file Votre référence ISBN: 978-0-494-24957-4 Ourfile Notre référence ISBN: 978-0-494-24957-4

NOTICE:

The author has granted a nonexclusive license allowing Library and Archives Canada to reproduce, publish, archive, preserve, conserve, communicate to the public by telecommunication or on the Internet, loan, distribute and sell theses worldwide, for commercial or noncommercial purposes, in microform, paper, electronic and/or any other formats.

The author retains copyright ownership and moral rights in this thesis. Neither the thesis nor substantial extracts from it may be printed or otherwise reproduced without the author's permission.
AVIS:

L'auteur a accordé une licence non exclusive permettant à la Bibliothèque et Archives Canada de reproduire, publier, archiver, sauvegarder, conserver, transmettre au public par télécommunication ou par l'Internet, prêter, distribuer et vendre des thèses partout dans le monde, à des fins commerciales ou autres, sur support microforme, papier, électronique et/ou autres formats.

L'auteur conserve la propriété du droit d'auteur et des droits moraux qui protège cette thèse. $\mathrm{Ni}$ la thèse ni des extraits substantiels de celle-ci ne doivent être imprimés ou autrement reproduits sans son autorisation.
In compliance with the Canadian

Privacy Act some supporting forms may have been removed from this thesis.

While these forms may be included in the document page count, their removal does not represent any loss of content from the thesis.
Conformément à la loi canadienne sur la protection de la vie privée, quelques formulaires secondaires ont été enlevés de cette thèse.

Bien que ces formulaires aient inclus dans la pagination, il n'y aura aucun contenu manquant. 


\section{ACKNOWLEDGEMENT}

First and foremost, I would like to give my gratitude to my parents for their support and understanding. I would like to thank Prof. James Nemes with providing me with the opportunities to learn and for giving me his support, trust and advice. I also would like to

give thanks to Steve Kacani for his guidance and help with the fabrication of the experimental setup.

I would like to acknowledge the financial support of NSERC and DRDC. 


\section{ABSTRACT}

Woven fibres and yarns are generally used in the form of a laminate embedded into a matrix. However, these materials are increasingly being used in the pure and the woven form such as fabric for ballistic protection clothing and confinement chambers for jet engines. These applications have created a demand for numerical modelling of the fabrics and more in depth information about the behaviour of fibrous materials and yams. Manufacturers of yarns usually provide some quasistatic material parameters for the single fibre form of the material. However, this information cannot be scaled up linearly for a yarn consisting of many fibres. Also, the strain rate at which this information is obtained is not in the same order of magnitude as the strain rates observed in ballistic applications.

The purpose of this study is to gain an understanding of parameters that affect the strength of yarns. Quasistatic and dynamic strength of various yarns are obtained using hydraulic and Hopkinson bar testing methods respectively and the rate dependency of the failure strength of each yarn is quantified. Weibull models are applied to each set of tests to observe whether the parameters obtained can be used as size independent material properties. The scaling effect will also be studied experimentally in order to observe the effect of specimen size to the failure stress of yarn. 


\section{RÉSUMÉ}

Les fibres tissés et les filés sont généralement utilisés sous forme de stratifié incorporé dans une matrice. Cependant, ces matériaux sont de plus en plus utilisés sous leur forme pure et tissée telle que pour l'habillement de protection balistiques et pour les chambres d'emprisonnement des moteurs d'avions. Ces applications ont créé une demande croissante de modélisation numérique des tissus et de l'établissement d'informations plus détaillées sur le comportement des matériaux fibreux et des filés. Les fabricants des filés fournissent habituellement quelques paramètres matériels quasi-statiques pour la forme mono fibre du matériel. Cependant, cette information ne peut pas être mise à l'échelle par une interpolation linéaire pour représenter un filé se composant de plusieurs fibres. En outre, vitesse de déformation auquel cette information est obtenue n'est pas du même ordre de grandeur que celles observées dans les applications balistiques.

Le but de cette étude est de développer une compréhension des paramètres qui affectent la résistance des filés. Les résistances quasi-statique et dynamique de divers filés sont obtenues respectivement par essai hydraulique et de barre de Hopkinson permettant la quantification de résistance ultime de chaque filé en fonction de la vitesse de déformation. Des modèles de Weibull sont appliqués à chaque ensemble d'essais pour vérifier si les paramètres obtenus peuvent être utilisés comme propriétés matérielles indépendantes de la taille des échantillons. L'effet d'échelle sera également étudié expérimentalement afin de relier l'effet de la taille de spécimen à limite de rupture du filé. 


\section{TABLES OF CONTENTS}

ACKNOWLEDGEMENT ............................................................................................

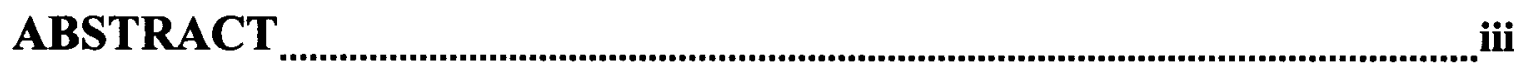

RÉSUMÉ

TABLE OF CONTENTS ...................................................................................

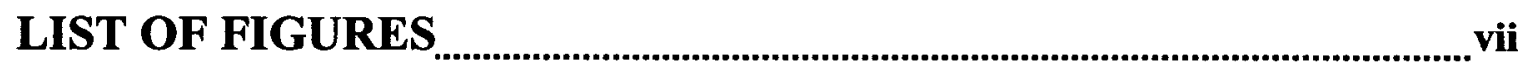

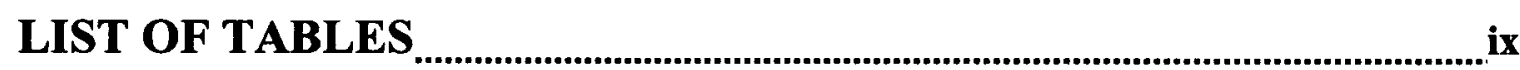

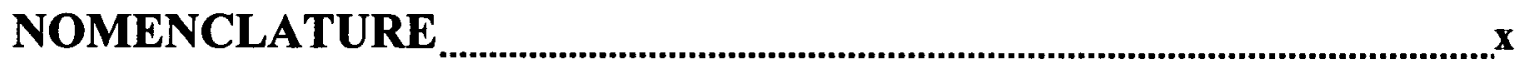

1.0 INTRODUCTION

2.0 LITERATURE REVIEW

2.1 Probabilistic Models .......................................................................................3

2.2 Single Fibre Versus Yarn...............................................................................6

2.3 Effect of Twist.....................................................................................................9

2.4 New High Strength Fibres

2.5 Brief History of Hopkinson Bar Technique .................................................12

2.6 High Strain Rate Testing...................................................................................13

3.0 SPLIT HOPKINSON BAR THEORY ....................................................

3.1 One-Dimensional Longitudinal Wave Propagation......................................17

4.0 EXPERTIMENTAL PROCEDURE

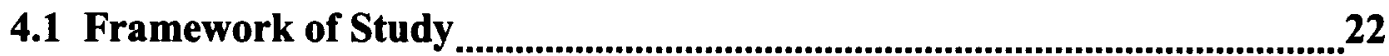

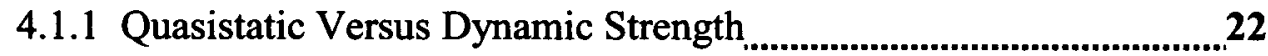

4.1.2 Scale Effect..................................................................................25

4.2 Tensile Hopkinson Bar Setup....................................................................

4.2.1 Physical Setup .................................................................................26

4.2.2 Acquisition and Instrumentation .....................................................29

4.2.3 High Speed Photography ...................................................................33 
4.3 Quasistatic Setups

4.3.1 Single Fibre Testing Setup ..............................................................33

4.3.2 Multi Fibre Testing Setup....................................................................34

4.4 Description of the Grips and Preparation of the Specimens.......................36

4.4.1 Mechanical Gripping Method .............................................................36

4.4.2 Epoxy Gripping Method ...................................................................... 37

4.4.3 Combined Gripping Method ................................................................. 40

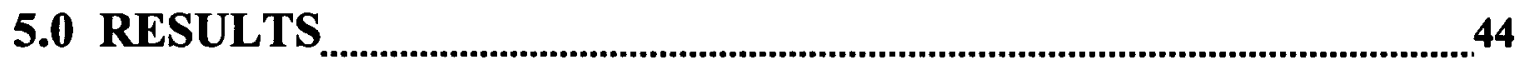

5.1 Quasistatic and Dynamic Results ...................................................................45

5.1.1 Strain Data from the High Speed Camera Images ............................... 48

5.2 Effect of Specimen Volume on Failure Stress..............................................63

5.3 Weibull Analysis................................................................................................. 70

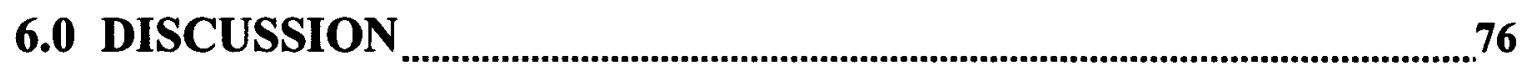

6.1 Failure Strength Results ............................................................................76

6.2 Weibull Parameters......................................................................................7 7

6.3 Scale Effect Results .......................................................................................77

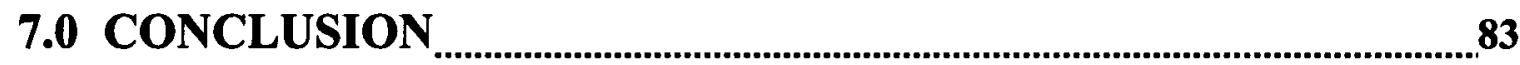

7.1 Future Work

8.0 REFERENCES 


\section{LIST OF FIGURES}

Figure 3.1 - Schematics of compression (top) and tension (bottom) Hopkinson bar ........ 15

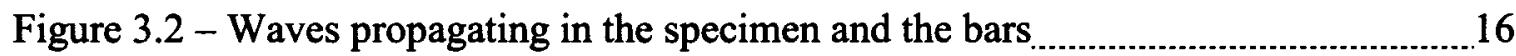

Figure 3.3 - Waves propagating in the bars $\ldots$

Figure 3.4 - Specimen of gage length, $1_{0}$, undergoing compressive deformation $\ldots . . . . . . . . .20$

Figure 4.1 - Schematic diagram of the Hopkinson bar...................................................27

Figure 4.2 - Top view of the two-cable setup (transmitted bar assembly not shown).......27

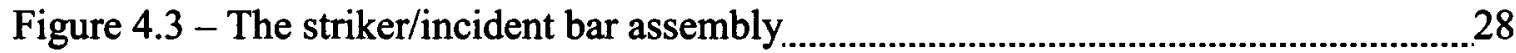

Figure 4.4 - Circuit schematic of a two arm active Wheatstone bridge ............................... 31

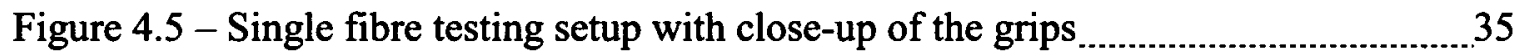

Figure 4.6 - Multi fibre testing setup with close-up of the grips

Figure 4.7 - A picture of a specimen with woven yarn on the aluminium plates ............... 37

Figure 4.8 - Mould plate for producing dog-bone specimens with epoxy tabs .................. 38

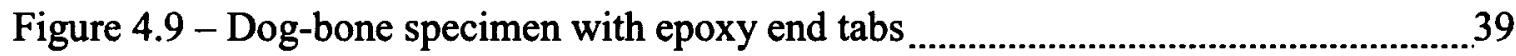

Figure 4.10 - A picture of the mould plate for the combined gripping method $\ldots$

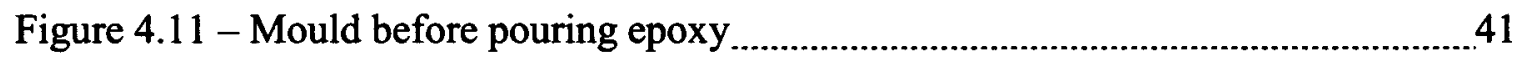

Figure 4.12 - An image of a specimen made with button tabs after removal from mould

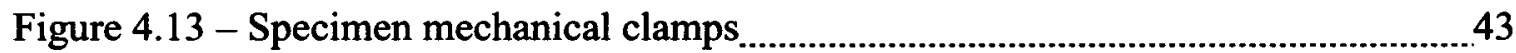

Figure 5.1 - Sample voltage signal from strain gage with each wave labelled...................46

Figure 5.2 - Comparison between the displacements in the gage section versus the tabs. 47

Figure 5.3(a) - Images 1 to 4 from testing Twaron (frame rate $=50 \mu \mathrm{s}) \ldots \ldots \ldots \ldots \ldots \ldots \ldots . . . . . . . . . . . . . . .50$

Figure 5.3(b) - Images 5 to 8 from testing Twaron (frame rate $=50 \mu \mathrm{s}$ ) $\ldots \ldots \ldots \ldots \ldots \ldots \ldots \ldots \ldots \ldots$

Figure 5.4 - Quasistatic and dynamic results for Kevlar 129 (1154 fibres).......................53

Figure 5.5 - Quasistatic and dynamic results for Kevlar KM2 (1166 fibres).....................54

Figure 5.6 - Quasistatic and dynamic results for Kevlar LT (1080 fibres) ........................55

Figure 5.7 - Quasistatic and dynamic results for Twaron (1350 fibres)...........................56

Figure 5.8 - Quasistatic and dynamic results for Zylon (1268 fibres)............................... 57

Figure 5.9 - Dynamic stress versus strain plot for Kevlar 129 (1154 fibres) .....................58 
Figure 5.10 - Dynamic stress versus strain plot for Kevlar KM2 (1 166 fibres) 58

Figure 5.11 - Dynamic stress versus strain plot for Kevlar LT (1080 fibres) 59

Figure 5.12 - Dynamic stress versus strain plot for Twaron (1350 fibres) 59

Figure 5.13 - Dynamic stress versus strain plot for Zylon (1268 fibres). 60

Figure 5.14 - Quasistatic results for specimens of Kevlar 129 (2308 fibres, $\mathrm{GL}=24 \mathrm{~mm}$ ) 65

Figure 5.15 - Quasistatic results for specimens of Kevlar 129 (1154 fibres, $\mathrm{GL}=100 \mathrm{~mm}$ ) 66

Figure 5.16 - Quasistatic results for specimens of Kevlar 129 (1154 fibres, $\mathrm{GL}=170 \mathrm{~mm}$ ) 66

Figure 5.17 - Plot used for evaluation of Weibull parameters for Kevlar KM2 71

Figure 6.1 - Plot of the relation between the normalized failure stress versus normalised specimen volume along with the error bar (1 STD) 83 


\section{LIST OF TABLES}

Table 4.1 - Data used for obtaining yarn cross section 24

Table 5.1 - Dynamic and quasistatic strength of each yarn along with their ratio 60

Table 5.2 - Strength of a single fibre of Kevlar 129 at gage lengths of 5 to $100 \mathrm{~mm}$.......63

Table 5.3 - Tensile strength of Kevlar 129 for different specimen sizes .............................68

Table 5.4 - Scale and shape factors for different yarns along with accuracy of fit 72

Table 5.5 - Weibull parameters obtained for Kevlar 49 by Amaniampong and

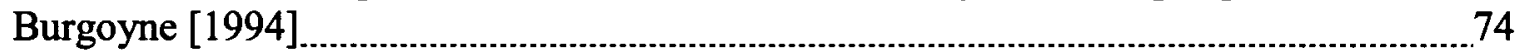

Table 5.6 - Scale and shape factors for Kevlar 129 specimens

Table 6.1 - Parameter for the relation between failure stress of Kevlar 129 and the specimen volume along with the accuracy of fit parameter 82 


\section{NOMENCLATURE}

\begin{tabular}{|c|c|}
\hline Variable & Definition \\
\hline a & Weibull scale factor \\
\hline$A_{1}$ & Cross sectional area of the incident bar $\left[\mathrm{m}^{2}\right]$ \\
\hline $\mathrm{A}_{\mathbf{T}}$ & Cross sectional area of the transmitted bar $\left[\mathrm{m}^{2}\right]$ \\
\hline$A_{0}$ & Specimen cross sectional area $\left[\mathrm{m}^{2}\right]$ \\
\hline $\mathbf{b}$ & Weibull shape factor $[\mathrm{Pa}]$ \\
\hline $\mathrm{c}_{0}$ & Wave speed in a given material $[\mathrm{m} / \mathrm{s}]$ \\
\hline$c_{I}$ & Wave speed in the incident $b a r[\mathrm{~m} / \mathrm{s}]$ \\
\hline $\mathbf{c}_{\mathbf{T}}$ & Wave speed in the transmitted bar $[\mathrm{m} / \mathrm{s}]$ \\
\hline $\mathbf{E}$ & Young's Modulus of a given material $[\mathrm{Pa}]$ \\
\hline $\mathbf{E}_{\mathrm{I}}$ & Young's Modulus of the incident bar material $[\mathrm{Pa}]$ \\
\hline $\mathrm{E}_{\mathrm{T}}$ & Young's Modulus of the transmitted bar material $[\mathrm{Pa}]$ \\
\hline$f\left(x-c_{0} t\right), g\left(x-c_{0} t\right)$ & General solution functions to the wave equation \\
\hline $\mathrm{F}(\sigma)$ & Probability of failure at a given stress \\
\hline $\mathbf{L}$ & Length $[\mathrm{m}]$ \\
\hline$l_{0}$ & Gage length of specimen [m] \\
\hline $1_{\mathrm{f}}$ & Single fibre gage length $[\mathrm{m}]$ \\
\hline $\mathrm{m}, \mathrm{n}, \mathrm{p}$ & $\begin{array}{l}\text { Parameters for the relation between the average failure stress and } \\
\text { the specimen volume }\end{array}$ \\
\hline $\mathrm{N}$ & Total population size for the median rank approximation \\
\hline$P_{1}$ & Force acting at the incident side of the specimen $[N]$ \\
\hline $\mathrm{P}_{2}$ & Force acting at the transmitted side of the specimen $[\mathrm{N}]$ \\
\hline$P_{\text {avg }}$ & Average force acting on the specimen $[\mathrm{N}]$ \\
\hline $\mathbf{R}_{\mathbf{o}}$ & Nominal resistance of the strain gages $[\Omega]$ \\
\hline $\mathrm{R}_{1}, \mathrm{R}_{2}, \mathrm{R}_{3}, \mathrm{R}_{4}$ & Resistors at different positions of the Wheatstone bridge [ $\Omega]$ \\
\hline $\mathrm{R}^{2}$ & Measure of the accuracy of a linear fit \\
\hline $\mathrm{t}$ & Time $[\mathbf{s}]$ \\
\hline
\end{tabular}




$\begin{array}{cl}u & \text { Displacement in the axial direction of the bar [m] } \\ v_{1} & \text { Velocity of the specimen end of the incident bar [m/s] } \\ v_{2} & \text { Velocity of the specimen end of the transmitted bar [m/s] } \\ V_{\mathrm{o}} & \text { Input voltage to the Wheatstone bridge [V] } \\ \mathrm{V}_{\text {out }} & \text { Output voltage of the Wheatstone bridge [V] } \\ \mathrm{V}^{*} & \text { Specimen volume normalised by the single fibre specimen volume } \\ \mathrm{X} & \text { Length variable along the axis of the bars [m] } \\ \beta & \text { Gumbel location factor [Pa] } \\ \delta & \text { Gumbel scale factor [Pa] } \\ \delta_{\mathrm{g}} & \text { Displacement in the gage length [m] } \\ \delta_{\mathrm{t}} & \text { Displacement in the tabs of specimen [m] } \\ \varepsilon_{\mathrm{I}} & \text { Strain history of the incident wave } \\ \varepsilon_{\mathrm{R}} & \text { Strain history of the reflected wave } \\ \varepsilon_{\mathrm{s}}, \varepsilon_{\mathrm{s}, \mathrm{avg}} & \text { Specimen and average specimen strain history } \\ \varepsilon_{\mathrm{T}} & \text { Strain history of the transmitted wave } \\ \varepsilon_{s} & \text { Strain rate history of the specimen } \\ \rho & \text { Average specimen stress [Pa] } \\ \sigma_{\mathrm{s}, \text { avg }} & \left.\text { Ansity of a given material [kg/m }{ }^{3}\right] \\ \sigma_{\mathrm{f}, \text { avg }} & \text { Angineering stress [Pa] }\end{array}$




\subsection{INTRODUCTION}

Synthetic fibres have been widely used to produce high strength fabrics and composites in many different fields such as aerospace, personal protection and recreational applications. These materials have the advantages of light weight, high strength and high stiffness in comparison to conventional materials. These fibres, whether used in the form of fabrics or as yarns, undergo deformations that can result in their failure. There are various mechanisms that can bring about their failure which is very dependent on the application in which they are used. Fatigue failure can be observed in aerospace and recreational application because of the cyclic nature of the loading conditions. Sudden failures also occur because of high rate impact loading.

Many considerations are taken into account when designing a structure to withstand their working conditions. In most applications, linear stress analysis and static failure criteria are used as the foundation of design parameters. The strength of a structure can depend on various material properties and loading conditions. The material properties can be affected through strain rate dependencies which are commonly observed in polymeric materials. Large safety factors and conservative design practices are often used in structures in which dynamic material behaviour is unknown.

In order to optimize design of the structure, it is of great importance to characterize the material properties at the appropriate strain rates. In applications where woven fabrics are used, reliable and accurate models are needed to determine the properties of the 
fabric. Depending on the scale of a fabric model considered, different sets of material parameters are used as inputs to the fabric model. A unit cell approach can be used to construct a model for the macro behaviour of woven fabrics. The unit cell of a fabric at a macro level can be considered to be a bundle of fibres or a yarn as it will be referred to in this study. Hence, to produce accurate numerical models for the fabric, material properties of the unit cell would have to be defined. These material properties would have to reflect the range of strain rates at which the fabric is being deformed. Important material parameters that play a role in the modelling of the fabric are the elastic modulus of the fibres as well as their failure strength and strain. Interfibre interactions are also important to characterise the behaviour of the woven fabric.

The focus of this study is to investigate the parameters affecting the tensile strength of various synthetic yarns. High strain rate tests will be performed on several different yarns and their high rate strengths will be compared to the quasistatic strengths. Five different yarns are tested dynamically and quasistatically: Kevlar 129, Kevlar KM2, Kevlar LT, Twaron and Zylon. A miniature Hopkinson bar setup is designed specifically for this study and will be used to perform high strain rate tests while standard quasistatic equipment will be used to perform low strain rate tests. Probabilistic models generally used to describe the failure strength of brittle materials are implemented and the failure criteria parameters obtained. The effect of the specimen size on the strength of the yarn will be studied for Kevlar 129. Using these observations, a model is proposed to relate the strength of the yarn to the volume of the yarn under stress. 


\subsection{LITERATURE REVIEW}

Intuitively, design parameters of a structure are highly dependent on the material properties of the structure in mind. The deformation and failure limits of a structure could be a function of the elastic, plastic and strength properties of the material used. Synthetic fibres like most brittle materials show elastic behaviour with no pronounced plastic behaviour at the onset of failure. A voluminous amount of literature treats models and various parameters that can be used to describe the behaviour of synthetic fibres which will be discussed in this chapter.

\subsection{Probabilistic Models}

High strength polymeric and brittle materials show large scatter in their material properties. Hence, statistical models are often used to describe and predict their failure. Brittle materials exhibit little or no plastic deformation. Plastic deformation in ductile materials provides for the reduction of stress concentration around the material defects and therefore sudden and variable failure behaviour are not observed in ductile materials. With the lack of plastic deformation in brittle materials, their failure properties become highly dependent on the number and the size of defects within the volume undergoing deformation.

In brittle materials it is observed that the failure stress decreases with increasing volume of material tested [Hertzberg, 1996]. Increasing the volume tested, increases the number of defects in the material as well as increasing the probability of the existence of a large 
defect which in turn decreases the failure stress. Probabilistic models have been used by various authors for brittle material and high strength yarns to quantify the probability of failure at a given stress level and specimen size.

Brittle fibres exhibit large variability in failure strength and strain. This variability is due to the variation of the fibre diameter, presence of flaws on the surface of fibre as well as the interior of the fibre. Variation in the fibre diameter is also observed when comparing batches of the same material which can be attributed to the variability within the manufacturing process [Schwartz et al., 1984]. As mentioned previously, because of these variations, statistical models are used to predict the behaviour of yarns and fibres. A number of authors have conducted experimental and theoretical studies on this topic.

A two-parameter Weibull distribution is a common distribution used to model aramid and other fibres. It takes the following form:

$$
F(\sigma)=1-\exp \left[-\left(\frac{\sigma}{a}\right)^{b}\right]
$$

where $F(\sigma)$ is the probability of failure of the fibre or yarn at a specific gage length with the applied stress of $\sigma$. Parameters $a$ and $b$ are scale and shape factors, respectively. The scale parameter, $a$, is analogous to the average failure stress of the material and is always a positive number with units of stress. The shape factor, $b$, is a dimensionless number greater or equal to zero. When the shape factor approaches infinity the probability of failure for all stress values below the scale factor, $a$, is zero [Hertzberg, 1996]. 
Amaniampong and Burgoyne [1994] investigated the variability of the failure strength and strain for Kevlar 49 and polyester yarns. They stated that failure strains of both materials can be represented by a two-parameter Weibull distribution while failure strengths of Kevlar 49 and polyester can be represented by the Gumbel distribution and a two-parameter Weibull distribution, respectively.

The Gumbel distribution is a special case of the Extreme Value Distribution which takes the following form:

$$
F(\sigma)=1-\exp \left[-\exp \left(\frac{\sigma-\beta}{\delta}\right)\right]
$$

where $F(\sigma)$ is the probability of failure of the fibre or yarn at a specific gage length with the applied stress of $\sigma$. Parameters $\beta$ and $\delta$ are location and scale factors, respectively.

Schwartz et al. [1984] studied the variability of the strength of a single aramid fibre and found that the failure load and tenacity (failure load over linear density) of a single fibre can be fitted to a two-parameter Weibull distribution. They state that the fit is better for tenacity since the variation of linear density (i.e. diameter) along the length of the fibre is quite significant and this contributes to the variability to the failure load since it is not normalized by the linear density. Schwartz et al. also examined the effect of gage length on the strength of the single fibre. They found that Weibull theory, using parameters obtained from a $5 \mathrm{~cm}$ gage length as a reference, over-predicted the strength at shorter gage lengths and under-predicted the strength at longer lengths. They proposed that this departure from theory could be caused by the dependence of the Weibull shape factor, $b$, on the gage length of the material. The authors further stated that the Weibull shape 
factor, $b$, maybe not be a material constant for a single fibre of aramid, a conclusion also reached for silicon carbide and sapphire filaments.

Dai and Piggot [1993] studied the effect of varying the gage length on the strength of a single fibre of carbon and Kevlar. They attempted to use the Weibull failure model to each type of fibre and to obtain the Weibull parameters. They found the Weibull model did not provide for good strength estimation for carbon fibres at various gage lengths. However, they found good agreement for Kevlar fibres but they did not provide the results because of the large variation in the diameter of Kevlar fibres. This further hint at the short range correlation for the strength along the length. This variation is attributed to the variation of the diameter which results in the large variation of linear density that Schwartz [1984] pointed out. Dai and Piggot stated that for a more accurate model, actual flaw distribution is needed to be able to construct a model that would relate the fibre strength to its length.

\subsection{Single Fibre Versus Yarn}

The manufacturers of high strength fibres usually provide quasistatic properties for a single fibre of the material. However, these materials are seldom used in the single fibre form and the properties which are of interest are the properties of a bundle of these fibres. It is well known that the strength of a yarn is not predicted accurately by averaging the strength of the individual fibres. During the uniaxial tension deformation of a yarn, the individual fibres are under multi-axial stress conditions. One component is the tension along the axis of the fibre and the other being the lateral compression. This lateral 
pressure produces friction and entanglement of the fibres which in turn can cause a phenomenon called fragmentation. Fragmentation is the multiple breaking of an individual fibre at different segments. This breakage continues until the lengths of the fibre fragments reach a minimum value. Pan et al. [2001] points out that this process is not always observed and it depends on factors such as yarn structure, twist level and fibre, diameter. They also state that the fragmentation is observed in thick filament yarns.

A number of different models have been devised to estimate this difference between the fibre and yarn properties. These models involve a finite number of fibres of the same length in which variations in diameter, strength, and other defects are incorporated. The models become increasingly more complex when the individual fibres may not share the load equally such as the case of yarns and ropes.

Pan et al. [2001] performed a survey of literature regarding the relationship between the strengths of a fibre, a bundle, and a yarn. They defined the difference between a bundle and a yarn to be that fibres in a yarn have some twist while a bundle has no twist and only consists of parallel fibres. Pan et al. concluded that the main two factors that determine the strength difference between fibre and yarn are the occurrence of the fragmentation process and the fibre strength variation.

Daniels [1945] developed a model for bundles consisting of a large number of Weibull fibres of the same length. Daniels stated that the average strength of a bundle takes the 
following form in term of Weibull parameters $(a$ and $b)$ and the length of the component fibres $\left(l_{f}\right)$ :

$$
\sigma_{\text {bundle,avg }}=\left(l_{f} a b\right)^{-1 / b} \cdot \exp \left(-\frac{1}{b}\right)
$$

Coleman [1958] developed a theoretical model for the average failure strength of a single aramid fibre using the weakest link theory. He stated that the average failure strength takes the following form in terms of Weibull parameters ( $a$ and $b$ ) and the length of the component fibres $\left(l_{f}\right)$ and the statistical gamma function:

$$
\sigma_{\text {fibre,avg }}=\left(l_{f} a\right)^{-1 / b} \cdot \Gamma\left(1+\frac{1}{b}\right)
$$

He also produced the same model as the one proposed by Daniels [1944] for the relationship between the strength of a bundle and a fibre assuming no material rate dependency. He stated that the ratio of the tensile strength of the yarn over the strength of the fibre decreases monotonically with the increasing dispersion of the fibre strength. Coleman also concluded that the tensile strength of a yarn is of the same order of magnitude as a single fibre of the same material but it is less than the mean failure stress of the single fibre. He states that the following conclusion also applies to material with time dependent properties.

An inverse approach was used by Xia and Wang [1998] to obtain properties for a single fibre. They used a theoretical model to obtain single fibre strength distribution from yarn strength distribution. This method is used to obtain Weibull parameters for a single fibre 
of Kevlar 49. Xia and Wang used this approach along with the experimental data from Hopkinson bar tests for Kevlar 49.

\subsection{Effect of Twist}

As mentioned above, lateral pressure felt by fibres in yarn during uniaxial tension plays a role in the overall strength of a yarn. The introduction of twist in a yarn effects the interaction of the fibres with each other. Twist is generally introduced as a way of increasing the lateral cohesion of yarn and making its handling easier. Studies have shown that the strength of a yarn increases with the introduction of twist up to a maximum value and then decreases with further twist introduced.

Naik and Madhavan [2000] performed an analytical study on elastic properties of twisted yarn. They attributed a number of factors that plays into the interaction between the yarns. On the outer region of a twisted yam, the outer fibres move inward and displace less tensioned fibre while in the inner region the lateral compression provides for microbuckling of the inner-most fibres that do not experience the same degree of twist. Naik and Madhavan conclude that twisted yarns have a lower axial modulus compared to untwisted yarns; this finding is supported by experimental results by Weinberg and Schwartz [1987].

Mulkern and Raftenberg [2002] performed an experimental study of the strengths of Kevlar KM2 yarn and fabric. Quasistatic tests were performed on twisted and untwisted yarn as a part of his investigation. The experimental results showed that with the 
introduction of twist the failure strength of the yarn increased until a maximum value after which further twist decreased the strength. In this study a constant gage length of $25 \mathrm{~cm}$ was used. The strength of the yarn reached a maximum at a twist value of 1.38 turns $/ \mathrm{cm}$ of the gage length. This corresponded to a twist multiplier of 1.2 which agreed with Yang [1993] who performed similar tests on Kevlar yarns. Twist multiplier is a measure of the twist in a yarn with consideration for the fibre count in the yarn. Fine yarns require more twist than thick yarns in order to produce the same lateral adhesion force. Yang defines the twist multiplier to be:

$$
T M=\frac{\tau(\text { turns } / \text { inch }) \sqrt{\text { denier }}}{73}=\frac{\tau(\text { turns } / \text { cm }) \sqrt{\text { denier }}}{29}
$$

Mulkern and Raftenberg attributed the increase in strength to be caused in part by the frictional effect between the filaments.

Weinberg and Schwartz [1987] studied the effect of twist on failure stress and modulus of Kevlar 29 yarns and Kevlar 29 prepreg yarns. They found that introduction of twist to prepreg samples did not produce an increase in failure strength while the yarn responded to the twist with maximum failure stress at approximately $1 \mathrm{turn} / \mathrm{cm}$. The experimental results also showed a decrease in modulus with increasing twist as predicted by the analytical model by Naik and Madhavan [2000].

\subsection{New High Strength Fibres}

Manufacturers of high strength fibres focus a lot of resources toward enhancing their product by improving the manufacturing process to produce more crystalline and uniform 
yarns. For example, Kevlar KM2, which is produced by Du Pont, is a more crystalline form of the previous Kevlar fibres that have been used in fabric armour. Aramid fibres are also sold by Teijin Twaron under the trade name of Twaron. The introduction of Zylon to the market by Toyobo has further pushed the envelope in this field by producing fibres with higher failure stresses than aramid fibres. The high strength of Zylon has made it the new favourite material for support and reinforcement of high magnetic field coil.

A study of the properties of Zylon/epoxy composite was carried out by Huang et al. [2002]. They performed uniaxial tension and compression on the composite and found that Zylon fibres in a composite to have a tensile strength of $4.3 \mathrm{GPa}$ and a very low transverse compression strength. These results focus on the behaviour of the fibres in a composite and may not be directly related to the focus of this study, although they do point to the high strength of Zylon. Another point worth noting is that the interfacial adhesion between Zylon fibres and epoxy matrix is poor as reported by Wang et al. [2001], which maybe the reason for the low transverse compressive stresses obtained by Huang et al. [2002].

So far various models and parameters that can describe and affect the strength of yarns have been introduced. The remainder of this section will describe the literature related to the Hopkinson bar technique which is used to obtain stress versus strain properties of materials at high strain rates. The theory behind the high rate testing method will be discussed separately in the next chapter. 


\subsection{Brief History of Hopkinson Bar Technique}

The Split Hopkinson bar technique is commonly used to determine the stress versus strain behaviour of materials at high rates. Its cost effectiveness and reliability have made it a standard method for obtaining stress versus strain data for various types of material. Since its original setup, many improvements have been incorporated and various types of loading conditions such as compression, tension, torsion and punch can be applied at high rates.

In 1913, the original setup was developed by Bertram Hopkinson which involved a long bar and a short billet with the short billet being held in place on the long bar by a layer of grease. When the long bar was impacted, a pressure wave would travel down the bar until it reached the end after which it would send the short billet flying off. By repeating the experiment for various billet lengths and measuring the momentum of the billet, Hopkinson would obtain maximum pressure and the total duration of the impact.

Kolsky introduced major improvements to the setup by introducing a second long bar and sandwiching a specimen between the two bars. He also related the stress and strain in the specimen to the strain history in the two bars. With the addition of modern electronics and computer processing tools, this setup is quite similar to the ones used today. In some literature they refer to this testing method as the Kolsky bar. 


\subsection{High Strain Rate Testing}

High strain rate testing of yarns and fibres has been the subject of research of various authors and a wide range of results have been reported. There are conformities and contradictions among the results produced. One of the biggest challenges in testing yarns is gripping the yarns while minimizing slip and damage to the fibres. Each researcher uses their own method of producing specimens and gripping the yarns which can introduce irregularity and discrepancies between experimental results. There are standard test methods described by ASTM used to obtain material properties various materials. The ASTM D4018-81 is the standard testing method for carbon filaments, graphite yarns and strands which was studied as the initial guidelines to develop the gripping method used in this study. The remainder of this chapter will discuss various authors' findings regarding the effect of strain rate on the behaviour of yarns and fibres.

Amaniampong and Burgoyne [1994] performed experimental tests on Kevlar 49 and polyester yarns. Some of their findings regarding the modeling were mentioned earlier and their experimental findings are discussed here. A limited range of strain rates $(0.033$ $-0.66 \mathrm{~s}^{-1}$ ) were considered in their study at a constant gage length of $560 \mathrm{~mm}$ and they found that average strength of aramid yarns decrease slightly with increasing strain rate. They state that although this is contrary to the theoretical prediction, the experimental data suggest otherwise. However, the limited range of strain rates considered provides inadequate information for the overall trend when extrapolated to the strain rate associated with ballistic loading conditions. 
Xia and Wang [1998] studied the effect of strain rate on Kevlar 49 yarns. A wide range of strain rates were considered $\left(10^{-4}\right.$ to $\left.10^{3} \mathrm{~s}^{-1}\right)$ at a constant gage length of $8 \mathrm{~mm}$. The tests were carried out using a Hopkinson bar for high rate tests and a commercial quasistatic setup for the low rate tests. Xia and Wang claimed that the modulus and the failure stress and strain of the yarns show dependence on the strain rate with an increasing trend observed with increasing strain rate. The failure strain and modulus showed little variation over the quasistatic strain rate range $\left(10^{-4}\right.$ to $\left.10^{-2} \mathrm{~s}^{-1}\right)$ but showed a stronger strain rate dependence at higher strain rates $\left(10^{2}\right.$ to $\left.10^{3} \mathrm{~s}^{-1}\right)$. The failure strength exhibited linear dependence to the logarithm of strain rate for the complete range. These findings have yet to be reproduced by other researchers.

Cheng and Chen [2005] conducted a study on the mechanical properties of a single fibre of Kevlar KM2 over a range strain rates $\left(0.00127-2451 \mathrm{~s}^{-1}\right)$. A gage length of $10 \mathrm{~mm}$ was used for the quasistatic tests while a gage length of $2 \mathrm{~mm}$ was used for the dynamic tests. The study focused on obtaining 5 material parameters needed to describe the deformation of a linear, elastic, transversely isotropic material by performing longitudinal, transverse and torsion experiments. Cheng and Chen investigated the loading rate effect in both longitudinal and transverse directions and found them to be insensitive to loading rate. 


\subsection{SPLIT HOPKINSON BAR THEORY}

In this chapter the theory behind the experimental method is discussed, starting with a brief description of the Hopkinson bar setup followed by the introduction of the assumptions and the development of the theoretical model. The theory involves the 1dimensional dynamic response of an elastic isotropic slender bar subjected to an impact at one end, resulting in a wave propagating along the length of the bar. The governing equation for longitudinal wave propagation will be introduced followed by the derivation of the equations of stress and strain for the specimen undergoing deformation.

A schematic of a split Hopkinson bar is shown in Figure 3.1. The diagram shows a compression and a tension version of the Hopkinson bar that is used to produce appropriate loading condition. The same theory is used to describe both tests and for the sake of simplicity the compression case is used for the introduction of the theory.

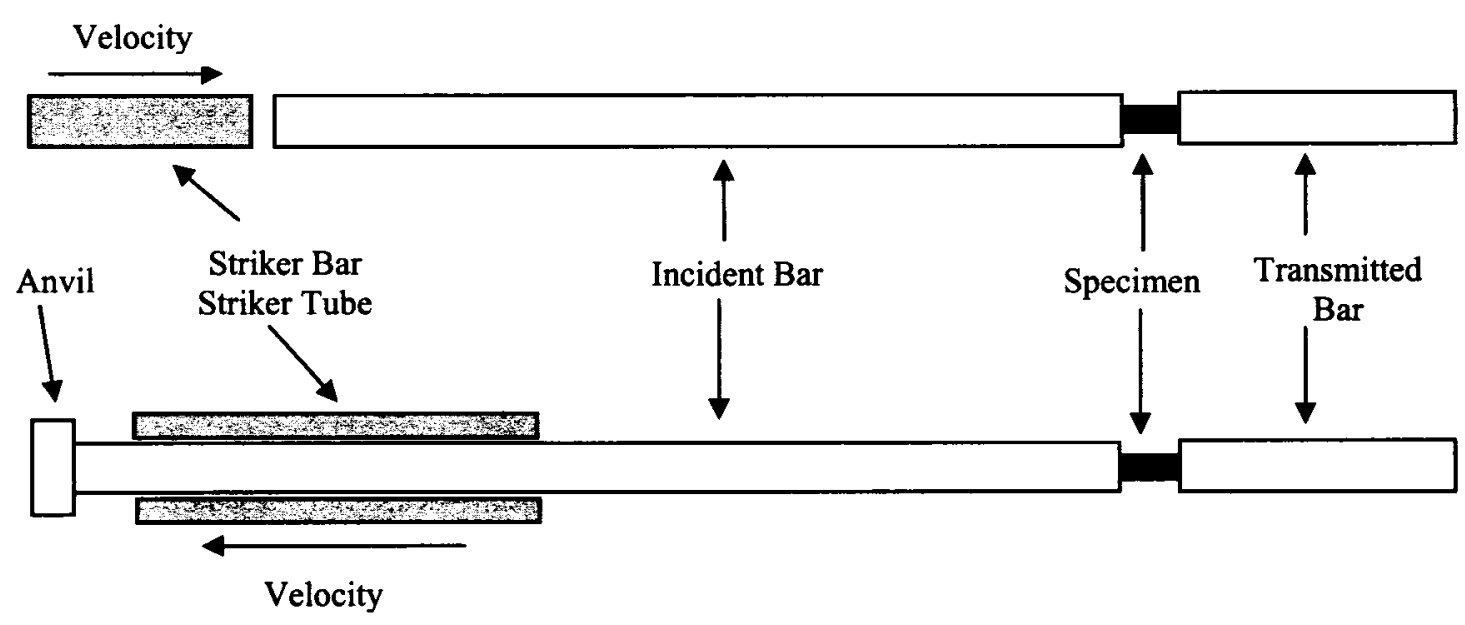

Figure 3.1 - Schematics of compression (top) and tension (bottom) Hopkinson bar 
A compression split Hopkinson bar consists of two slender bars of constant circular cross sectional area in between which a circular specimen of smaller cross section is sandwiched. As mentioned in the previous chapter, the historical setup only consisted of one bar with the specimen at one end; the term split is used because of the two bars used to sandwich the specimen. The term split can be dropped from the name for the sake of simplicity.

The two bars with the specimen in between is impacted at one end which produces an elastic stress wave that travels down the length of the bar. The bar that is impacted is called the incident bar and the bar on the other side of the specimen is called the transmitted bar as shown in Figure 3.1. Once the stress wave reaches the specimen, it begins to deform the specimen as it passes through it. At the interface of the specimen and the two bars, there is a step change in the cross sectional area. At each interface the stress wave is reflected back into the bar and transmitted though the cross section into the next medium. The magnitude of the transmitted and the reflected waves depends on the deformation of the specimen as well as the ratio of the cross sectional areas and the modulus of the bars and the specimen. Figure 3.2 shows the waves propagating in the specimen and the bars.

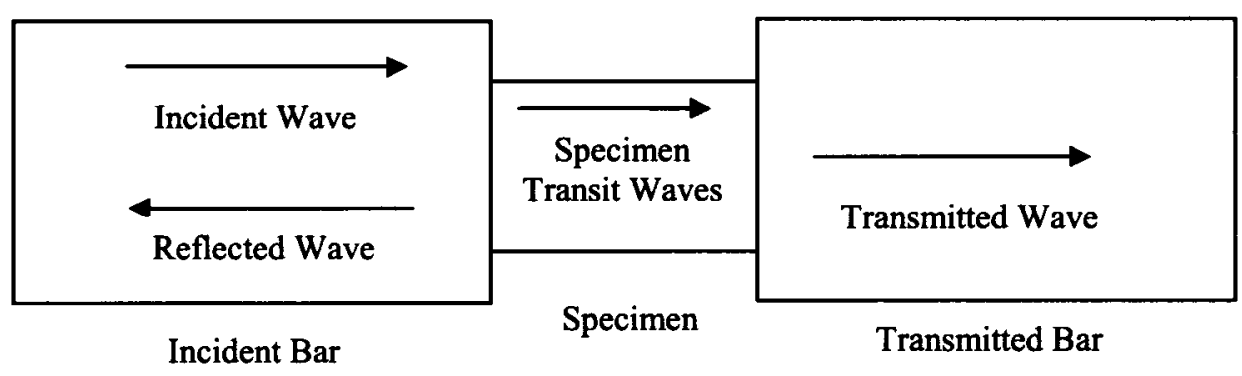

Figure 3.2 - Waves propagating in the specimen and the bars 
The measurements made in a Hopkinson bar setup are the dynamic strain readings in the two bars during the deformation of the sandwiched specimen. In the incident bar, the initial wave and the reflected wave are measured while in the transmitted bar, the wave transmitted through the specimen is measured. These measurements are made using foil strain gages bonded to the surface of the bars using a Wheatstone bridge. The details of the acquisition setup are discussed in the next chapter. Now that the basics of the setup are described, the theoretical model will be introduced.

\subsection{One-Dimensional Longitudinal Wave Propagation}

Consider a differential element of a slender isotropic bar undergoing linear elastic deformation caused by a compressive impact. The slender bar will have much smaller deformation in the radial direction than the axial direction which leads to the 1dimensional wave approximation. One-dimensional longitudinal wave propagation is used to describe the motion of the wave along the length of the bar [Al-Mousawi et al., 1997]. The wave propagation equation is a result of applying a force balance to an element of the slender bar. It takes the following form:

$$
\frac{\partial^{2} u}{\partial x^{2}}=\frac{1}{c_{0}^{2}} \frac{\partial^{2} u}{\partial t^{2}}
$$

where $u$ is the particle displacement and material wave speed, $c_{0}$, is defined to be:

$$
c_{0}=\sqrt{\frac{E}{\rho}}
$$


By using this equation along with simple linear elasticity, the deformations and stresses applied to the specimen can be obtained. The general solution to the wave propagation equation (3.2) takes the following form:

$$
u=f\left(x-c_{0} t\right)+g\left(x+c_{0} t\right)
$$

where $f\left(x-c_{0} t\right)$ and $g\left(x+c_{0} t\right)$ are arbitrary functions.

Considering a wave moving in the positive $\mathrm{x}$-direction the solution simplifies to:

$$
u=f\left(x-c_{0} t\right)
$$

By differentiating this expression in term of time and the variable $\mathrm{x}$, we obtain velocity and strain of a cross section:

$$
\begin{aligned}
& v=\frac{\partial u}{\partial t}=-c_{0} \frac{\partial f\left(x-c_{0} t\right)}{\partial\left(x-c_{0} t\right)}=-c_{0} f^{\prime} \\
& \varepsilon=\frac{\partial u}{\partial x}=\frac{\partial f\left(x-c_{0} t\right)}{\partial\left(x-c_{0} t\right)}=f^{\prime}
\end{aligned}
$$

By combining these two equations (3.5), we obtain an expression for the velocity history of the cross section of the bar in terms of the material wave speed and strain history:

$$
v=\frac{\partial u}{\partial t}=-c_{0} \varepsilon
$$

By integrating the equation for velocity we obtain the displacement in the bar, which is conventionally taken to be positive for the compression Hopkinson bar setup [AlMousawi et al., 1997]:

$$
u=c_{0} \int \varepsilon d t
$$


By applying this equation to the two faces of the bars that sandwiched the specimen, the specimen displacements can be obtained. This can be visualized by considering Figure 3.3 which shows the specimen with the incident and transmitted face having the subscript of 1 and 2, respectively. Using equations (3.6) and (3.7) and the sign convention noted previously, the velocity and displacement of the each face of the specimen can be obtained:

$$
\begin{aligned}
& v_{1}=c_{I}\left(\varepsilon_{I}-\varepsilon_{R}\right) \\
& v_{2}=c_{T} \varepsilon_{T} \\
& u_{1}=c_{I} \int\left(\varepsilon_{I}-\varepsilon_{R}\right) d t \\
& u_{2}=c_{T} \int \varepsilon_{T} d t
\end{aligned}
$$

where $c_{I}$ and $c_{T}$ are the material wave speeds for the incident and transmitted bar respectively. The strain histories in the bars are noted by $\varepsilon$ and the each of the strain history terms are shown in Figure 3.3 below.

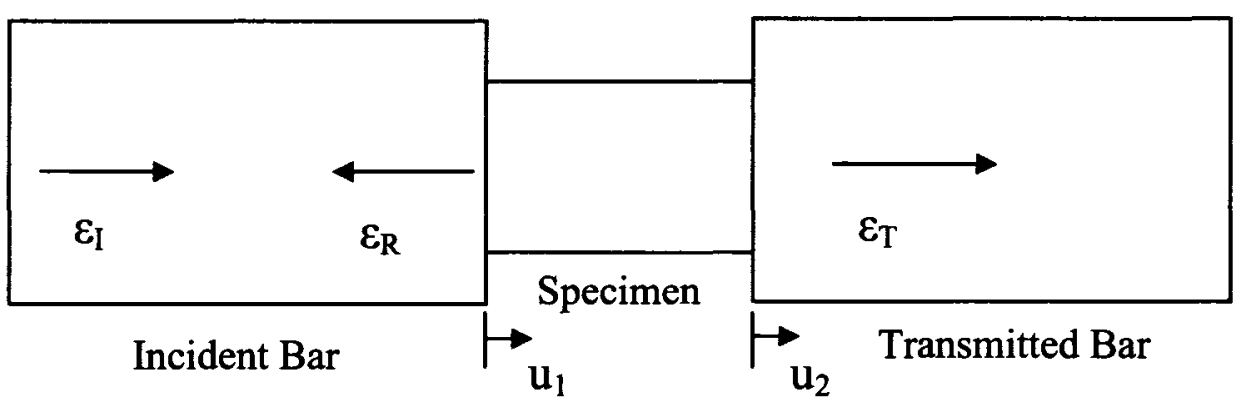

Figure 3.3 - Waves propagating in the bars

The velocity and displacement expressions for the face of the incident bar involves two strain history terms $\left(\varepsilon_{\mathrm{I}}\right.$ and $\left.\varepsilon_{\mathrm{T}}\right)$ because of the reflected wave that superimposes on the incident wave. The expression for the transmitted bar only involves one strain history since there is no overlapping of waves in the transmitted bar. The variables $c_{I}$ and $c_{T}$ are 
the wave velocities in the incident and transmitted bar, respectively, which in the general case may be different.

For a short specimen, the stress state can be assumed to be uniform. For a given gage length of $l_{0}$ and specimen cross sectional area of $A_{0}$, the specimen strain and average stress can be obtained. Since the bars are elastically deformed, the force histories of each end of the specimen can be related to the cross sectional area, the Young's modulus and the axial strain histories of each bar. Figure 3.4 shows the specimen undergoing compressive deformation with compressive forces acting at both ends.

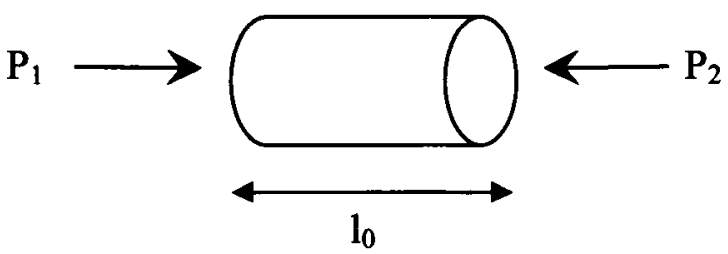

Figure 3.4 - Specimen of gage length, $1_{0}$, undergoing compressive deformation

The force at each end of the specimen can be expressed in the following form with $E$ and $A$ denoting the modulus and cross sectional area of each of the bars.

$$
\begin{aligned}
& P_{1}=E_{I} A_{I}\left(\varepsilon_{I}+\varepsilon_{R}\right) \\
& P_{2}=E_{T} A_{T} \varepsilon_{T}
\end{aligned}
$$

The average stress acting on the specimen is:

$$
\sigma_{s, \text { avg }}=\frac{P_{a v g}}{A_{0}}=\frac{P_{1}+P_{2}}{2 A_{0}}=\frac{A_{I} E_{I}\left(\varepsilon_{I}+\varepsilon_{R}\right)+A_{T} E_{T} \varepsilon_{T}}{2 A_{0}}
$$


If a state of stress equilibrium is valid during the deformation, the forces at the two ends of the specimen would be equal to each other $\left(\mathrm{P}_{1} \approx \mathrm{P}_{2}\right)$. Consequently, the expression for the average specimen stress simplifies to:

$$
\begin{aligned}
& P_{1} \approx P_{2} \Rightarrow A_{I} E_{I}\left(\varepsilon_{1}+\varepsilon_{R}\right)=A_{T} E_{T} \varepsilon_{T} \\
& \sigma_{s, \text { avg }}=E_{T}\left(\frac{A_{T}}{A_{0}}\right) \varepsilon_{T}
\end{aligned}
$$

From the velocity and the displacement expressions (equations (3.8) and (3.9)), the specimen strain and strain rate can be quantified. The expressions for the strain and the strain rate of the specimen take the following forms:

$$
\begin{gathered}
\varepsilon_{s}=\frac{u_{1}-u_{2}}{l_{0}}=\frac{1}{l_{0}} \int\left(c_{I}\left(\varepsilon_{I}-\varepsilon_{R}\right)-c_{T} \varepsilon_{T}\right) d t \\
\dot{\varepsilon}_{s}=\frac{v_{1}-v_{2}}{l_{0}}=\frac{c_{I}\left(\varepsilon_{I}-\varepsilon_{R}\right)-c_{T} \varepsilon_{T}}{l_{0}}
\end{gathered}
$$

Starting from the 1-dimensional assumption and by applying the wave propagation equation, the equations for the state of stress and strain of the specimen were derived. In the next chapter, the experimental procedure will be discussed. The dynamic and quasistatic test setups and procedure are described. The various gripping mechanisms that were experimented with will be described along with the specimen preparation procedure. The details of the data acquisition setup and conversion of the voltage histories obtained from the strain gages to strain histories will also be discussed in the next chapter. 


\subsection{EXPERTIMENTAL PROCEDURE}

In this chapter, the dynamic and quasistatic experimental procedures will be described. The various gripping mechanisms tested and the specimen preparation will be introduced and discussed in detail. Prior to describing the experimental techniques, the parameters that will be studied experimentally and the framework of the study of each of the parameters will be laid-out.

\subsection{Framework of Study}

\subsubsection{Quasistatic Versus Dynamic Strength}

Five different yarns are the subject of the quasistatic and dynamic tests. For each material, the quasistatic and dynamic tensile strengths are quantified. Note that the specimens may consist of two or four loops of yarn, in order to for them to have approximately the same cross sectional area. Yarns with smaller cross sectional area, such as Kevlar LT and Zylon, are made from four loops of the yarn while the others are made from two loops. The strength of brittle materials are affected by the volume of the material under stress, therefore by matching the cross sectional area and the gage length this effect can be minimised and comparisons between different yarn strengths can be made. Therefore, attention should be paid to the cross sectional area values when interpreting results. 
Listed below are the yarns studied along with their nominal value of their bundle size in units of dtex. Dtex stands for Decitex which is a measure of the weight of the yarn in grams per 10,000 meters of yarn.

- Kevlar 129 (dtex 940)

- Kevlar KM2 (dtex 950)

- Kevlar LT (dtex 440)

- Twaron (dtex 1100)

- Zylon (dtex 560)

All of the tests described are uniaxial tensile tests along the axis of the fibre. For each parameter such as yarn type, cross sectional area or gage length, a set of 10 tests are performed and the average strength is obtained. The quasistatic strength of each of the yarns is obtained using a hydraulic testing machine produced by MTS Systems Corporation. The dynamic testing is performed on each of the materials with the same specimen cross sections as in the quasistatic tests. This will allow the observation of any rate dependent behaviour that each material may have while avoiding any scale effects that specimens of different sizes can exhibit.

Also for the sake of comparison of the strength between different yarns, the specimen size for each material should be comparable. Although each yarn was of different cross section (i.e. dtex), the specimens made from these yarns were approximately the same cross sectional area. This was accomplished by looping the finer yarn and matching the cross sectional area of thicker yarns. As previously mentioned, Kevlar LT and Zylon 
were looped four times whereas the others were looped twice. All the specimens used in this part of the study had a gage length of $8 \mathrm{~mm}$.

The following lists the specimens tested for quasistatic and dynamic strength:

- 1154 fibres of Kevlar 129 (2 loops), cross section: $1.31 \times 10^{-7} \mathrm{~m}^{2}$

- 1166 fibres of Kevlar KM2 (2 loops), cross section: $1.32 \times 10^{-7} \mathrm{~m}^{2}$

- 1080 fibres of Kevlar LT (4 loops), cross section: $1.22 \times 10^{-7} \mathrm{~m}^{2}$

- 1350 fibres of Twaron (2 loops), cross section: $1.53 \times 10^{-7} \mathrm{~m}^{2}$

- 1268 fibres of Zylon (4 loops), cross section: $1.44 \times 10^{-7} \mathrm{~m}^{2}$

The specimen cross sectional areas were obtained from the number of fibres in the yarn and the nominal single fibre diameter. The nominal single fibre diameter for each yarn was provided by manufacturer while the number of fibres in a yarn was calculated from the yarn dtex, the material density and the nominal single fibre diameter. Table 4.1 shows the single fibre diameter and the density of each material along with the number of fibres in a yarn of given dtex.

Table 4.1 - Data used for obtaining yarn cross section

\begin{tabular}{|c|c|c|c|}
\hline Material (dtex) & Single Fibre Dia. & Density $\left[\mathbf{K g} / \mathbf{m}^{\mathbf{3}}\right]$ & \# Fibres in Yarn \\
\hline Kevlar 129 (940) & $12 \mu \mathrm{m}$ & 1440 & 577 \\
\hline Kevlar KM2 (950) & $12 \mu \mathrm{m}$ & 1440 & 583 \\
\hline Kevlar LT (440) & $12 \mu \mathrm{m}$ & 1440 & 270 \\
\hline Twaron (1100) & $12 \mu \mathrm{m}$ & 1440 & 675 \\
\hline Zylon (560) & $15 \mu \mathrm{m}$ & 1560 & 317 \\
\hline
\end{tabular}




\subsubsection{Scale Effect}

A detailed study of the scale effect is performed by varying the volume of the material under stress by either increasing the cross sectional area or the gage length of the specimens. Varying the specimen size was considered to be an appropriate parameter since the total volume of the yarn would be under uniaxial tensile stress. Therefore, by varying the cross sectional area or gage length, the volume under uniaxial tensile stress would be changed. As mentioned in Chapter 2, by increasing the volume of a brittle material, the probability of existence of a critical defect is increased. This in turn increases the likelihood of failure at a given stress and hence decreases the maximum failure stress [Hertzberg, 1996]. The aim of this study is to obtain an expression relating the failure stress of the specimen to the size of the specimen. The study of the scale effect was carried out on Kevlar 129 yarn at quasistatic strain rates.

A broad range of specimen sizes were considered with a set of 10 tests performed for each specimen size. Single fibre tests were performed using a precision ballscrew testing machine manufactured by SDL Atlas. The larger specimen sizes were tested on the higher capacity hydraulic testing machine. The details of the two test setups and the testing procedures will be discussed later in this chapter. 
The following specimen sizes were tested for the scale effect:

- Single fibre of Kevlar 129, gage length of $5 \mathrm{~mm}$, cross section: $1.13 \times 10^{-10} \mathrm{~m}^{2}$

- Single fibre of Kevlar 129, gage length of $16 \mathrm{~mm}$, cross section: $1.13 \times 10^{-10} \mathrm{~m}^{2}$

- Single fibre of Kevlar 129, gage length of $25 \mathrm{~mm}$, cross section: $1.13 \times 10^{-10} \mathrm{~m}^{2}$

- Single fibre of Kevlar 129, gage length of $50 \mathrm{~mm}$, cross section: $1.13 \times 10^{-10} \mathrm{~m}^{2}$

- Single fibre of Kevlar 129, gage length of $100 \mathrm{~mm}$, cross section: $1.13 \times 10^{-10} \mathrm{~m}^{2}$

- 1154 fibres of Kevlar 129, gage length of $24 \mathrm{~mm}$, cross section: $1.31 \times 10^{-7} \mathrm{~m}^{2}$

- 2308 fibres of Kevlar 129, gage length of $24 \mathrm{~mm}$, cross section: $2.61 \times 10^{-7} \mathrm{~m}^{2}$

- 1154 fibres of Kevlar 129, gage length of $100 \mathrm{~mm}$, cross section: $1.31 \times 10^{-7} \mathrm{~m}^{2}$

- 1154 fibres of Kevlar 129, gage length of $170 \mathrm{~mm}$, cross section: $1.31 \times 10^{-7} \mathrm{~m}^{2}$

Now that the framework of the study is in place, the dynamic and quasistatic testing setups are described. This is followed by the description of the various gripping mechanisms and the method of preparation of the specimens.

\subsection{Tensile Hopkinson Bar Setup}

\subsubsection{Physical Setup}

The tension Hopkinson bar assembly consists of four major parts: the gas gun, the striker/incident bar assembly, the transmitted bar assembly and the attachment mechanism. Figure 4.1 shows a schematic diagram of the setup. 

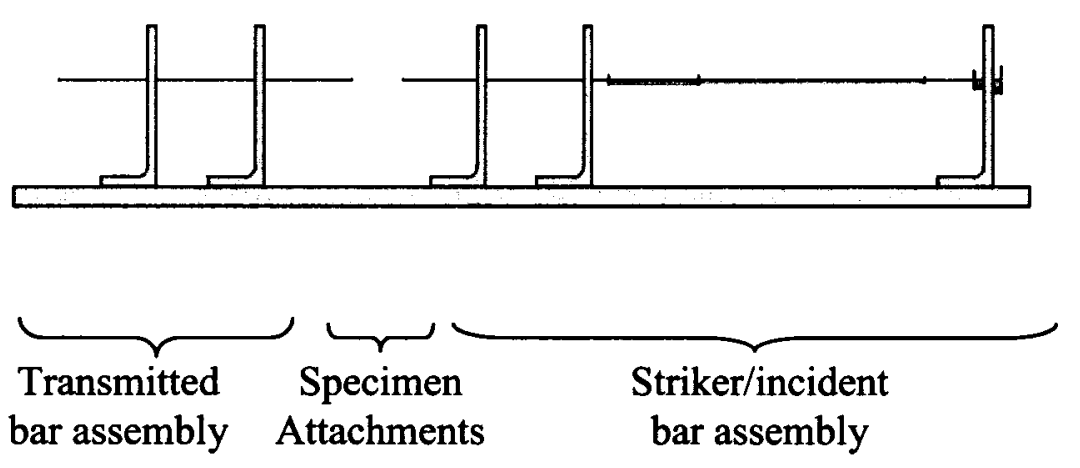
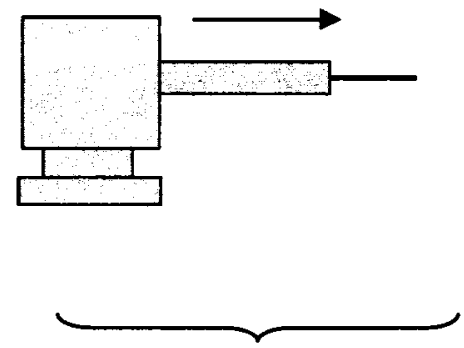

Gas gun

Figure 4.1 - Schematic diagram of the Hopkinson bar

For the tensile Hopkinson bar constructed here an existing gas gun was utilized. The gas gun uses nitrogen to propel a sabot that accelerates a $9.53 \mathrm{~mm}(3 / 8$ ") diameter aluminium striker bar in the direction shown in Figure 4.1. In order to produce a tensile pulse, the striker bar is connected to the striker tube by means of steel cables from both sides of the gas gun as shown in Figure 4.2.

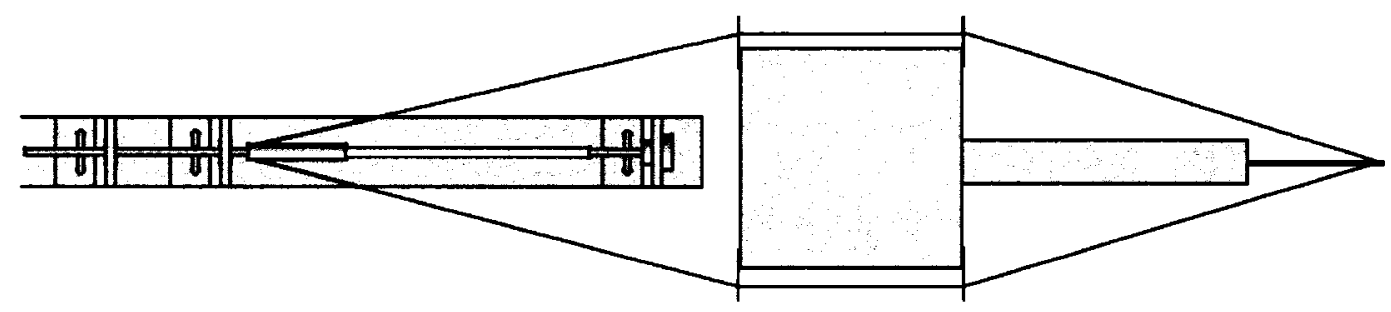

Figure 4.2 - Top view of the two-cable setup (transmitted bar assembly not shown)

The striker/incident bar assembly consists of a $6.35 \mathrm{~mm} \mathrm{(1/4")} \mathrm{diameter} \mathrm{hardened} \mathrm{stainless}$ steel bar that is kept aligned by 3 brass bushings that are contained in the L-shaped steel supports. The incident bar is $1.12 \mathrm{~m}$ long. An aluminium striker tube (6.35 mm (1/4") ID, 
$12.7 \mathrm{~mm}(1 / 2 ")$ OD, $19.7 \mathrm{~cm}$ (7.75") long) slides on the incident bar. Figure 4.3 shows the details of the striker/incident bar assembly.

One end of the incident bar is threaded for specimen attachment and the other end has a $12.7 \mathrm{~mm}(1 / 2 ")$ diameter steel anvil attached. The anvil is free to slide inside a Delran bushing that is supported on the farthest right support. Once the gas gun is fired, the striker tube is launched forward by the connecting steel wires until it reaches the anvil. After impact, the compressive wave generated travels down the anvil until it reaches the free end, where it reflects back into the bar as a tension wave. The tension wave travels down the incident bar and reaches the specimen at the opposite end of the bar.

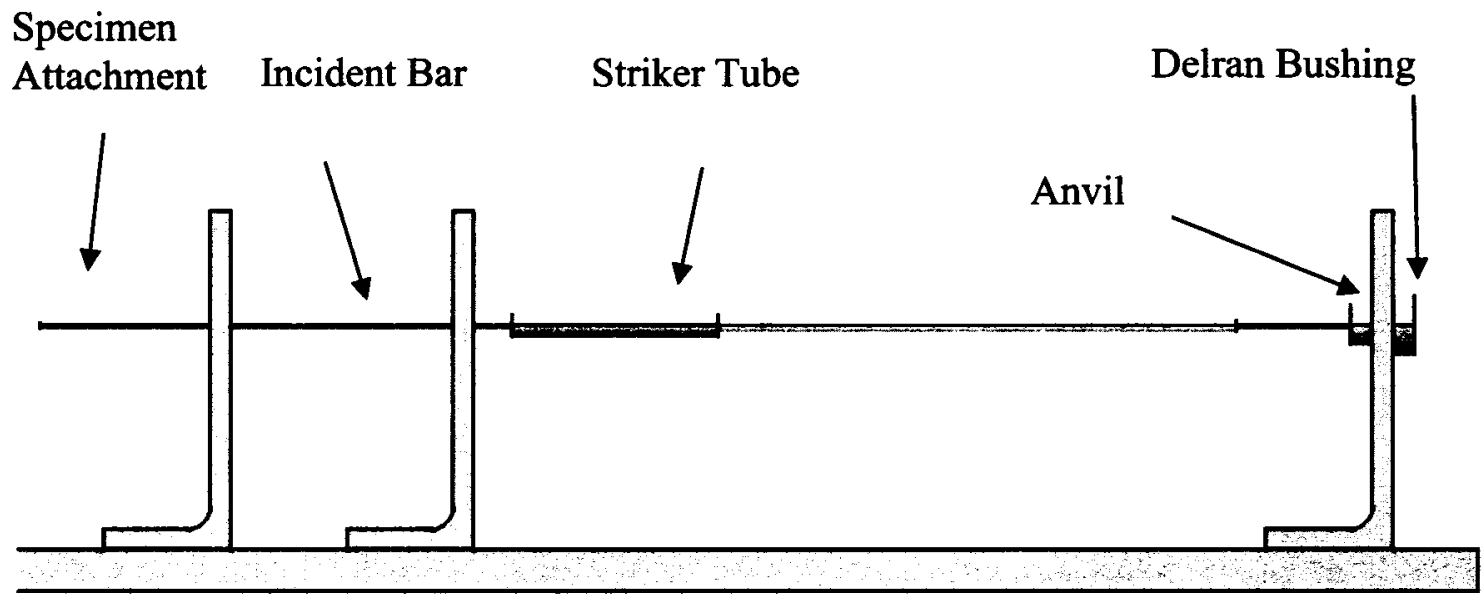

Figure 4.3 - The striker/incident bar assembly

The transmitted bar assembly consists of a $12.7 \mathrm{~mm}(1 / 2$ ") diameter aluminium bar sliding through brass bushings that are supported by steel supports. The transmitted bar is 0.71 $m$ (28") long. One end of this bar is free and the other is threaded for specimen attachment. The transmitted bar was made from Aluminium in order to maximize the 
signal obtained from the strain gauges on the bar. Since the modulus of aluminium is lower than steel, for a given stress level, the aluminium bar would experience higher strains which produces a higher output from the strain gages. The diameter of the transmitted bar is chosen to be equal to the diameter of the clamps. This was done to minimise the distortion of the transmitted wave. This is not true for the case of the incident bar. There is a cross sectional difference between the specimen clamps and the incident bar which causes distortions in the reflected signal and some difficulty in obtaining strain data for the high rate tests using the strain gages. This issue will be addressed in Chapter 5 and an alternative method of obtain strain using high speed photography is proposed.

For each test carried out on the Hopkinson bar setup, the gas gun was pressurised to 345 $\mathrm{kPa}(50 \mathrm{psi})$. The acquisition setup was prepared for the capture of the signals with the incident signal acting as the trigger event. Once the test was carried out, the signals obtained from the oscilloscope were processed. The average specimen stress was calculated using equation (3.12). The strain and strain rate was calculated using equations (3.13) and (3.14). As mentioned previously, a discussion of the reflected signal and methods of obtaining strain data will be presented in Chapter 5.

\subsubsection{Acquisition and Instrumentation}

Two pairs of strain gauges are used to acquire data from the tests. A pair of strain gauges was placed on each of the incident and transmitted bars. Each pair of the strain gages are placed diametrically opposed on the surface of the bar and also connected to two 
opposing arms of the Wheatstone bridge. See Figure 4.4 for the schematic of the bridge and the position of the strain gage on the circuit. This setup of the gages provides for the cancellation of any bending signal that may occur in the bar since each strain gage would experience the opposite sign but equal magnitude strain under bending. Apart from this benefit, another advantage of using a pair of strain gages is that the output of the Wheatstone bridge is double in comparison to using a single strain gage.

The strain gauges on the incident bar were placed $40.5 \mathrm{~cm}$ from the anvil end of the bar between two of the L-shaped supports. The gages on the transmitted bar are $21 \mathrm{~cm}$ from the mid point of the specimen gage length. Gage type 113014-939 from Measurement Group Inc., having a resistance of $350 \mathrm{ohms}$ and a gage factor of 2.105 was utilized. Two Wheatstone bridges were used to obtain voltage readings from each pair of strain gages. The bridge was built from the circuit diagram shown in Figure 4.4. A constant voltage source was used to power each bridge at a voltage of $10 \mathrm{~V}$. The voltage source was produced by Kikusui with the model number PMC35-2A. Line and load regulations of the voltage source were $3 \times 10^{-3} \mathrm{~V}_{\mathrm{rms}}$ and the ripple was $5 \times 10^{-3} \mathrm{~V}_{\mathrm{rms}}$.

The output voltage of a Wheatstone bridge is given by the following equation which is obtained by applying Ohm's law to the bridge circuit $\left(\mathrm{V}_{\mathrm{o}}=10 \mathrm{~V}\right)$.

$$
V_{\text {out }}=V_{o}\left[\frac{R_{1}}{R_{1}+R_{4}}-\frac{R_{2}}{R_{2}+R_{3}}\right]
$$

Consider the two strain gages attached to two opposing arms on the Wheatstone bridge (e.g. $R_{2} \& R_{4}$ or $R_{1} \& R_{3}$ ). The strain gages are bonded to the surface of a bar which is 
undergoing uniaxial strain with a nominal resistance of $R_{0}$. The deformation of the strain gage increases its resistance to $\mathrm{R}_{4}=\mathrm{R}_{2}=\mathrm{R}_{\mathrm{o}}+\Delta \mathrm{R}$. The two other resistors of the bridge are matched to the nominal resistance of the strain gages, i.e. $R_{1}=R_{3}=R_{0}$.

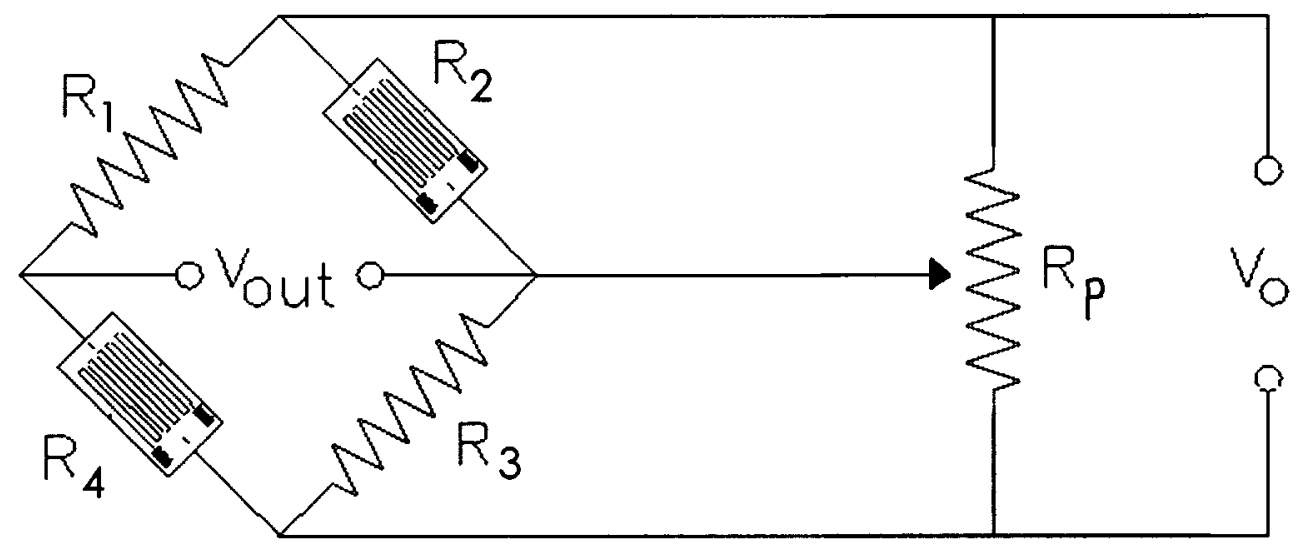

Figure 4.4 - Circuit schematic of a two arm active Wheatstone bridge

By plugging in the expressions for the resistances mentioned above into equation (4.0), the following expression is obtained for the output voltage:

$$
V_{\text {out }}=V_{o}\left[\frac{\Delta R}{2 R_{o}+\Delta R}\right]
$$

The denominator is simplified by recognizing that the change in the resistance of a strain gage is very small compared to $2 R_{0}$. Therefore, the term $\Delta R$ is omitted from the denominator. Hence the expression simplifies to:

$$
V_{\text {out }}=V_{o}\left[\frac{\Delta R}{2 R_{o}}\right]
$$


The gage factor, $\phi$, relates the change in resistance of the strain gage to the strain measured by the strain gauges and is defined to be the following:

$$
\phi=\frac{\Delta R}{R_{o}} / \frac{\Delta L}{L}=\frac{\Delta R}{R_{o} \varepsilon}, \quad \varepsilon=\frac{\Delta L}{L}
$$

By substituting the gage factor definition into equation (4.2), the following is obtained:

$$
V_{\text {out }}=\frac{V_{o} \phi \varepsilon}{2}
$$

By rearranging the above expression we obtain an equation for the strain measured by the strain gages in terms of the gage factor and the input and output voltages.

$$
\varepsilon=\frac{2 V_{o u t}}{\phi V_{o}}
$$

A point worth mentioning is that the potentiometer, $R_{P}$ as shown in Figure 4.4, does not play a role in the actual measurements from the strain gage. Its purpose is for adjusting the zero output level of the bridge at the beginning of each test.

A digital oscilloscope was used to capture the output voltage from the Wheatstone bridge. The oscilloscope was a Nicolet Pro 40 series which has a 12-bit digitizer with a maximum sampling rate of 10 million samples per second and a minimum range of $30 \mathrm{mV}$. The incident and transmitted signal were both captured at the maximum rate. The minimum range was used to capture the transmitted signal because of the small magnitude of the signal produced. The incident and reflected signals were of higher magnitude; therefore the range was set at $60 \mathrm{mV}$. An input filter built-in the oscilloscope was used to filter the noise from the data. The filter covered the range of $100 \pm 10 \%$ kHz. 


\subsubsection{High-speed Photography}

In order to observe the specimen deformation during the high rate tests, a digital high speed camera was used to take a series of photographs. The camera used was made by The Cooke Corporation under the brand name of HSFC Pro. The camera was equipped with 8 high resolution $C C D$ image sensors that could capture frames with a minimum duration of $8 \mathrm{~ns}$ between each image with a maximum of 8 images per test. The camera was triggered using the oscilloscope with the incident signal acting as the triggering event.

This camera was used to take a series of 8 pictures during the Hopkinson bar tests of various yarns. These pictures can be used to gain an understanding of the failure sequence of the fibres in the yarn as well as a way to obtain strain data independent from the strain gage readings. The pictures will be presented and discussed in Chapter 5 .

\subsection{Quasistatic Setups}

\subsubsection{Single Fibre Testing Setup}

The testing machine used to obtain the strength of a single fibre is made by SDL Atlas (M350-5kN). This machine is equipped with $20 \mathrm{~N}$ load cell with an accuracy of $\pm 0.0001 \mathrm{~N}$. The setup was also equipped with pneumatically actuated rubber padded grips made for gripping fine yarns. As mentioned earlier, Kevlar 129 was chosen to be the yarn studied for the scale effect. A set of 10 tests were performed on single fibres removed from a Kevlar 129 yarn of dtex 940 for gage lengths of 5, 16, 25, 50 and 100 
$\mathrm{mm}$. For each test, the maximum load to failure was recorded. The maximum load was then used with the single fibre cross sectional area to obtain the failure stress. The cross sectional area was assumed to be circular and constant with diameter of $12 \mu \mathrm{m}$. All the tests on single fibre were carried out at the strain rate of $10^{-3} \mathrm{~s}^{-1}$. The average failure load was $0.4 \mathrm{~N}$ which is well within the range of accuracy of the $20 \mathrm{~N}$ load cell. Figure 4.5 shows the testing setup with a close-up of the grips used.

\subsubsection{Multi Fibre Testing Setup}

A hydraulic testing machine was used for obtaining load versus displacement data for the yarn specimens. This machine was equipped with a $25 \mathrm{kN}$ load cell and a $10 \mathrm{~mm}$ displacement cell. The load and displacement cells provided sufficient accuracy and range to test the different combinations of gage lengths and cross sectional areas. The failure loads were on the order of $1 \mathrm{kN}$ which was considered to be within the accuracy of the load cell.

The quasistatic tests provided force versus displacement data which were used with the cross sectional area and the gage length of the specimens to produce stress versus strain plots. The description of the grips and the preparation of the specimens are discussed in the next section. Figure 4.6 shows the hydraulic testing machine along with a close-up of the grips. All the tests were carried out at the strain rate of $10^{-5} \mathrm{~s}^{-1}$. 


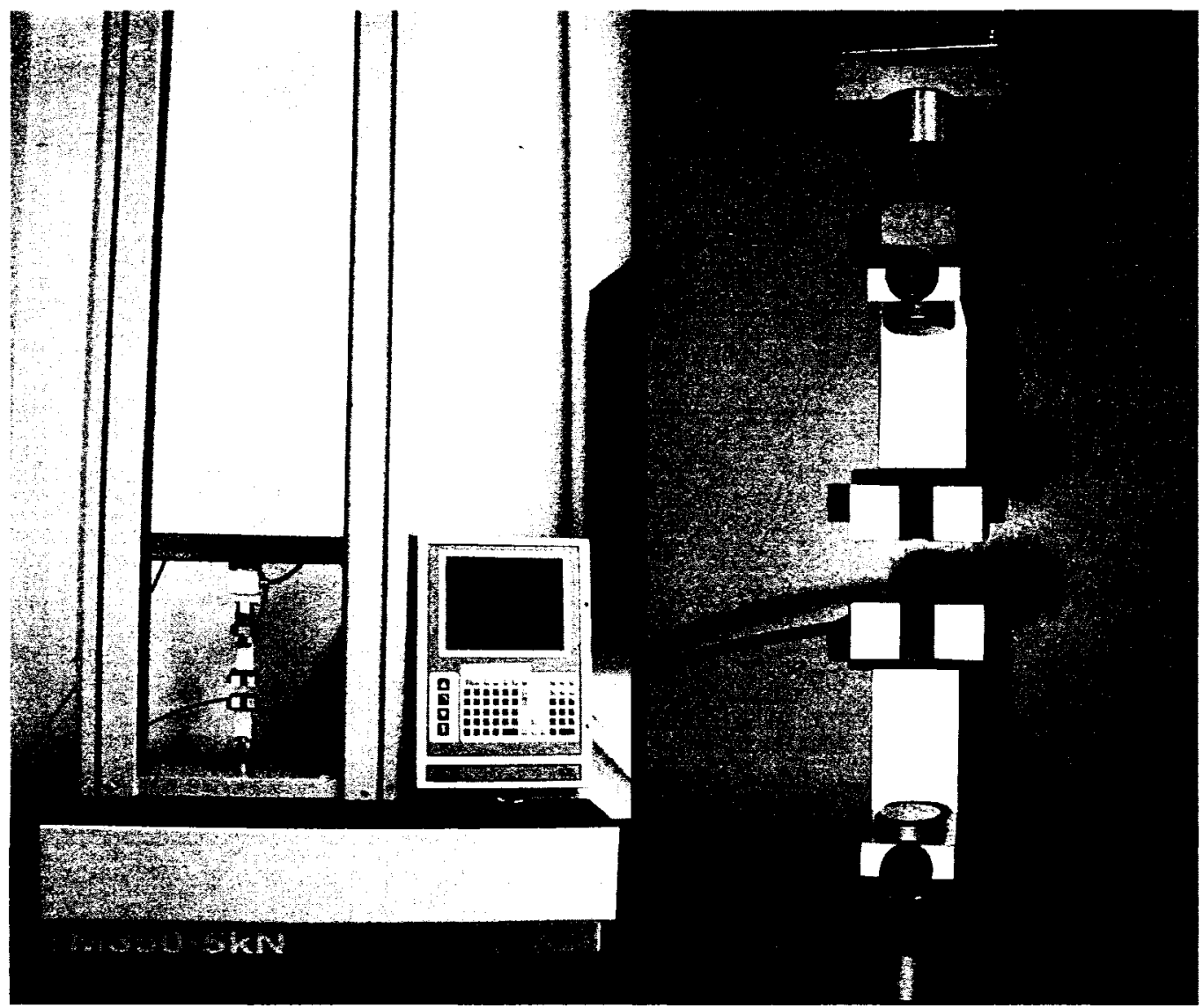

Figure 4.5 - Single fibre testing setup with close-up of the grips

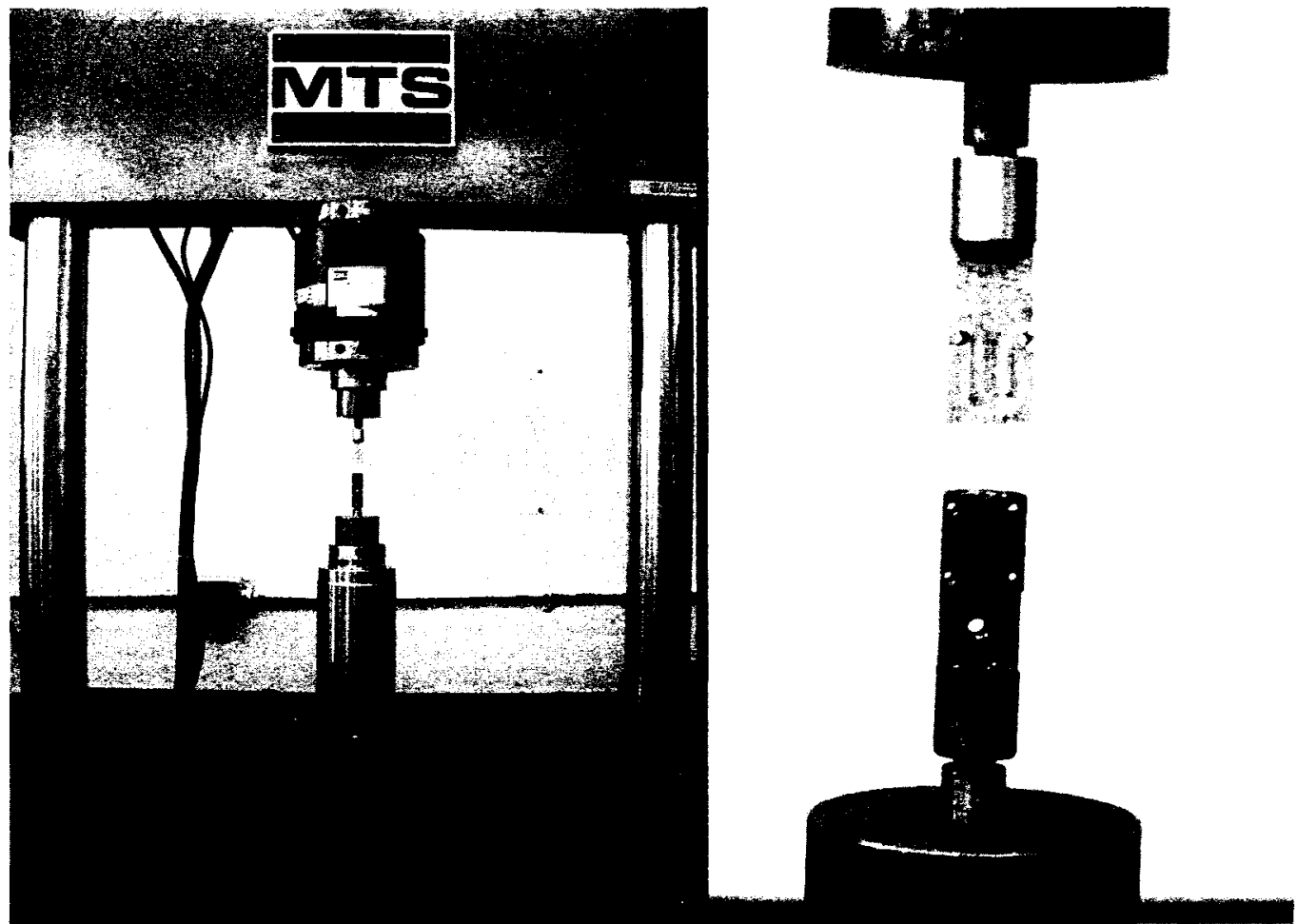

Figure 4.6 - Multi fibre testing setup with close-up of the grips 


\subsection{Description of the Grips and Preparation of the Specimens}

The design of a suitable gripping mechanism for testing of yarns was a challenging task. The principal requirements are to find a gripping method that minimizes slip while maintaining the fibre tension required to bring the yarn to failure and to insure that the failure of the yarns occurs in the gage section such that the failure is not initiated by the grips. In addition to these requirements, dynamic testing using Hopkinson bar methods requires that the gage section of the yarns be kept relatively short so that the displacement produced by the impact is sufficient to achieve failure in the yarns. A number of different gripping mechanisms were considered for the static and the dynamic experiments. Mechanical, epoxy and combined mechanical/epoxy grips were experimented with. A combination of mechanical and epoxy gripping mechanism proved to be the most successful. This gripping mechanism and the preparation of the specimens will be described in detail.

\subsubsection{Mechanical Gripping Method}

The first gripping method attempted was mechanical. In this method, yarns were weaved through holes on an aluminium plate, which was then clamped to grips, which were threaded onto the incident and transmitted bars. Four holes were drilled through an aluminium plate through which the Kevlar fibres were threaded to make a pattern that would keep the fibres in place by friction. Figure 4.7 shows a picture of a prepared specimen. This method resulted in a minimum of slip, which allowed yarns to be tested

to failure. However, failure often occurred at the edge of the aluminium plate indicating that the grip was shearing the yarn. Attempts to round the corner of the plate were 
partially successful, but were unable to completely remove the influence of the grip on specimen failure. A variation of this method in which plastic plates were used in place of the aluminium was also tried, however, the strength of the plates were insufficient to withstand the load required to cause failure in the yarns.

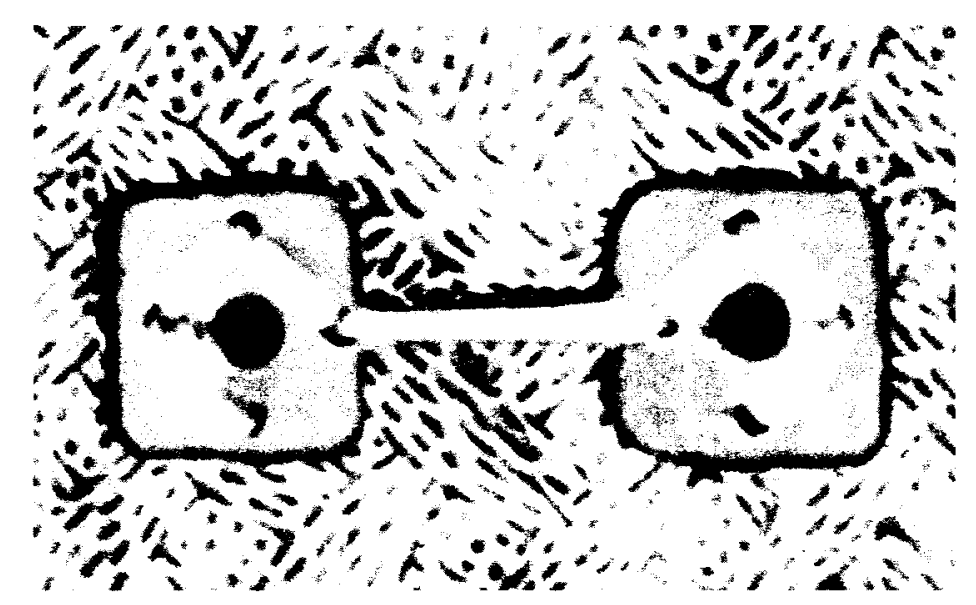

Figure 4.7 - A picture of a specimen with woven yarn on the aluminium plates

\subsubsection{Epoxy Gripping Method}

A two-piece aluminium mould shown in Figure 4.8 was CNC-machined to make dogbone specimens having epoxied end tabs. The mould plate is fastened to an aluminium plate while the epoxy cures. Dog-bone specimens were moulded using epoxy and yarn. The epoxy used throughout this study was produced by MIA Chemicals Inc. with the brand name of MIA-POXY 100 / Hardener 95. The mixing ratio of the epoxy by weight was 100 units of resin per 24 units of hardener. The curing of this epoxy occurred at room temperature which prevented the yarns from being exposed to high temperatures. The adherence between the epoxy and the fibres was sufficient to deform the fibres until failure when used with the final gripping mechanism. 


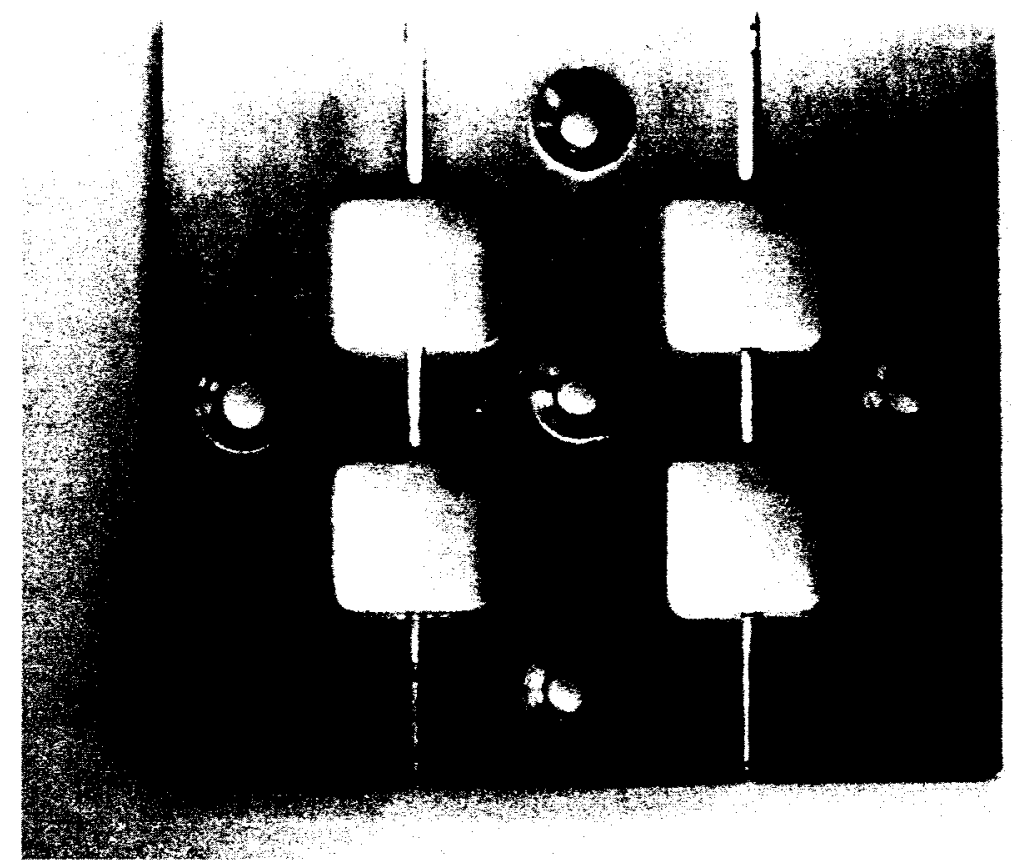

Figure 4.8 - Mould plate for producing dog-bone specimens with epoxy tabs

The pure epoxy specimens were prepared in the following manner. The fibres were placed into the slot and kept taut using clamps. A mixture of mould release agent and wax was pressed into the middle of the slot between the rectangular cavities where the fibres form the gauge length of the specimen. This was done to prevent the epoxy from flowing into the slot and adhering to the fibres. The bonding of the epoxy to the fibres would prevent the free movement and sliding of the fibres. It was observed in experiments that specimens with epoxy in the gage section failed at lower stresses. This was thought to be due to the introduction of shear stresses between fibres caused by the adhesion. 
The wax prevented the epoxy from flowing into the gauge length area. The effect of the wax was significantly improved by adding mould release agent that prevented the fibres from adhering to epoxy. Careful sample preparation and application of mould release agent to the gage length area minimized the amount of epoxy in the gage section. The wax used was produced by Dexter under the brand name of Ceara Cernauba J-1. The mould release agent used was produce by Chemlease under the brand name of Chemlease 70 Semi-Permanent Release Agent.

Once the gage section was prepared, the epoxy mixture was poured into the rectangular cavities. The epoxy was allowed to cure for 24 hours before being removed from the mould. Figure 4.9 shows a dog-bone specimen produced by the mould.

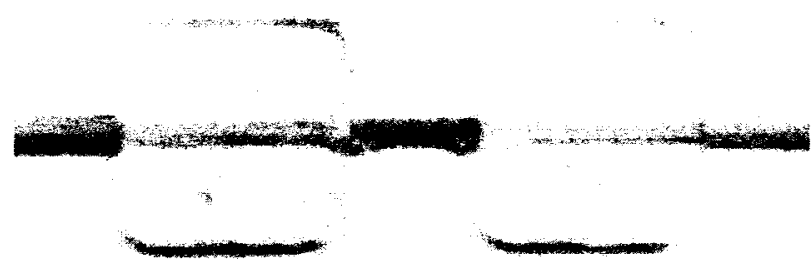

Figure 4.9 - Dog-bone specimen with epoxy end tabs

There were a number of difficulties when using the mould. The preparation of the mould and curing of the epoxy was time consuming. The bubbles in the epoxy tend to weaken the epoxy and cause the tabs to fail prior to reaching the yarn failure load. This problem was minimized by careful mixing of the epoxy as well as allowing the bubbles to escape before using the epoxy. 
This method provided a way to grip the yarn while avoiding shearing of the fibres as observed in the mechanical method, however in many cases slippage occurred and the failure of the yarns could not be achieved.

\subsubsection{Combined Gripping Method}

The method which ultimately proved to be most successful was a combination of the mechanical and epoxy gripping methods described in the previous sections. The epoxied end tab specimens provided a means to grip the fibres without shearing while the woven end plate specimens reduced the slippage of the fibres significantly. A new mould was designed to incorporate both ideas into one gripping mechanism. The length of the gage section was $8 \mathrm{~mm}$. Figure 4.10 shows a picture of the combined grip mould plate.

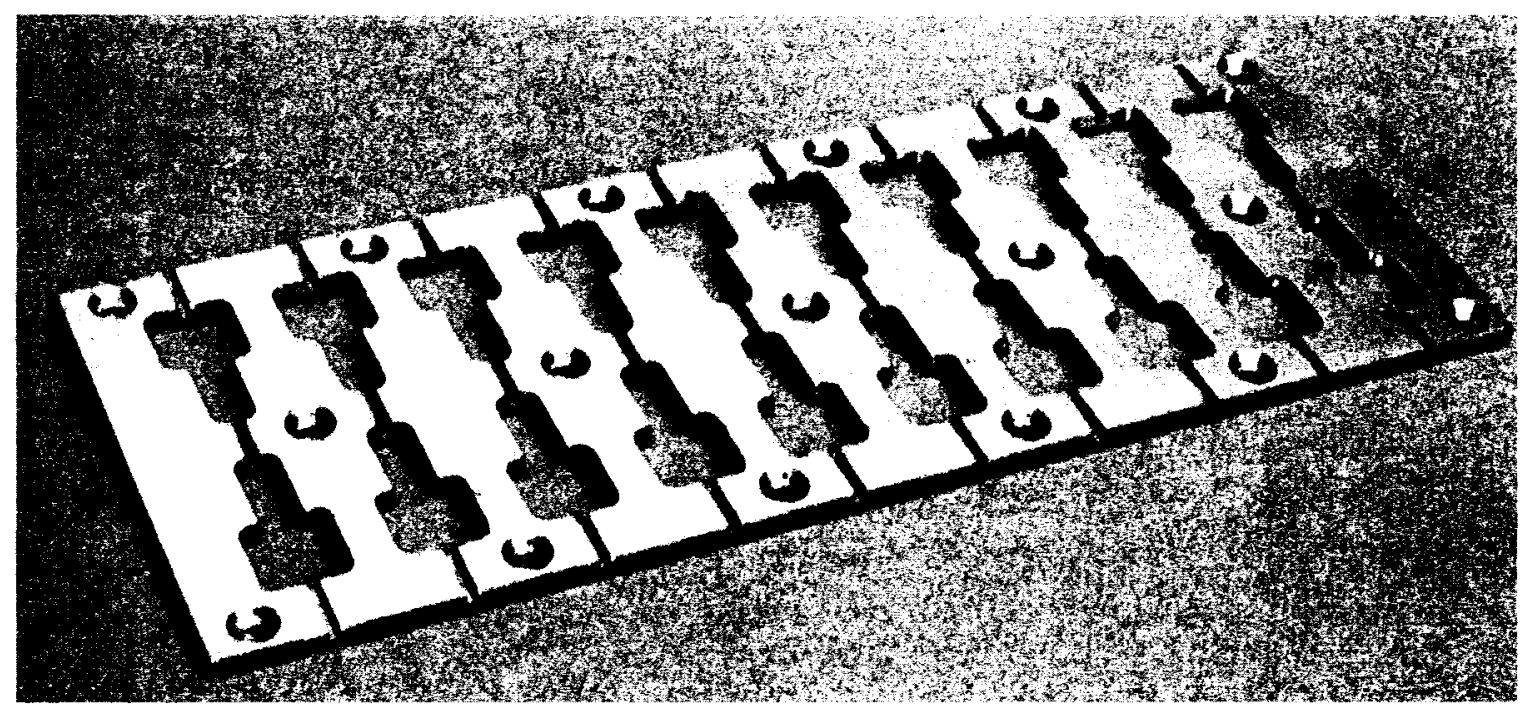

Figure 4.10 - A picture of the mould plate for the combined gripping method

Aluminium plates with holes were inserted into the wider section of the mould cavity and fixed in place by epoxy. Once the epoxy is set, the yarns are woven into the aluminium 
plates on both sides of each specimen and tightened in place. As mentioned in the previous section, wax and mould release agent was pressed into the middle groove in the gauge length area to prevent epoxy from flowing into the gage section. The epoxy was poured to cover the yarns in the mould cavity. The mould was left at room temperature for 24 hours until the epoxy cures. Figure 4.11 shows a picture of the mould before epoxy was poured.

The aluminium tabs used to weave the end tabs were eventually replaced with plastic buttons of similar dimensions. This change allowed faster fabrication of the specimen while still providing a mechanical grip for the yarn. Larger gage length specimens (100 $\mathrm{mm}$ and $170 \mathrm{~mm}$ ) were made using the same specimen preparation method. Figure 4.12 shows a specimen made with plastic buttons after it was removed from the mould.

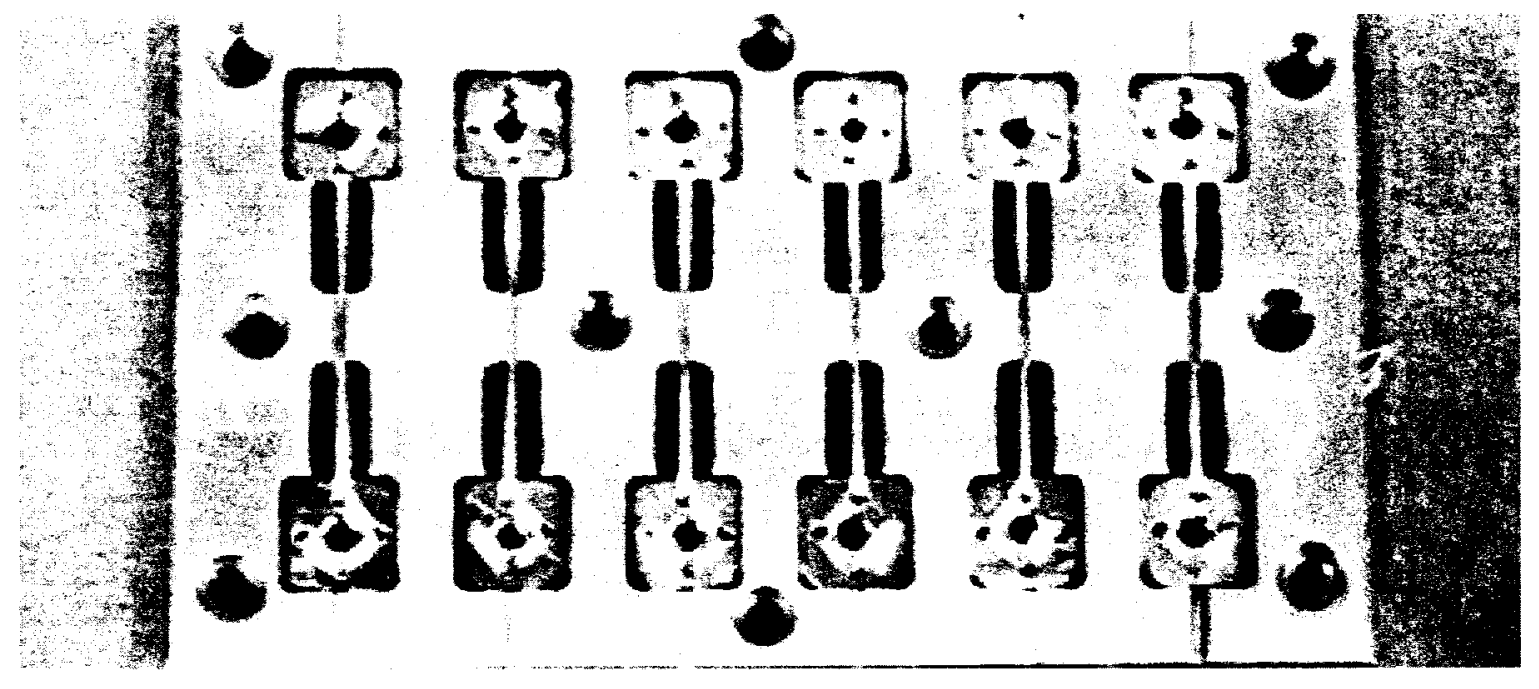

Figure 4.11 - Mould before pouring epoxy 


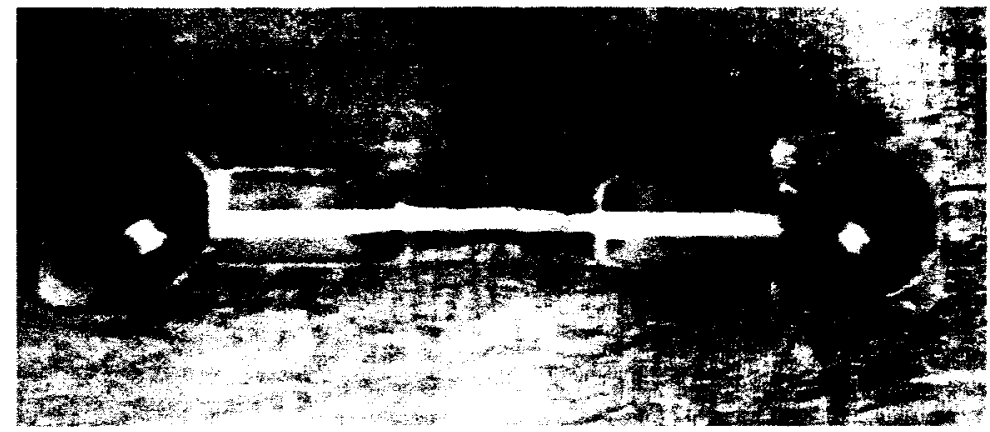

Figure 4.12 - An image of a specimen made with button tabs after removal from mould

The specimen was connected to the Hopkinson bar by mechanical clamps, which were threaded for attachment to the bars. The clamps were machined to match the dimensions of the moulded specimens. A photograph of the clamps is shown in Figure 4.13. One of the clamps was made of aluminium while the other one was made of steel. This was done to match the material property of the Hopkinson bars on each side of the specimen and to facilitate wave propagation. Once the specimen was placed into the clamp, a cover plate was fastened to keep the specimen in place. The same mechanical clamps were used in quasi-static testing, where instead of the clamps being threaded to the incident and transmitted bars; they were attached to the studs of the hydraulic testing machine.

The combined gripping method proved to be successful. The slippage was minimized with the failure occurring in the middle of the gage length in both quasistatic and dynamic tests. 


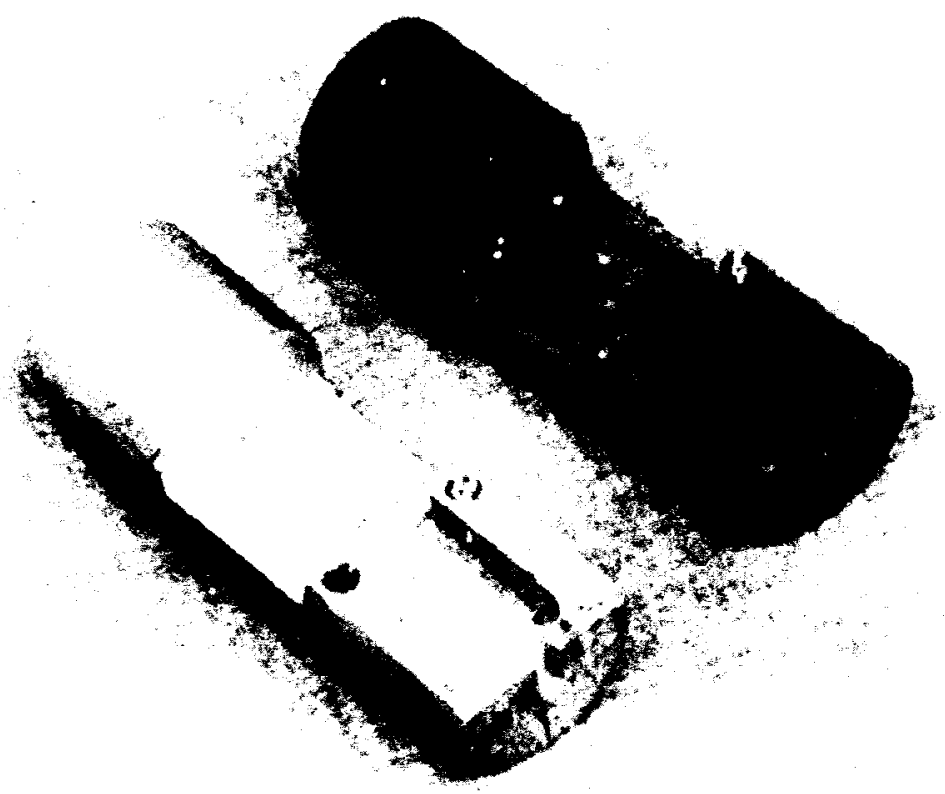

Figure 4.13 - Specimen mechanical clamps 


\subsection{RESULTS}

In this chapter the experimental results for each of the yarns will be presented in the form of stress versus strain plots for the quasistatic and dynamic tests. The dynamic results are initially presented as stress versus time plots and then using the average strain data obtained from the high speed camera pictures, the dynamic stress versus time plots are converted to stress versus strain. An average strength value is reported for the quasistatic and dynamic tests along with the error brackets and the standard deviation for each set of population and their ratio of the strengths is used as a measure of rate sensitivity of each material. The strength results are compared and contrasted to those reported in the literature.

Weibull parameters are obtained for each set of quasistatic and dynamic tests. An explanation of the significance of the Weibull parameters is made along with a comparison between the scale and shape factors reported in the literature. Weibull parameters are also reported for various specimen sizes tested in the scale study. These results will be used to show the variation and dependence of the Weibull parameters on the size of the specimen.

The variation of strength with the specimen size will be presented in the form of stress versus strain for specimens of different sizes. This will be followed by plotting the average failure stress versus the specimen volume in order to show the variation of the strength with increasing specimen size. 


\subsection{Quasistatic and Dynamic Results}

The results for the quasistatic and dynamic tests will be presented together for each of the yarns. The number of fibres in the specimens is stated in the figure caption along with average failure strength and the error bracket for each set of tests.

As mentioned in the experimental procedure chapter, the cross sectional area difference between the incident bar side and the clamp causes large distortions in the reflected wave as it encounters the discontinuity. Strain histories are calculated using the incident and reflected wave as shown in Equation 3.13 in Chapter 3. This distortion of the reflected wave produces inaccurate strain readings that do not represent the actual deformations. Therefore, acquisition of complete strain histories was hampered. However, an average strain rate was obtained from the images from the high speed camera which are used to convert the strain versus time plots to stress versus strain plots. These images will be presented in the next section.

Figure 5.1 shows a sample voltage history obtained from the oscilloscope with each wave identified. The incident wave can be approximated as a square wave that produces the high rate displacements needed to break the specimen. The reflected wave is shown with the distortions that were discussed previously visible as large oscillations. The transmitted wave is the portion of the incident wave that transmits through the specimen into the transmitted bar. The transmitted wave can be approximated as a triangular wave and it has smaller amplitude compared to the other waves. 


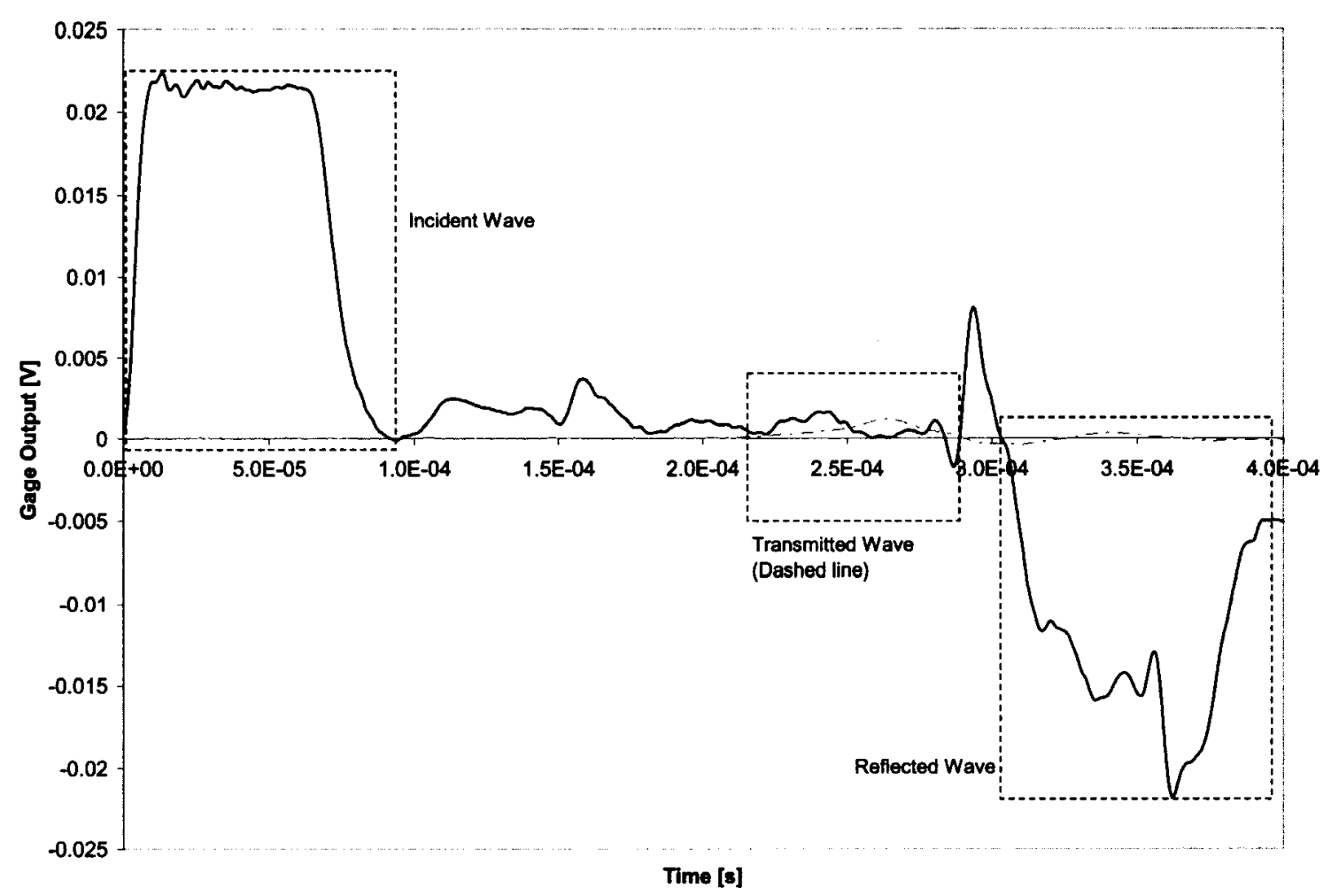

Figure 5.1 - Sample voltage signal from strain gage with each wave labelled

Another point of discussion is the definition of the effective gage length for specimens. Quasistatic test results on long gage length specimens (gage lengths of $100 \mathrm{~mm}$ and 170 $\mathrm{mm}$ ) showed that the failure strain is between $3-4 \%$ while in the specimens with the gage length of $8 \mathrm{~mm}$, the failure strains were 3 times higher. This difference was attributed to some of the deformations taking place outside the gage length, i.e. in the epoxy tabs. In the case of long gage length specimens, the displacement in the tabs would be of relatively smaller magnitude in comparison to the displacement that occurs within the gage section. However in the case of the shorter specimens, smaller displacement would be needed to break the specimens with a relatively high portion of that displacement occurring in the tabs. Figure 5.2 shows a schematic of a short and a long specimen with the displacement in the gage section, $\delta_{\mathrm{g}}$, and the displacement in the tabs, $\delta_{\mathrm{t}}$, labelled. 

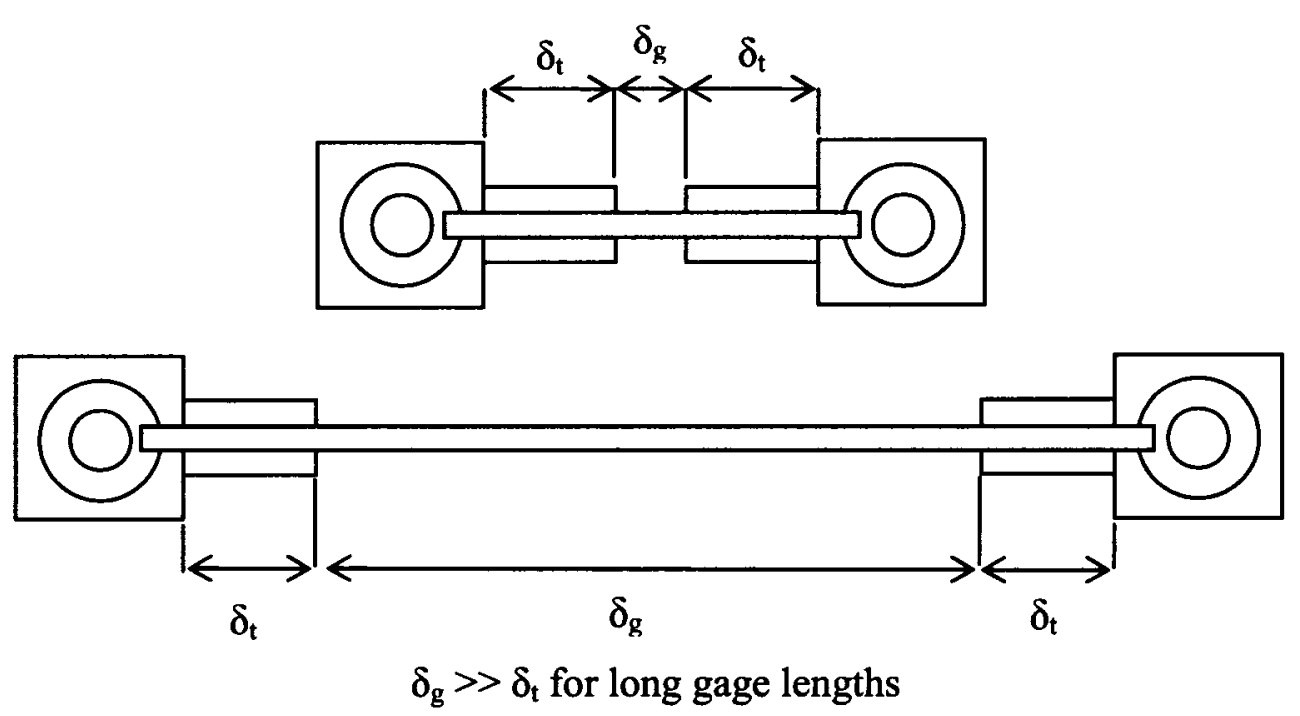

Figure 5.2-Comparison between the displacements in the gage section and in the tabs

Another argument could be formulated in terms of the force experienced by the tab section. Consider that approximately the same load would be experienced by the tabs for a long or short specimen at failure. Therefore, the tab displacement $\left(\delta_{t}\right)$ that would occur for the short and long specimens would be the same. The tab displacements would be much smaller than the displacement in the gage section of longer specimen, hence obtaining strain values with smaller deviation from the actual strain. However, the tab displacements are significant in comparison to the displacement in gage section for the short specimens.

With this in mind, the definition of the effective gage length for the short specimen was changed to include deformation within the tabs. By comparing the average failure strain of the $8 \mathrm{~mm}$ gage length specimens with the longer gage specimens, a correction factor was calculated in order to scale the failure strain of the short specimens to the failure 
strain of the longer specimens. The average failure strains of the long and short specimens were $4 \%$ and $12 \%$ respectively. Yang [1993] states the average failure strain of Kevlar fibres to be between 3-5\% validating the strain results of the longer gage length specimens. Therefore, the definition of the effective gage length of short specimens was increased to include part of the tab and to be $24 \mathrm{~mm}$ instead of $8 \mathrm{~mm}$ and scale the strain to ones obtained in long gage length specimens.

\subsubsection{Strain Data from the High Speed Camera Images}

As mentioned in Section 4.2.3, a set of 8 images was captured using the high speed camera during the dynamic tests. These images can be used to obtain strain data independent from the strain gage data. The duration between each frame was varied between each test to observe a different range of deformation of the specimens. The images of one of the tests with Twaron yarn will be presented. The duration between each frame is $50 \mu \mathrm{s}$. The displacements can be approximated by comparing the position of the free edge of the grip with the subsequent image. By averaging the displacement rate obtained between each frame and dividing it by the effective gage length of the specimen, the average strain rate is obtained. The average strain rate was calculated to be $800 \mathrm{~s}^{-1}$ using three sets of test images. Figure 5.3(a) \& 5.3(b) shows the sequence of images for a dynamic test on Twaron.

In this sequence of images, the yarn appears to be slack in image 1. The yarn appears to be taut in image 2 with the tensile wave passing through the specimen between images 2 to 4 . In image 3 , the yarn is engulfed in a cloud of wax which remains on the gage 
section after removal from the mould. As the fibres are strained, the dried wax separates from the gage section obscuring the image during the deformation. This limits the observations for the deformations of individual fibres; however the displacement for the whole yarn can still be obtained. Image 5 shows the fibres after breaking with the remaining images showing further separation of the fibres. 
Figure 5.3(a) - Images 1 to 4 from testing Twaron (frame rate $=50 \mu \mathrm{s}$ )

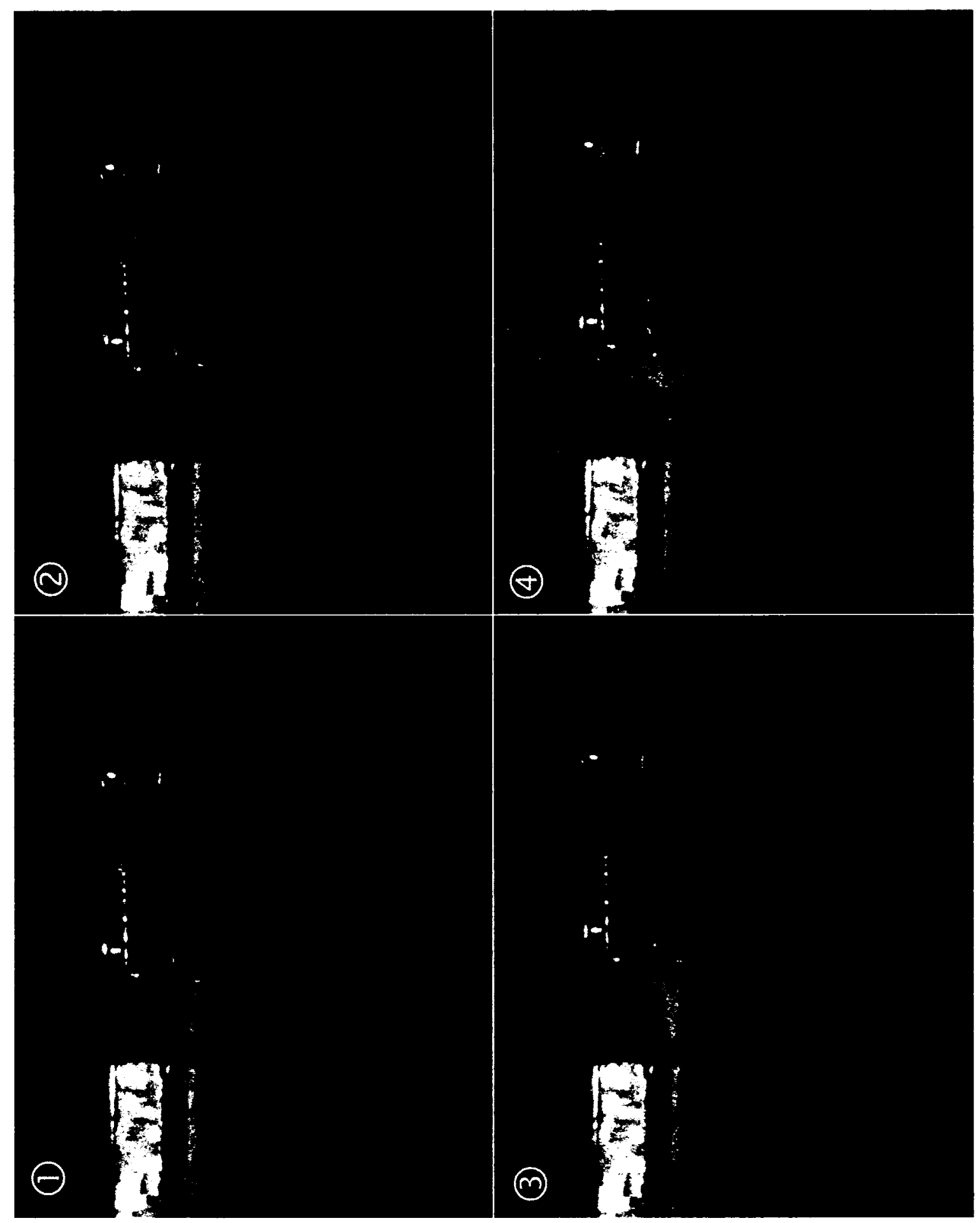


Figure 5.3(b) - Images 5 to 8 from testing Twaron (frame rate $=50 \mu \mathrm{s}$ )

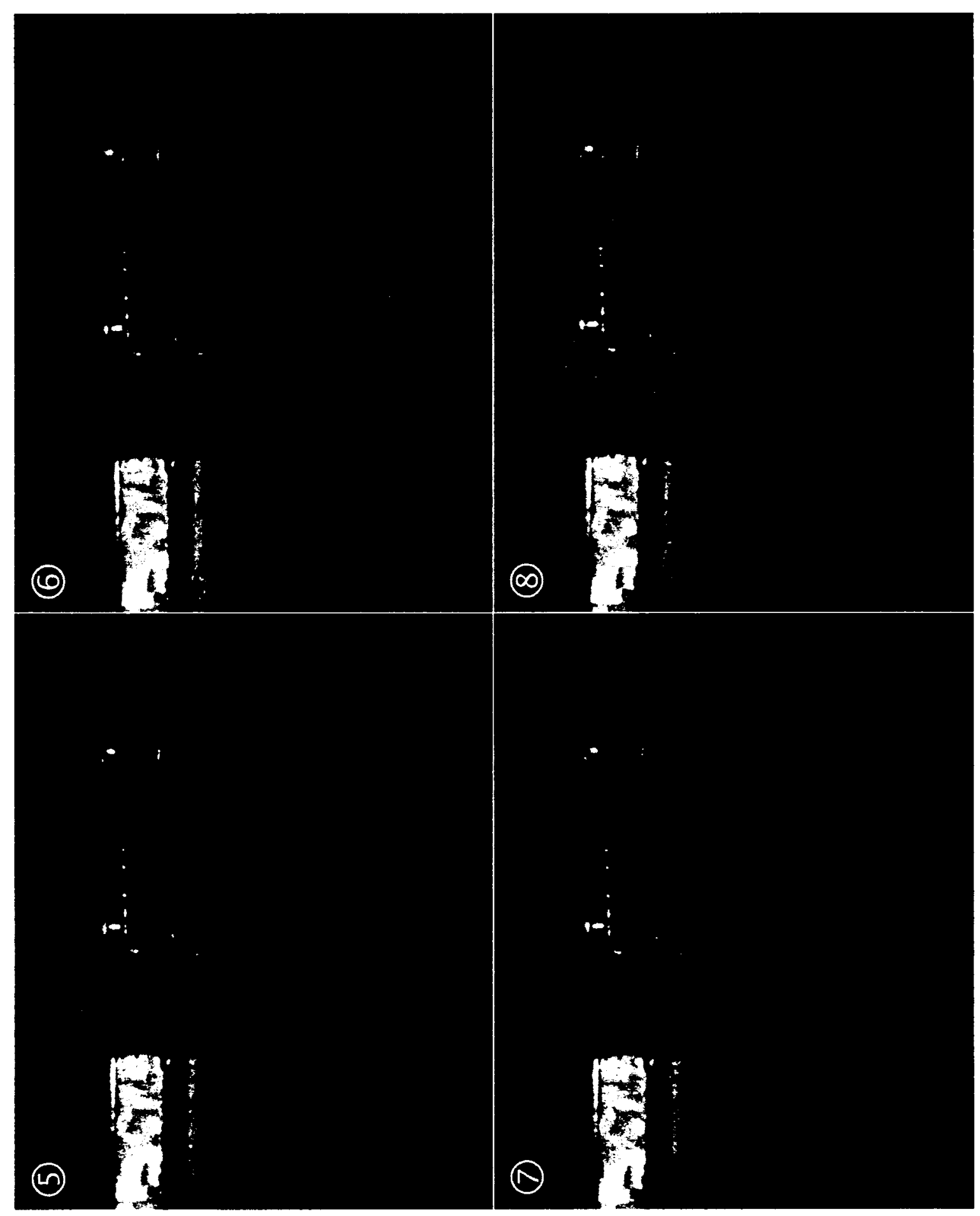


The stress versus time plots obtained for the dynamic tests can be converted to stress versus strain plots by using the average strain rate obtained from the camera images. By multiplying the duration of the deformation by the average strain rate, an approximation for the strain history can be made.

Now that the alternative method of obtaining strain data is discussed, the results for each yarn will be presented. Figures 5.4 to 5.8 show the quasistatic stress versus strain plots and dynamic stress versus time plots for each yarn tested along with number of fibres in the specimen and the error bracket in each plot. Figures 5.9 to 5.13 show the dynamic stress versus strain plots for each yarn with the strain data obtain using high speed camera images. For the sake of better presentation, all the presented curves are smoothed using a 15-point moving average plot. 

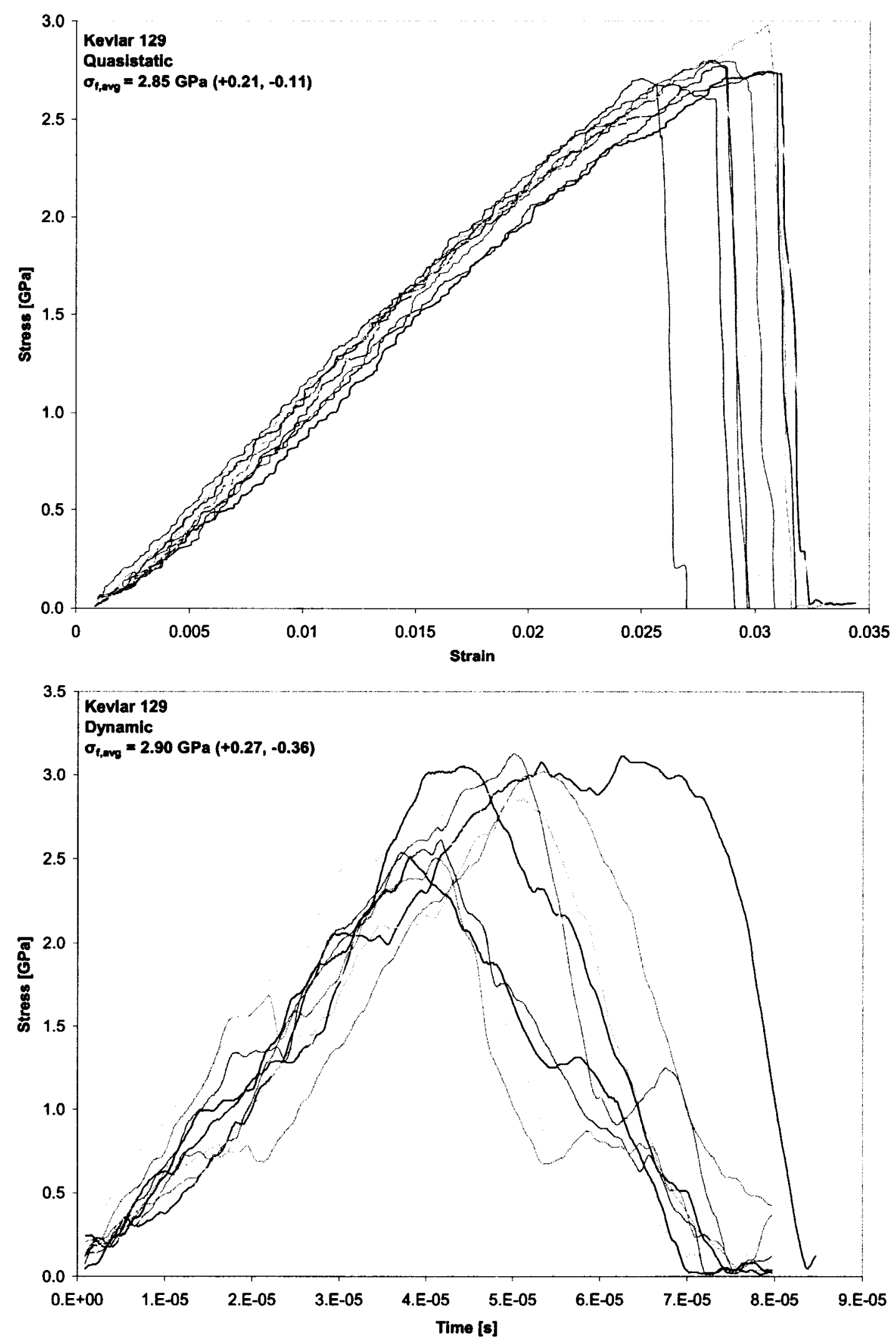

Figure 5.4 - Quasistatic and dynamic results for Kevlar 129 (1154 fibres) 

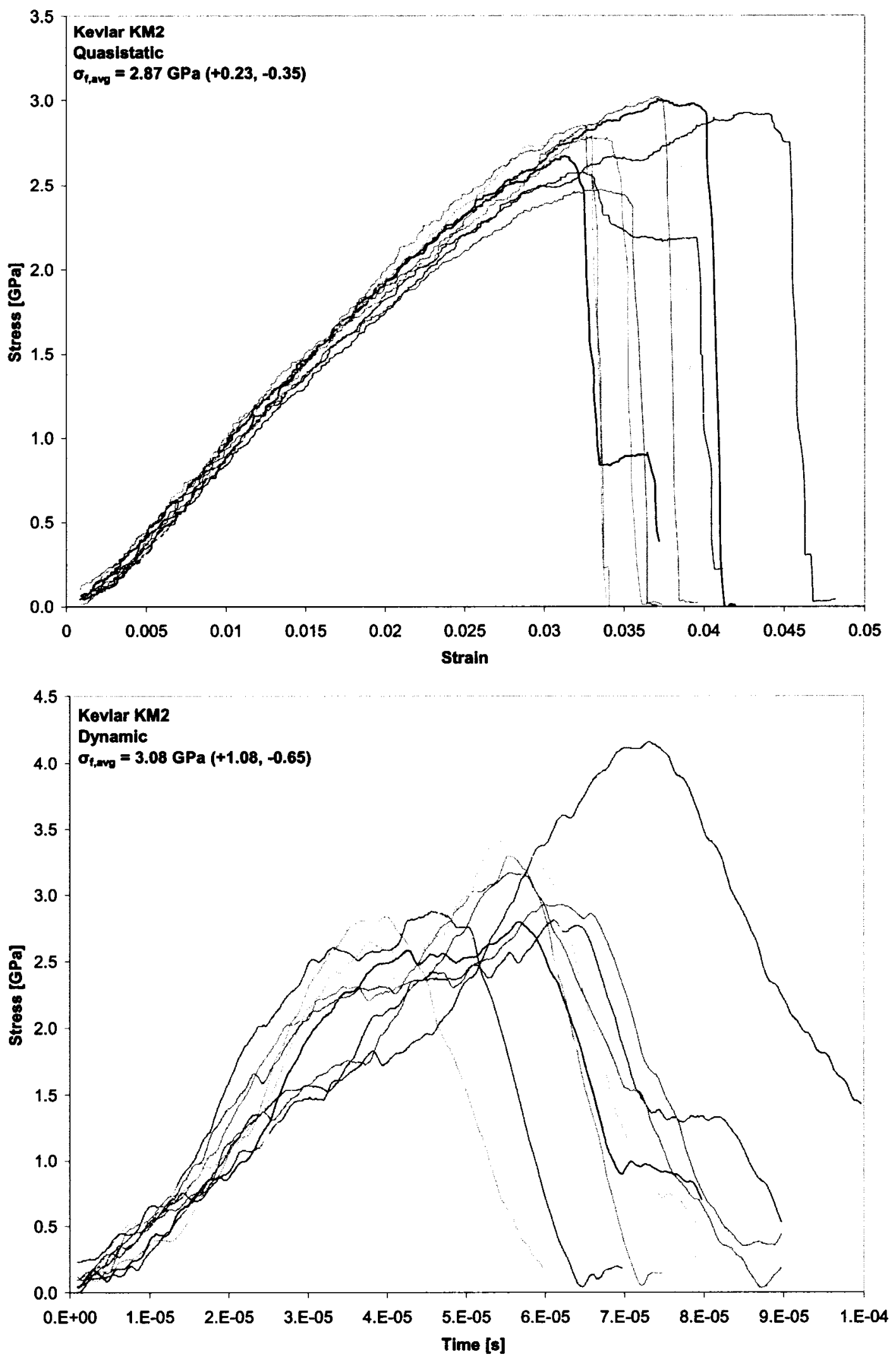

Figure 5.5 - Quasistatic and dynamic results for Kevlar KM2 (1166 fibres) 

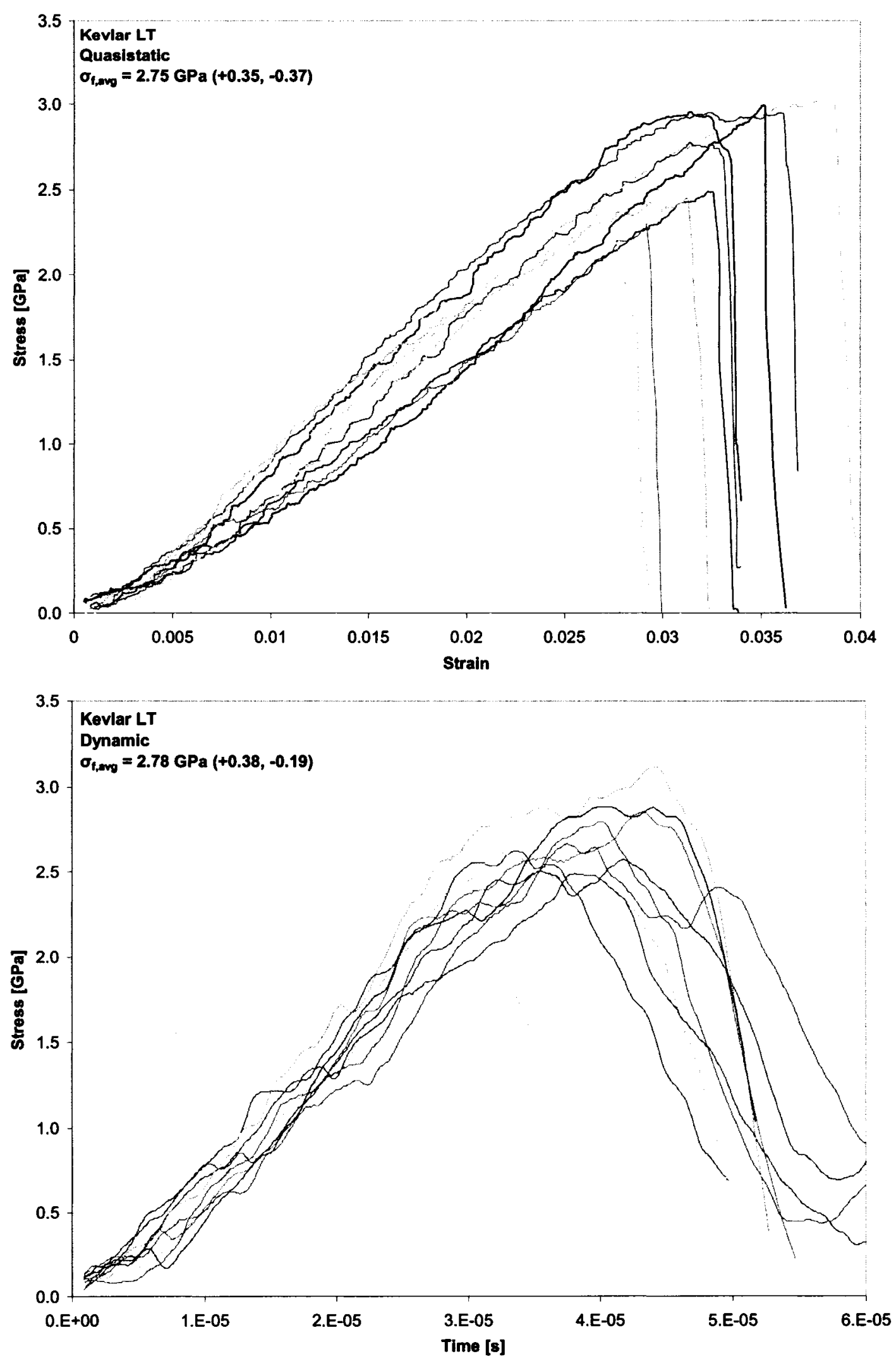

Figure 5.6 - Quasistatic and dynamic results for Kevlar LT (1080 fibres) 

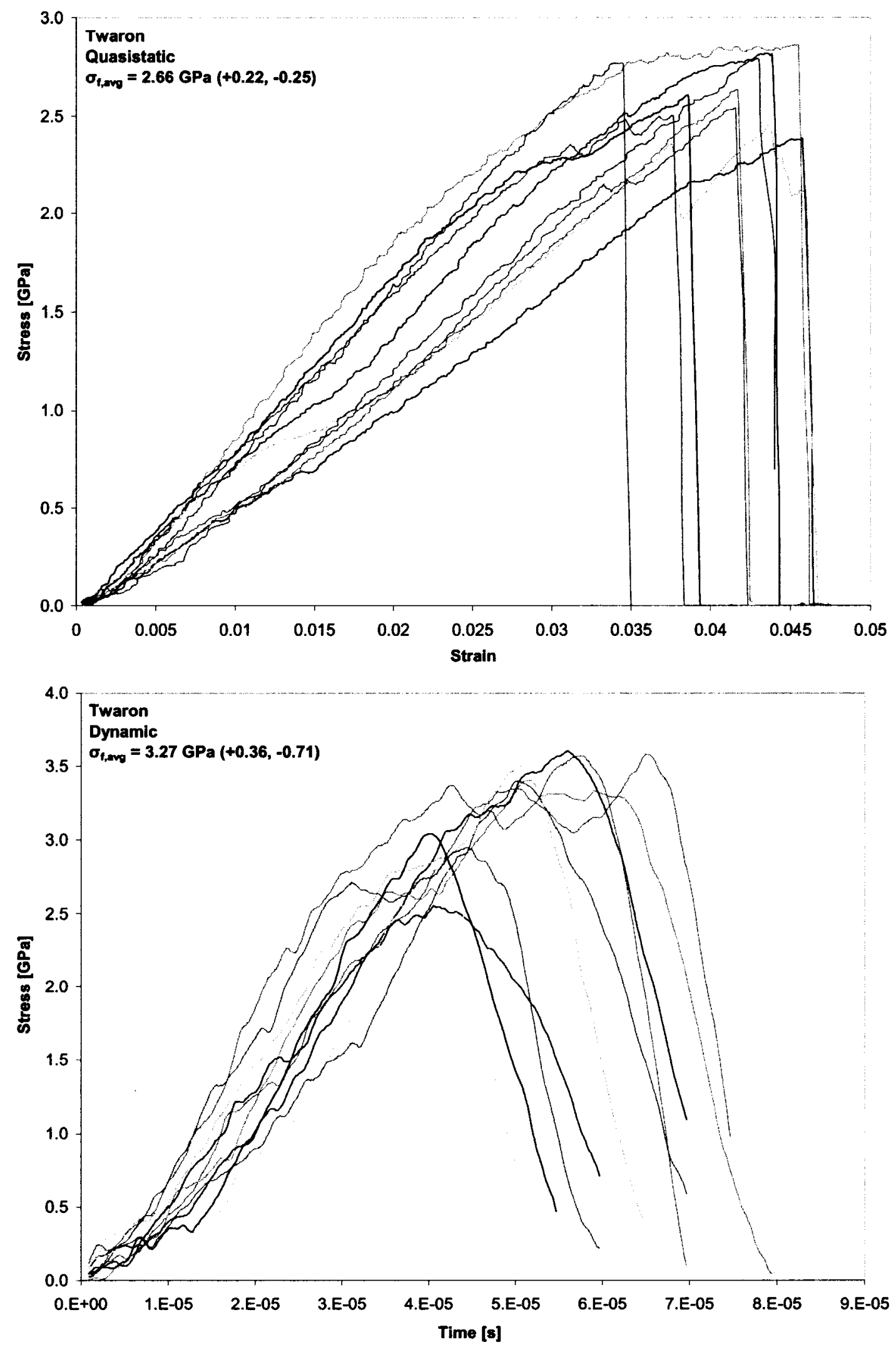

Figure 5.7 - Quasistatic and dynamic results for Twaron (1350 fibres) 

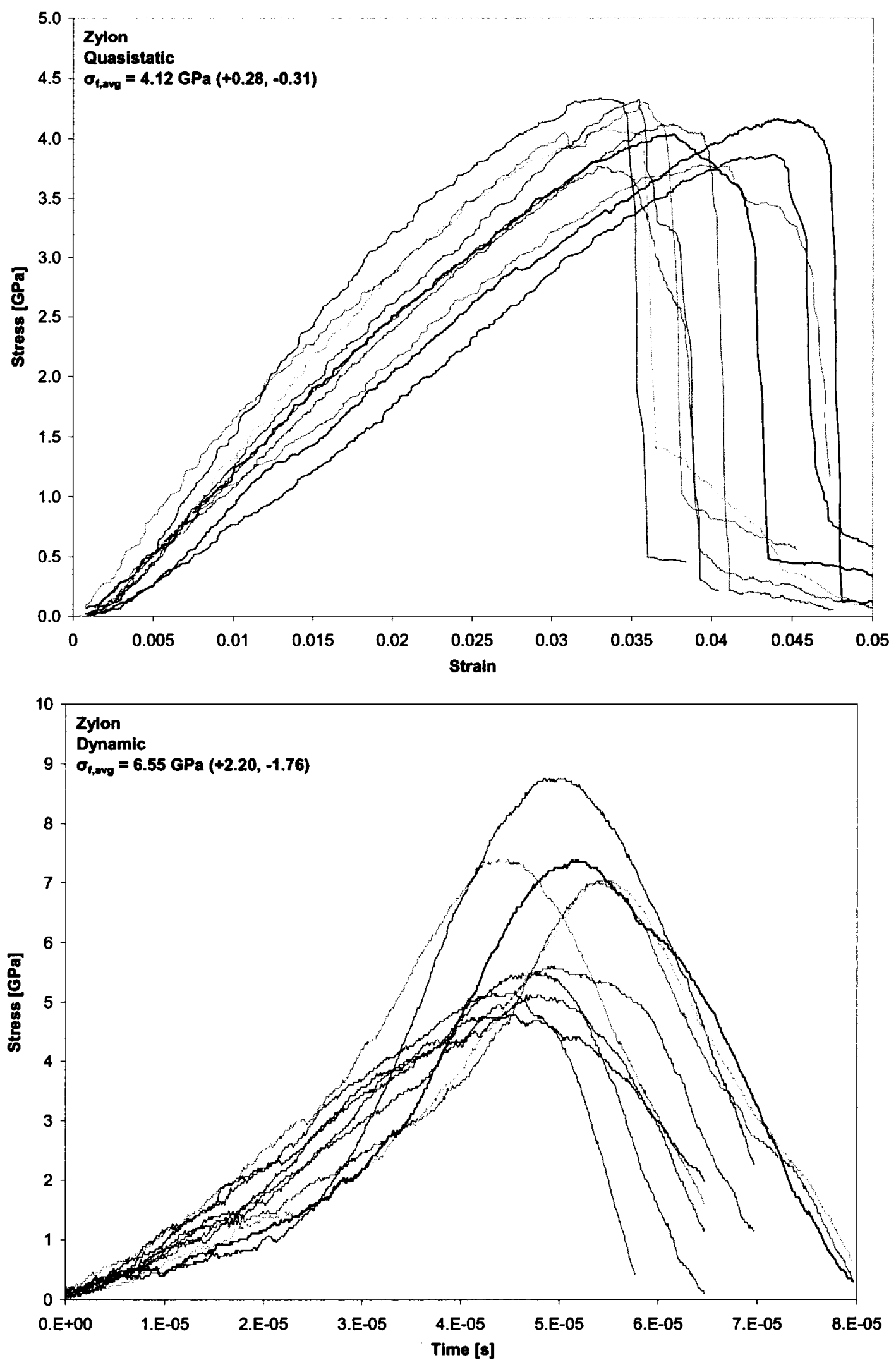

Figure 5.8 - Quasistatic and dynamic results for Zylon (1268 fibres) 


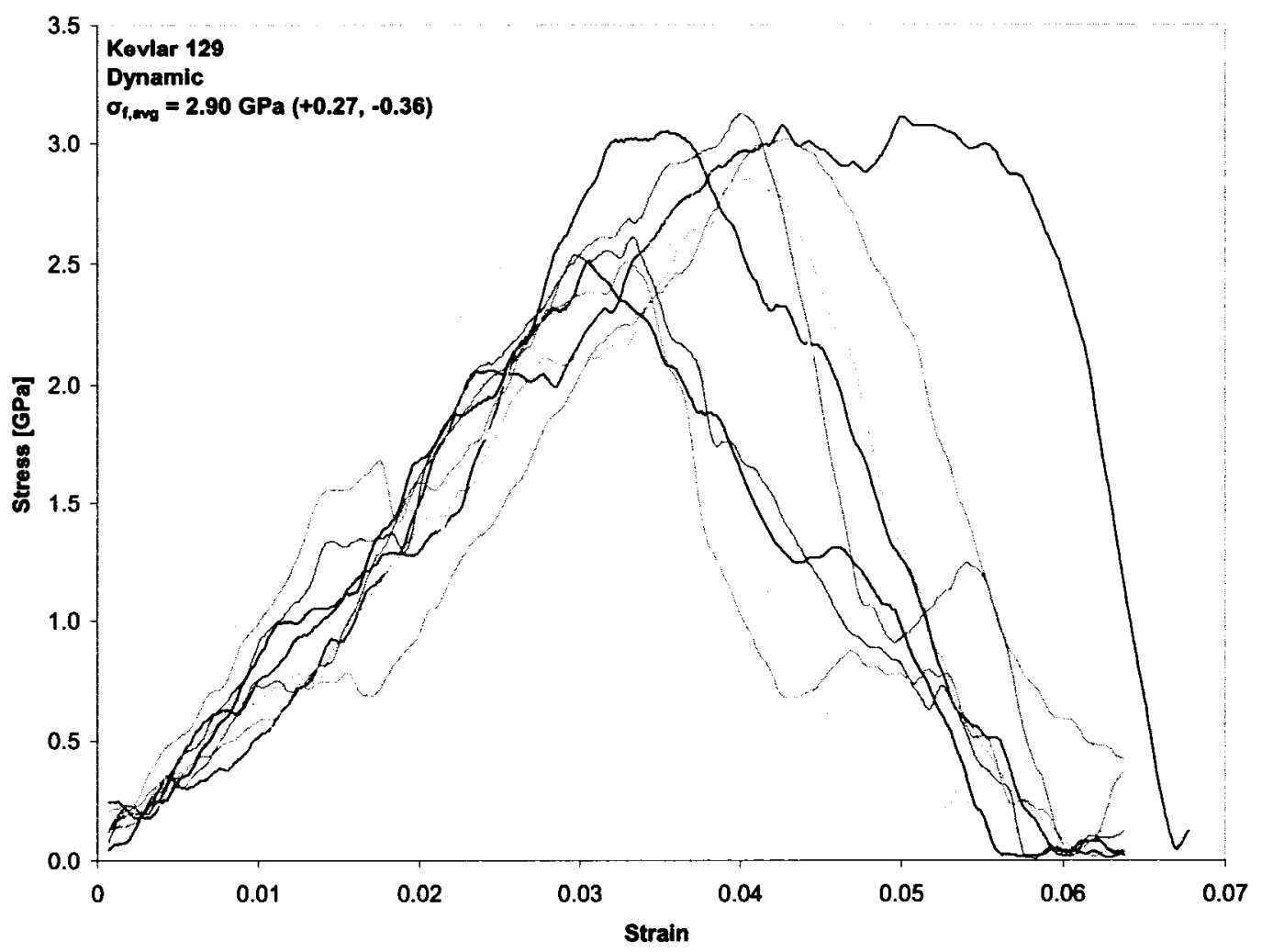

Figure 5.9 - Dynamic stress versus strain plot for Kevlar 129 (1154 fibres)

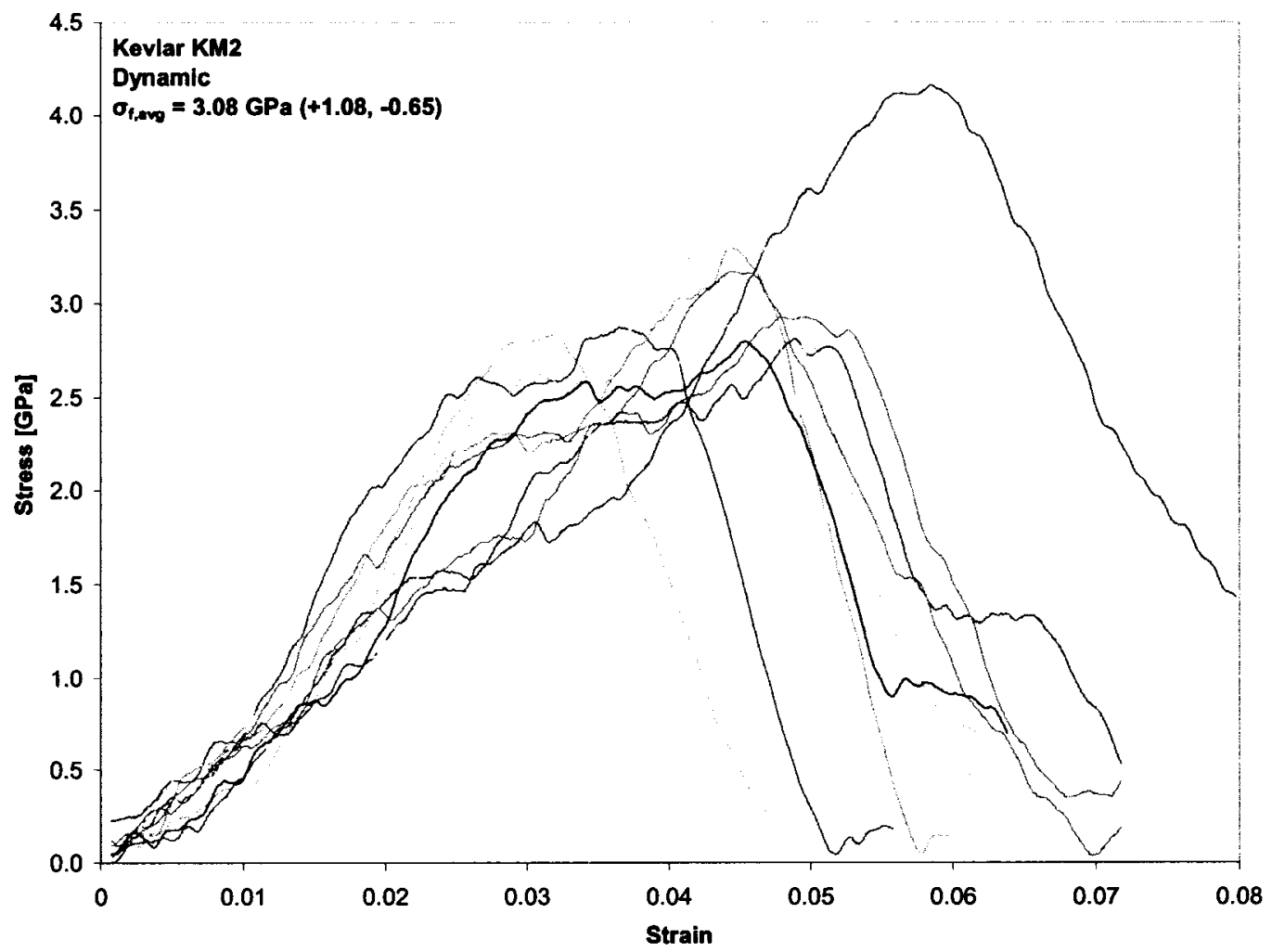

Figure 5.10 - Dynamic stress versus strain plot for Kevlar KM2 (1166 fibres) 


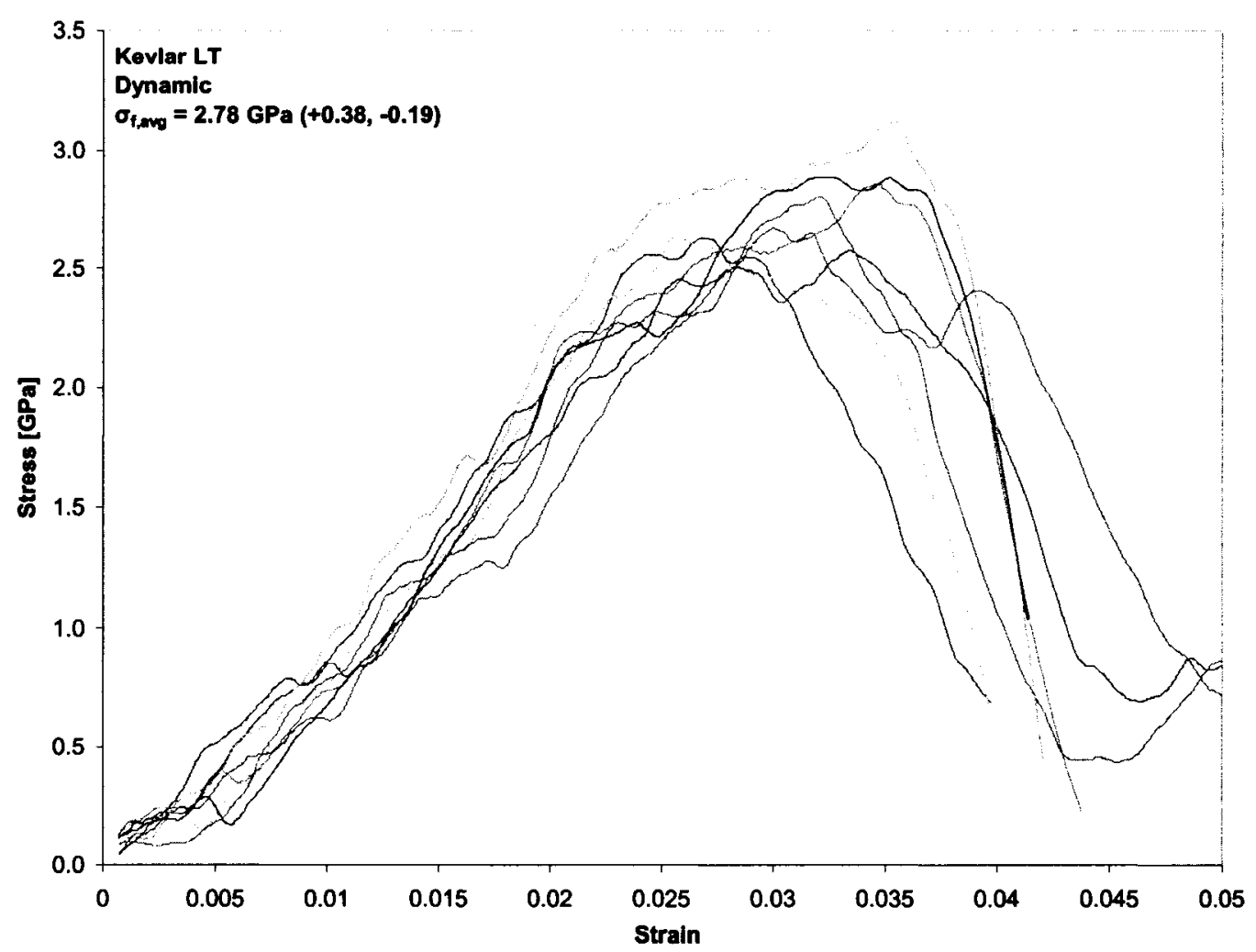

Figure 5.11 - Dynamic stress versus strain plot for Kevlar LT (1080 fibres)

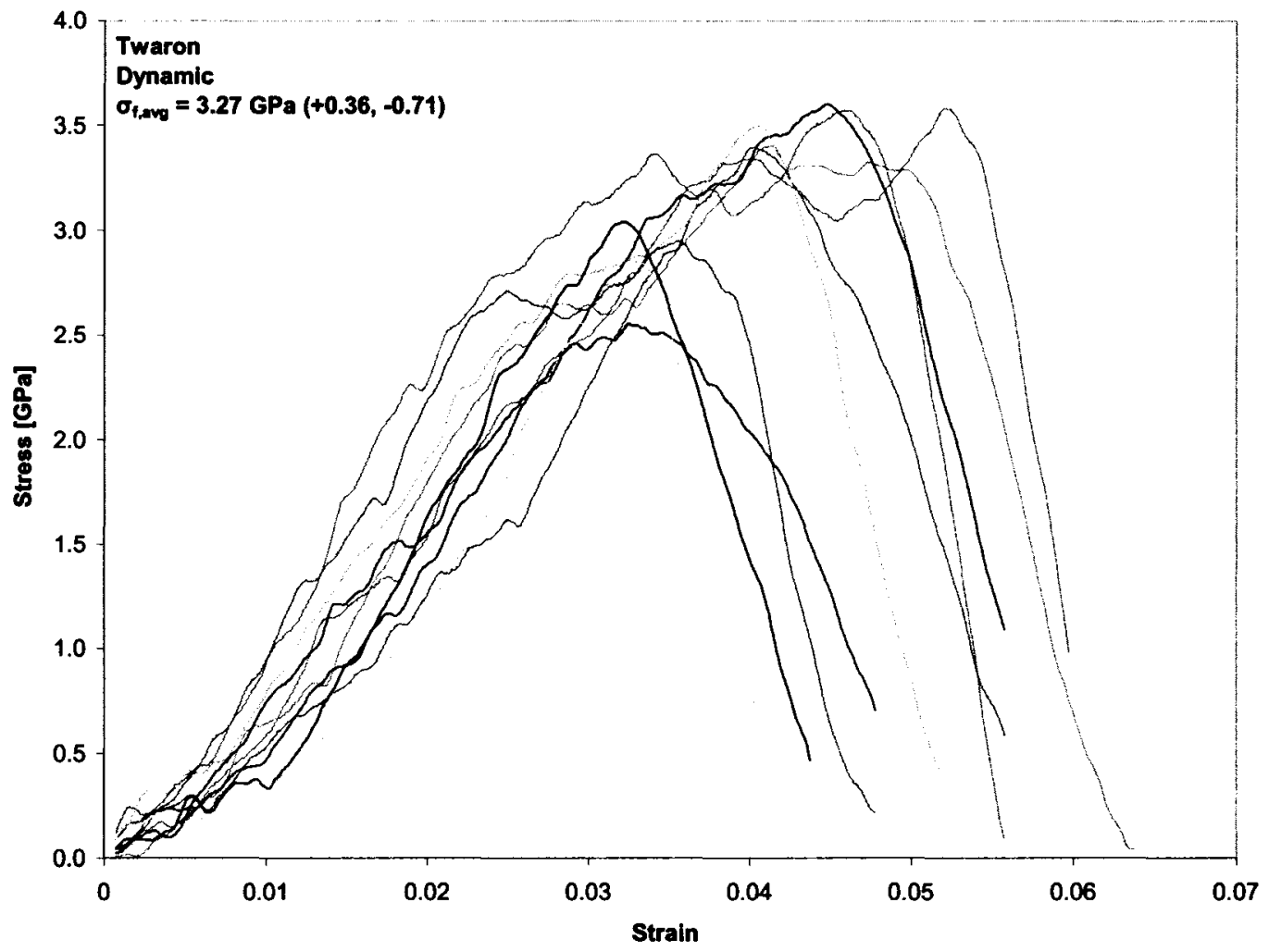

Figure 5.12 - Dynamic stress versus strain plot for Twaron (1350 fibres) 


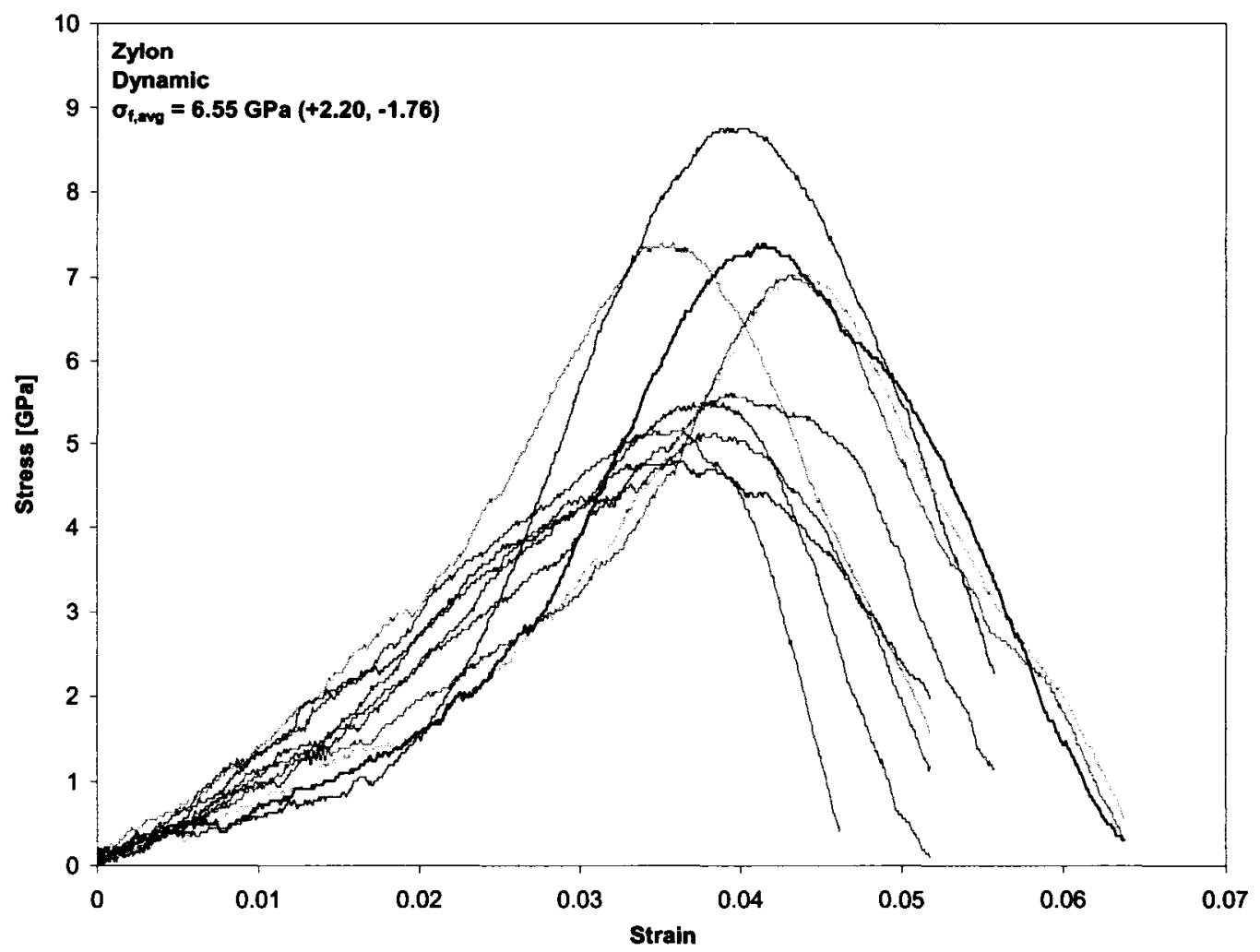

Figure 5.13 - Dynamic stress versus strain plot for Zylon (1268 fibres)

Table 5.1 lists the quasistatic and dynamic strength of the yarns along with the ratio of the dynamic strength over the quasistatic strength as a measure of the sensitivity of the tensile strength to the strain rate. The averages are based on 10 repeats.

Table 5.1 - Dynamic and quasistatic strength of each yarn along with their ratio

\begin{tabular}{|c|c|c|c|c|c|c|c|}
\hline \multirow[b]{2}{*}{ Kevlar 129} & \multicolumn{3}{|c|}{$\begin{array}{c}\text { Average Dynamic } \\
\text { Strength [GPa] }\end{array}$} & \multicolumn{3}{|c|}{$\begin{array}{c}\text { Average Quasistatic } \\
\text { Strength [GPa] }\end{array}$} & \multirow{2}{*}{$\frac{\text { Ratio D/Q }}{1.02}$} \\
\hline & 2.90 & $\begin{array}{l}+0.27 \\
-0.11 \\
\end{array}$ & STD 0.23 & 2.85 & $\begin{array}{r}+0.21 \\
-0.11 \\
\end{array}$ & STD 0.11 & \\
\hline Kevlar KM2 & 3.08 & $\begin{array}{l}+1.08 \\
-0.65 \\
\end{array}$ & STD 0.47 & 2.87 & $\begin{array}{l}+0.23 \\
-0.35 \\
\end{array}$ & STD 0.19 & 1.07 \\
\hline Kevlar LT & 2.78 & $\begin{array}{l}+0.38 \\
-0.19\end{array}$ & STD 0.17 & 2.75 & $\begin{array}{l}+0.35 \\
-0.37\end{array}$ & STD 0.28 & 1.01 \\
\hline Twaron & 3.27 & $\begin{array}{l}+0.36 \\
-0.71\end{array}$ & STD 0.37 & 2.66 & $\begin{array}{l}+0.22 \\
-0.25\end{array}$ & STD 0.18 & 1.23 \\
\hline Zylon & 6.55 & $\begin{array}{l}+2.20 \\
-1.76 \\
\end{array}$ & STD 1.32 & 4.12 & $\begin{array}{l}+0.28 \\
-0.31 \\
\end{array}$ & STD 0.22 & 1.59 \\
\hline
\end{tabular}


Mulkern and Raftenberg [2002] performed quasistatic tests on nine specimens of Kevlar KM2 containing 400 fibres at a gage length of $50 \mathrm{~cm}$, carried out at a strain rate of $4 \times 10^{-3}$ $\mathrm{s}^{-1}$. They found the average strength of the yarn to be $2.66 \mathrm{GPa}$ with an error bracket of $(+0.18,-0.24)$. The strength values obtained for Kevlar KM2 in this study and the ones reported by Mulkern and Raftenberg are comparable and within the error brackets of each other. However, the gage lengths of specimens used by them are significantly larger than the ones used in this study, which can contribute to the difference between the obtained strength parameters. Results on the dependence of strength on the specimen size are presented in Section 5.2. In addition, the strain rate used by Mulkern and Raftenberg is two orders of magnitudes higher than the quasistatic rate used here. However, this effect may be considered to be negligible on the strength since at a strain rate of $800 \mathrm{~s}^{-1}$, an increase of only $7 \%$ is observed in comparison to the quasistatic tensile strength.

Xia and Wang [1998] studied the strain rate dependence of the Young's modulus, the failure stress and the failure strain of Kevlar 49 over a strain rate range of $10^{-4}$ to $1350 \mathrm{~s}^{-1}$. They used a similar Hopkinson bar setup as used here to test Kevlar 49 specimens containing 18 bundles of the material. No information was provided about the number of fibres in the bundle. At each strain rate at least five tests were carried out. The failure stresses at each extreme of the strain rate range considered were reported as 2.34 and 3.08 GPa with an increase in strength with increasing strain rate. A similar increasing trend was observed for failure stress and Young's modulus. Taking the ratio of the quasistatic over dynamic strengths, an increase of $32 \%$ is evident. 
However, Xia and Wang provided no data on the error quantities or the scatter of the data. Considering that there were only five repeats performed at each strain rate, the strength parameter obtain may not be very accurate. When comparing the value of the failure stress with the ones obtained in this study for aramid yarns, it appears that the quasistatic strengths are consistently higher than their findings even though they were performed at a lower strain rate. This may be attributed to the need to perform a higher number of repeats and possibly to the size of the specimen since its details are not provided. This difference can also be the result of the lower strength of Kevlar 49 material [Yang, 1993]. The lack of information about the error quantities and also the limited number of repeats prevents firm comparisons to be made with their results.

Amaniampong and Burgoyne [1994] performed tests to obtain the tensile strength of Kevlar 49 yarns over a strain rate range of 0.033 to $0.66 \mathrm{~s}^{-1}$ at a constant gage length of $560 \mathrm{~mm}$. The number of fibres per yarn was not specified. They found that average strength of aramid yarns decreases slightly with increasing strain rate. In this study, a much broader range of strain rates $\left(10^{-5}\right.$ to $\left.800 \mathrm{~s}^{-1}\right)$ was considered with the strength quantified at the two extremes of the range. Therefore, a comparison with the exact range that they reported cannot be made, however it is interesting to contrast this with the findings of Xia and Wang that suggests an increase of $26 \%$ in the failure strength in the strain rate range of $10^{-5}$ to $140 \mathrm{~s}^{-1}$.

An extensive survey of the literature was carried out and a lack of yarn strength parameters for Zylon and Twaron was evident. Some papers were found regarding 
Zylon/epoxy composite and Twaron fabrics [Huang et al., $2002 \&$ Shim et al., 2001], however none of these papers explored the yarn properties of the materials.

\subsection{Effect of Specimen Size on Failure Stress}

Specimens with different gage lengths and cross sectional areas were tested to failure in order to observe the effect of specimen size on the failure stress of Kevlar 129. Single fibres of Kevlar 129 were tested at various gage lengths as well as multi fibre specimens of different cross sectional area and gage lengths. As mentioned previously, single fibre tests were carried out at gage lengths of $5,16,25,50$ and $100 \mathrm{~mm}$ with the maximum load being recorded during the deformation. A constant strain rate of $10^{-3} \mathrm{~s}^{-1}$ was maintained. Table 5.2 shows the failure stresses of single fibre tests ranked from the lowest to the highest.

Table 5.2 - Strength of a single fibre of Kevlar 129 at gage lengths of 5 to $100 \mathrm{~mm}$

\begin{tabular}{|c|c|c|c|c|c|}
\hline \multirow{2}{*}{ Rank, j } & \multicolumn{5}{|c|}{ Failure Stress [GPa] } \\
\cline { 2 - 6 } & $\mathbf{G L}=\mathbf{5} \mathbf{~ m m}$ & $\mathbf{G L}=\mathbf{1 6} \mathbf{~ m m}$ & $\mathbf{G L}=\mathbf{2 5} \mathbf{~ m m}$ & $\mathbf{G L}=\mathbf{5 0} \mathbf{~ m m}$ & $\mathbf{G L}=\mathbf{1 0 0} \mathbf{~ m m}$ \\
\hline 1 & 3.44 & 3.68 & 3.40 & 3.30 & 3.30 \\
\hline 2 & 3.50 & 3.73 & 3.68 & 3.47 & 3.54 \\
\hline 3 & 3.64 & 3.74 & 3.76 & 3.48 & 3.59 \\
\hline 4 & 3.93 & 3.78 & 3.77 & 3.53 & 3.64 \\
\hline 5 & 4.02 & 3.87 & 3.90 & 3.58 & 3.64 \\
\hline 6 & 4.04 & 3.98 & 3.93 & 3.61 & 3.71 \\
\hline 7 & 4.05 & 3.99 & 4.17 & 3.83 & 3.78 \\
\hline 8 & 4.08 & 4.04 & 4.17 & 3.95 & 3.80 \\
\hline 9 & 4.18 & 4.07 & 4.25 & 3.95 & 3.95 \\
\hline 10 & 4.29 & 4.32 & 4.31 & 4.02 & 3.95 \\
\hline Average & $\mathbf{3 . 9 2}$ & $\mathbf{3 . 9 2}$ & $\mathbf{3 . 9 3}$ & $\mathbf{3 . 6 7}$ & $\mathbf{3 . 6 9}$ \\
\hline
\end{tabular}


Tensile strength for a single fibre or yarn of Kevlar 129 is not widely reported in the literature. Yang [1993] gives the strength of a single fibre of Kevlar 129 to be $3.4 \mathrm{GPa}$, however no information about the gage length of the single fibre is given. However, tensile strengths for other aramid fibres such as Kevlar 29, 49 and KM2 have been reported.

Schwartz et al. [1984] performed quasistatic tensile tests on 50 single-fibre specimens of Kevlar 49 and 29 at a gage length of $5 \mathrm{~cm}$. They reported average failure forces for the two sets of tests. These failure forces were normalised by the linear density. However that is not the measure used in this study. Therefore, the failure forces reported by Schwartz et al. were normalised by the nominal cross sectional area of an aramid fibre (diameter of $12 \mu \mathrm{m}$ ). Average failure stresses of $3.40 \mathrm{GPa}$ and $3.20 \mathrm{GPa}$ were obtained for Kevlar 49 and Kevlar 29, respectively. The average failure stresses obtained above are significantly lower compared to the average failure stress of Kevlar 129 obtained in this study. However, Kevlar 29 and 49 were earlier forms of aramid that may not have as high performance characteristics as newer generation fibres such as Kevlar KM2 and 129.

Cheng and Chen [2005] performed tensile tests on a single fibre of Kevlar KM2 at a gage length of $10 \mathrm{~mm}$ at a strain rate of $1.27 \times 10^{-3} \mathrm{~s}^{-1}$. They reported the average tensile strength of the fibre to be $3.88 \pm 0.4 \mathrm{GPa}$ obtained from testing 25 specimens. Although Kevlar 129 and KM2 are not the same material, they are both from the newer generations 
of Kevlar products and the tensile strength reported by Cheng and Chen and the ones obtained in this study are very close.

Now that the single fibre strength results have been discussed, the results for multi fibre specimens will be presented in the following figures. Figure 5.14 shows the stress versus strain plots for Kevlar 129 specimens with gage length of $24 \mathrm{~mm}$ and a cross sectional area twice as that of the specimens presented in Figure 5.4 (2308 fibres instead of 1154 fibres). Figures 5.15 and 5.16 show the stress versus strain plots for gage lengths of 100 $\mathrm{mm}$ and $170 \mathrm{~mm}$, respectively (1154 fibres specimens). The strain rate for the various gage lengths was maintained to be at $10^{-5} \mathrm{~s}^{-1}$.

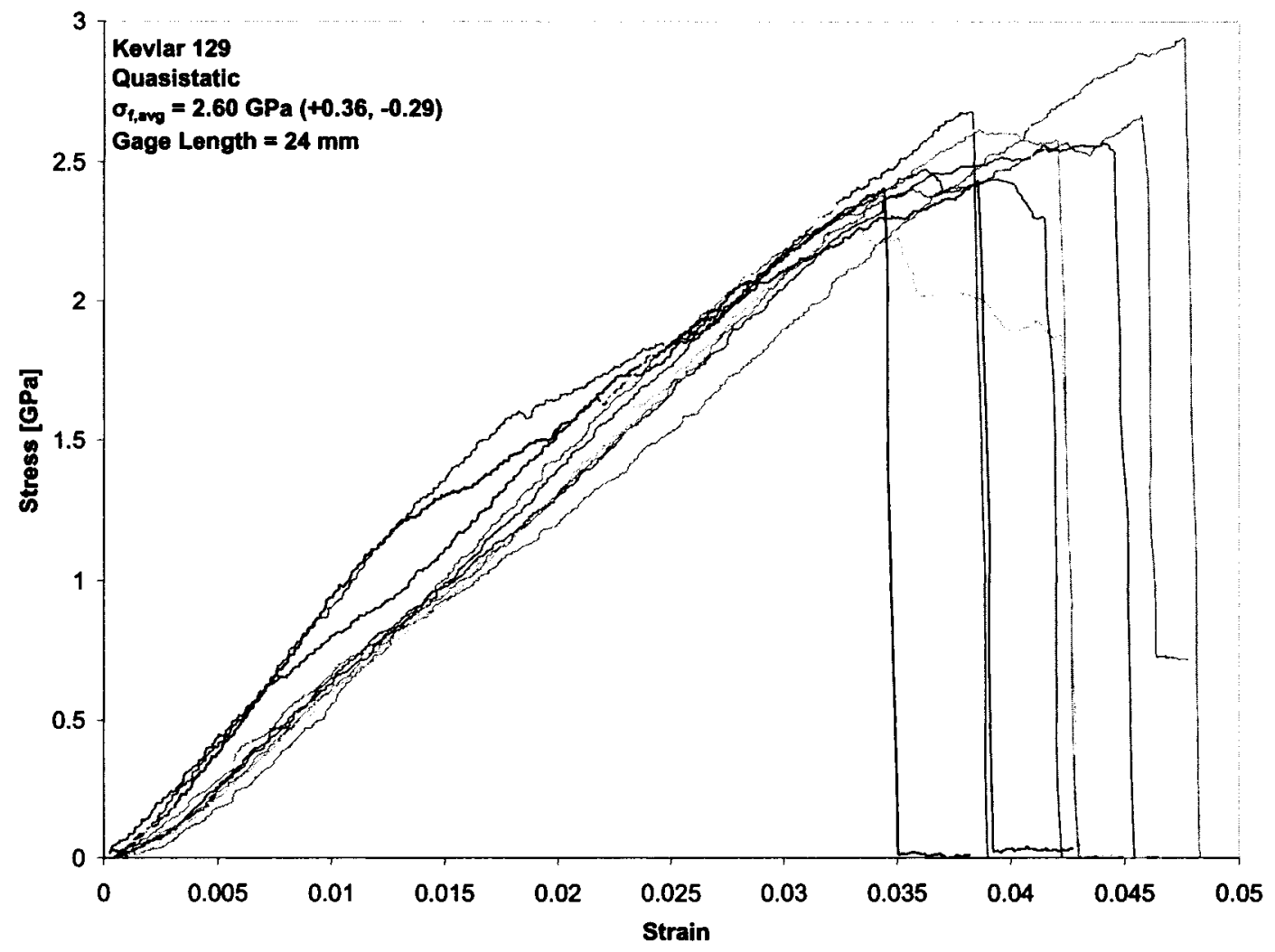

Figure 5.14 - Quasistatic results for specimens of Kevlar 129 (2308 fibres, GL=24 mm) 


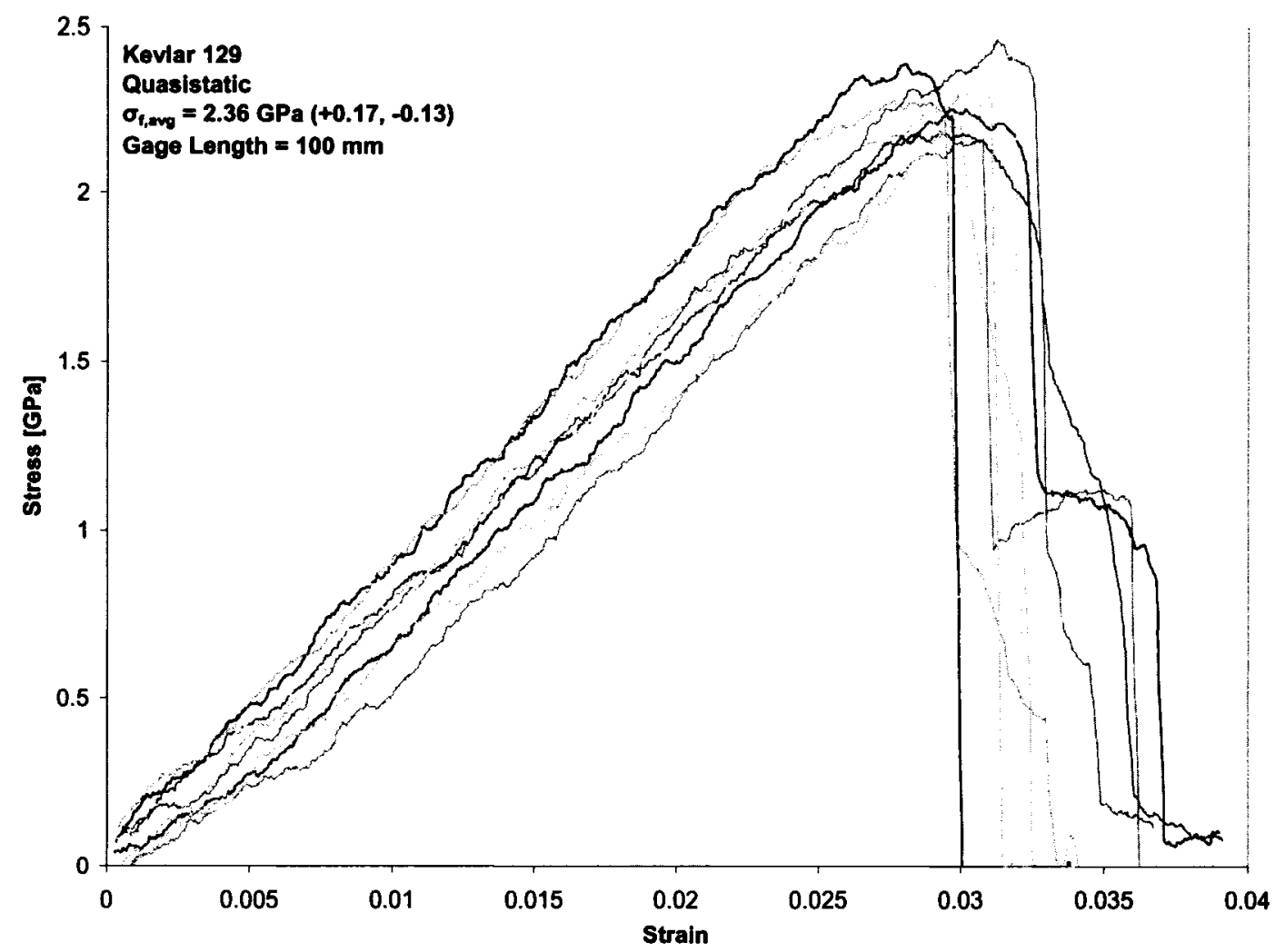

Figure 5.15 - Quasistatic results for specimens of Kevlar 129 (1154 fibres, GL=100 mm)

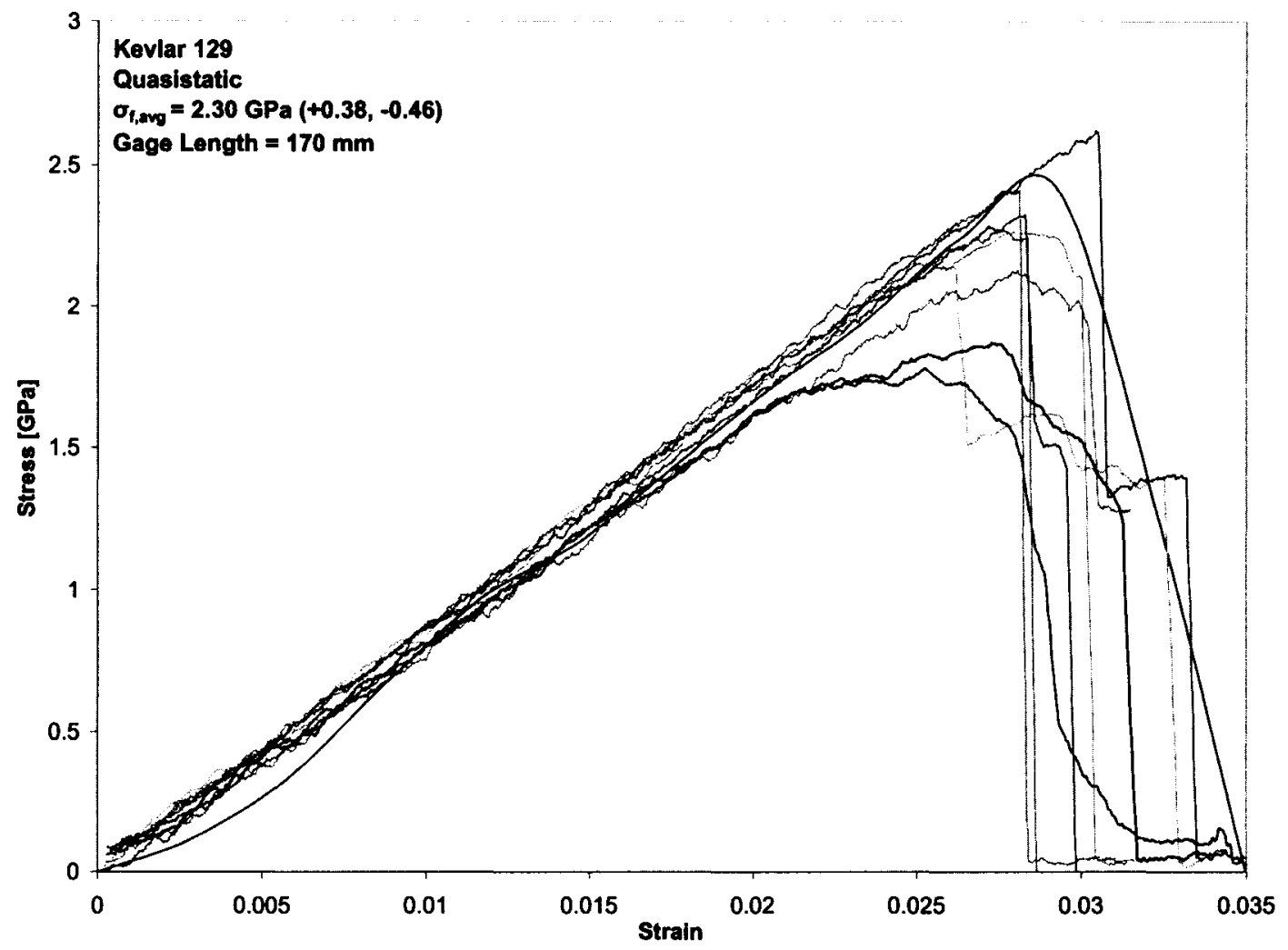

Figure 5.16 - Quasistatic results for specimens of Kevlar 129 (1154 fibres, GL=170 mm) 
The Young's modulus is calculated for Kevlar 129 at the gage length of 100 . This choice was made since no correction factor was used to redefine the gage length for these specimens ( 10 specimens). The slope of the stress versus strain plots were taken between strain values of 1 to $2 \%$. Modulus of a yarn approaches the modulus of a single fibre once all the fibres in the yarn are under tension, hence the reason for calculating the modulus between strains of 1 to $2 \%$. The average Young's modulus of Kevlar 129 was 83.8 $\mathrm{GPa}$ with standard deviation of $3.5 \mathrm{GPa}$ and an error bracket of $(+4.8,-6.2) \mathrm{GPa}$.

Cheng and Chen [2005] reported the modulus of a single fibre of Kevlar KM2 to be 84.6 $\pm 4.2 \mathrm{GPa}$ at a strain rate of $1.27 \times 10^{-3} \mathrm{~s}^{-1}$. Modulus values reported by them are in agreement with the modulus values obtained for Kevlar 129 in this study. Xia and Wang [1998] reported the modulus of a Kevlar 49 bundle at a strain rate of $10^{-4} \mathrm{~s}^{-1}$ to be 97 GPa. Xia and Wang stated that the specimens contained 18 bundles of Kevlar 49 at gage length of $8 \mathrm{~mm}$ but did not give any detail regarding the number of fibres in a bundle. Table 5.3 summarises the failure strength for various specimen sizes of Kevlar 129.

It can be seen that there is a significant drop in failure stress between the multi fibre specimens with gage lengths of $24 \mathrm{~mm}$ and $100 \mathrm{~mm}$ (1154 fibres specimens). The error brackets and the standard deviation ranges do not overlap, which confirms this drop in material tensile strength. Some authors [Dai and Piggot, 1993 \& Yue et al., 2000] have reported a decrease in the failure stress with increasing gage lengths, however they have not been able to draw firm conclusions because of the scatter in the data. 
Table 5.3 - Tensile strength of Kevlar 129 for different specimen sizes

\begin{tabular}{|c|c|c|c|}
\hline Specimen Size & \multicolumn{3}{|c|}{$\begin{array}{c}\text { Average Failure } \\
\text { Stress [GPa] }\end{array}$} \\
\hline $\begin{array}{l}\text { Single fibre } \\
\mathrm{GL}=5 \mathrm{~mm}\end{array}$ & 3.92 & $\begin{array}{l}+0.37 \\
-0.48\end{array}$ & STD 0.29 \\
\hline $\begin{array}{l}\text { Single fibre } \\
\mathrm{GL}=16 \mathrm{~mm}\end{array}$ & 3.92 & $\begin{array}{l}+0.40 \\
-0.24 \\
\end{array}$ & STD 0.20 \\
\hline $\begin{array}{l}\text { Single fibre } \\
\mathrm{GL}=25 \mathrm{~mm}\end{array}$ & 3.93 & $\begin{array}{l}+0.37 \\
-0.54\end{array}$ & STD 0.29 \\
\hline $\begin{array}{l}\text { Single fibre } \\
\mathrm{GL}=50 \mathrm{~mm}\end{array}$ & 3.69 & $\begin{array}{l}+0.35 \\
-0.37\end{array}$ & STD 0.25 \\
\hline $\begin{array}{c}\text { Single fibre } \\
\mathrm{GL}=100 \mathrm{~mm}\end{array}$ & 3.67 & $\begin{array}{l}+0.26 \\
-0.39\end{array}$ & STD 0.20 \\
\hline $\begin{array}{l}1154 \text { fibres } \\
\mathrm{GL}=24 \mathrm{~mm}\end{array}$ & 2.85 & $\begin{array}{l}+0.21 \\
-0.11\end{array}$ & STD 0.11 \\
\hline $\begin{array}{l}2308 \text { fibres } \\
\mathrm{GL}=24 \mathrm{~mm}\end{array}$ & 2.60 & $\begin{array}{l}+0.36 \\
-0.29\end{array}$ & STD 0.19 \\
\hline $\begin{array}{c}1154 \text { fibres } \\
\mathrm{GL}=100 \mathrm{~mm}\end{array}$ & 2.36 & $\begin{array}{l}+0.17 \\
-0.13\end{array}$ & STD 0.10 \\
\hline $\begin{array}{c}1154 \text { fibres } \\
\mathrm{GL}=170 \mathrm{~mm}\end{array}$ & 2.30 & $\begin{array}{l}+0.38 \\
-0.46\end{array}$ & STD 0.26 \\
\hline
\end{tabular}

Dai and Piggott [1993] performed quasistatic tests on single fibres of Kevlar 29 and 49 at different gage lengths. Ten different gage lengths were tested in the range of 0.3 to $50 \mathrm{~mm}$. For each gage length approximately 18 specimens were tested. Dai and Piggott stated that the strength of both types of single fibre Kevlar does not show any consistent dependence on the length.

Schwartz et al. [1984] carried out tensile tests quasistatically on single fibres of Kevlar 29 and 49 at various gage lengths. Five sets of tests were performed on single fibres removed from bundles at gage lengths of 1,5 and $30 \mathrm{~cm}$. Another set of tests was performed on single fibres cut from the same length of single fibre at gage lengths of 0.2 , $0.5,1,2$ and $12 \mathrm{~cm}$. Schwartz et al. stated that the data show stronger fibres at shorter 
gage lengths and weaker fibres at longer gage lengths. For the first set of 5 tests, a decrease of about $30 \%$ was observed on the failure force when comparing the $1 \mathrm{~cm}$ gage length to the $30 \mathrm{~cm}$ one. For the second set of tests, a decrease of $24 \%$ was observed on the failure force when comparing the $0.2 \mathrm{~cm}$ gage length to the $12 \mathrm{~cm}$ one. Comparing this to the results of the single fibre tests in this study, a drop of $6 \%$ was observed when comparing the gage lengths of 25 and $100 \mathrm{~mm}$. The range of the gage lengths tested by Schwartz et al. is much larger than the one in this study, which may explain the higher decrease in strength reported.

Amaniampong and Burgoyne [1994] observed the effect of gage length on the failure stress of Kevlar 49 yarns. They performed two batches of quasistatic tests at a strain rate of $0.17 \mathrm{~s}^{-1}$ for four different gage lengths between 327 and $676 \mathrm{~mm}$. The specimens contained 146 fibres for the longest gage lengths and 100 fibres for the other gage length values. The number of tests per gage length is not clearly stated, however it appears to be greater than 15. Amaniampong and Burgoyne stated that the yarn strength depends on the gage length; however this small change is masked by the data scatter.

In light of the previous comparisons with the literature, the scatter in the strength data may always be apparent for brittle materials even if the number of tests were significantly increased. A larger test population will have a larger scatter; however a large population will also obtain a more accurate average. Therefore, it may be too critical to dismiss the variation of average strength with length based on scatter quantities. The decease in the average failure stress with increasing volume of material is consistent with the behaviour 
of brittle materials [Hertzberg, 1996]. As a way to have a better understanding of this trend, it may be reasonable to normalise the scatter quantities with the number of tests performed as carried out by Mulkern and Raftenberg [2002].

\subsection{Weibull Analysis}

As discussed in Chapter 2, probability of the failure of a brittle material at a given stress is often described using Weibull modelling. Each set of tests presented above was analysed in order to obtain Weibull parameters for each population. These parameters are obtained graphically by plotting the linear rearrangement of the Weibull model. The Weibull model is rearranged to take a linear form where $a$ and $b$ are the Weibull parameters and $F(\sigma)$ is the probability of failure at a given stress:

$$
F(\sigma)=1-\exp \left[-\left(\frac{\sigma}{a}\right)^{b}\right] \Rightarrow \ln \left[\ln \left(\frac{1}{1-F(\sigma)}\right)\right]=b \ln \sigma-b \ln a
$$

The probability of failure is evaluated using the median rank approximation. The data is first ranked from the lowest to highest failure stress. Using the median rank approximation, the probability of failure takes the form of equation (5.2) [Amaniampong and Burgoyne, 1994], where $N$ is the total population and $j$ is the rank of specimen considered.

$$
F(\sigma)=\frac{j-0.3}{N+0.4}
$$


By using equation (5.1) and applying a linear fit to the points obtained, the shape and the scale factor can be evaluated from the slope and the $y$-intercept of the linear fit. Figure 5.17 shows the plot of Equation (5.1) for the quasistatic tests on Kevlar KM2 specimen (See Figure 5.5 for the experimental data). This analysis was repeated for the dynamic and quasistatic tests performed on each set of data presented in the previous section. Table 5.4 lists the various parameters obtained along with the R-squared value of the linear fit as a means of quantifying the accuracy of the fit.

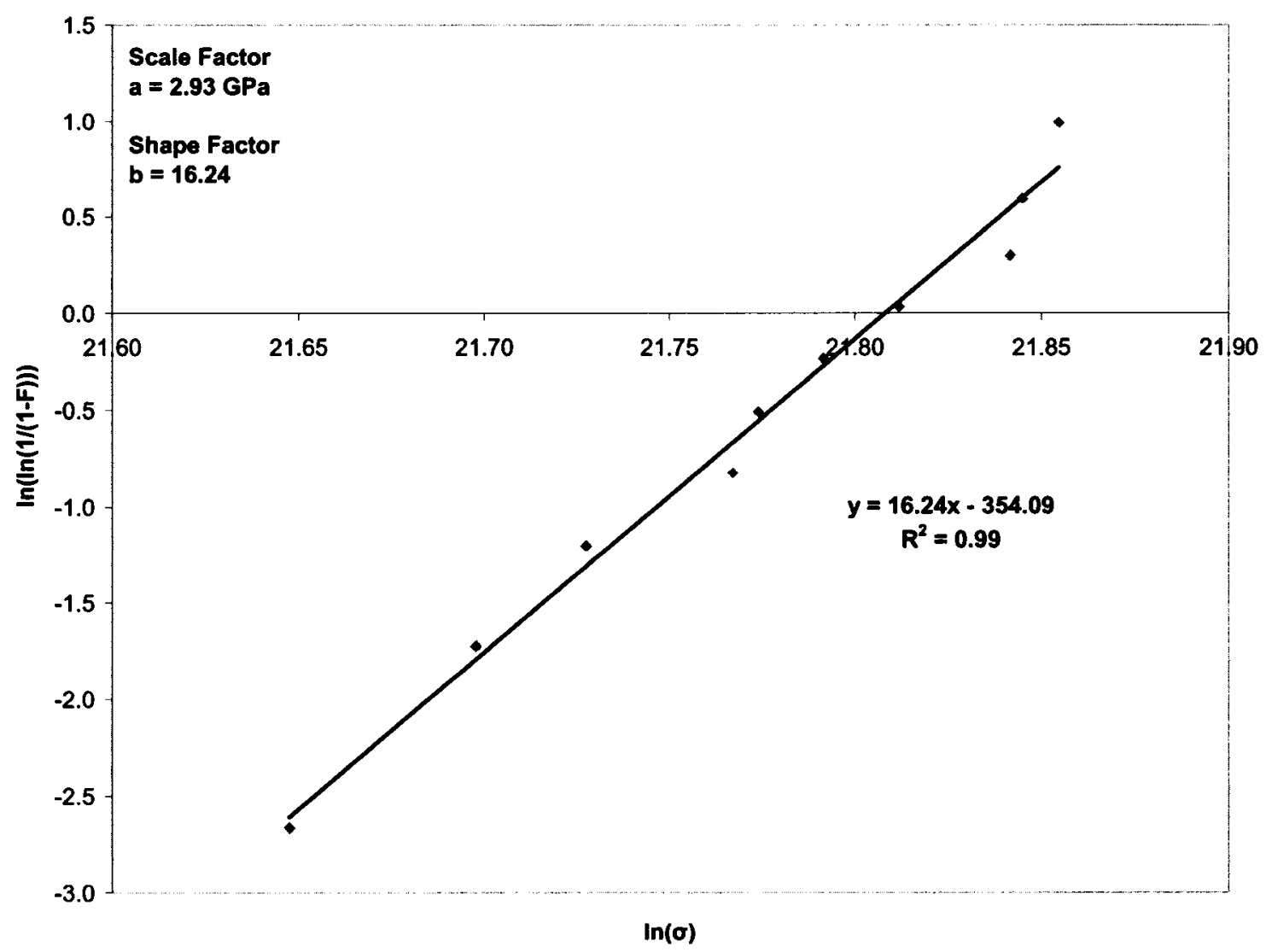

Figure 5.17 - Plot used for evaluation of Weibull parameters for Kevlar KM2 
Table 5.4 - List of scale and shape factors for different yarns along with accuracy of fit

\begin{tabular}{|c|c|c|c|}
\hline & a [GPa] & $\mathbf{b}$ & $\mathbf{R}^{\mathbf{2}}$ \\
\hline Kevlar 129 (Q) & 2.91 & 24.56 & 0.75 \\
\hline Kevlar KM2 (Q) & 2.93 & 16.24 & 0.99 \\
\hline Kevlar LT (Q) & 2.87 & 10.10 & 0.88 \\
\hline Twaron (Q) & 2.78 & 17.06 & 0.94 \\
\hline Zylon (Q) & 4.22 & 20.06 & 0.94 \\
\hline Kevlar 129 (D) & 2.99 & 13.12 & 0.94 \\
\hline Kevlar KM2 (D) & 3.27 & 6.92 & 0.81 \\
\hline Kevlar LT (D) & 2.84 & 16.69 & 0.78 \\
\hline Twaron (D) & 3.46 & 9.10 & 0.94 \\
\hline Zylon (D) & 7.13 & 5.09 & 0.88 \\
\hline
\end{tabular}

The R-squared parameter evaluates the accuracy of the linear fit through the given data points. An R-squared value of unity means an exact linear fit through the data points. A decrease in the value of the R-squared parameter means increasing deviation from the linear fit through the given points. The Gumbel model discussed in Chapter 2 was applied to the data population, deviating significantly from the linear form of the Weibull function. However, no improvement was observed on the linear fit with the Gumbel model, hence only Weibull parameters are reported.

The Weibull parameters listed in Table 5.4 show significant variation between each material. The scale parameter, $a$, normalises the applied stress. The scale parameter is analogous to the average strength of the yarn and this can be confirmed by comparing the scale parameter to the average strength reported earlier in the chapter. In fact the scale 
parameter can be considered a weighted average failure stress based on distribution of the failure stresses rather than the linear averages as reported in Table 5.1.

The shape parameter, $b$, shows very large variation between the materials and the testing methods. The shape parameter characterises the variability of the strength of the material and is analogous to the standard deviation of the strength of the material [Hertzberg, 1996]. Material with a more homogenous defect distribution would have a higher shape factor and hence more consistent tensile strength. As the shape factor increases, the dependence of the failure strength on the defect population and material volume under stress decreases. In general the dynamic test results have a lower shape factor than their corresponding quasistatic ones. This suggests a more random failure distribution in the dynamic tests compared to the quasistatic ones.

Amaniampong and Burgoyne [1994] performed quasistatic tests on two batches of Kevlar 49 yarns with gage lengths ranging between 327 and $676 \mathrm{~mm}$ at a strain rate of $0.17 \mathrm{~s}^{-1}$. The numbers of fibres in the specimens were 146 for the longest gage length and 100 fibres for the remaining gage lengths. A minimum of 15 specimens were tested at each gage length. Weibull parameters were obtained for each population. Table 5.5 shows the Weibull parameters obtained in his study with the two batches highlighted. The range of the scale parameter, $a$, and the shape parameter, $b$, is between 2.37-2.61 GPa and 13.3121.28, respectively. The specimen sizes used in their study are different than the ones used in this study. Nevertheless, the shape factors reported in Amaniampong and Burgoyne's study appear to be within the range of the ones obtained in this study for 
quasistatic tests on aramid fibres. The scale factors reported by them are lower than the ones obtained in this study. Since the scale factor is analogous to the average strength, this difference can be attributed to the difference in specimen size.

Table 5.5 - Weibull parameters obtained for Kevlar 49 by Amaniampong and Burgoyne [1994]

\begin{tabular}{|c|c|c|}
\hline Specimen Size & a [GPa] & b \\
\hline 146 fibres, GL $=676.2 \mathrm{~mm}$ & 2.57 & 16.40 \\
\hline 100 fibres, GL $=566.2 \mathrm{~mm}$ & 2.55 & 15.24 \\
\hline 100 fibres, GL $=466.2 \mathrm{~mm}$ & 2.56 & 15.35 \\
\hline 100 fibres, GL $=370.2 \mathrm{~mm}$ & 2.61 & 16.89 \\
\hline 149 fibres, GL $=633.4 \mathrm{~mm}$ & 2.39 & 14.05 \\
\hline 99 fibres, GL $=523.4 \mathrm{~mm}$ & 2.37 & 13.31 \\
\hline 100 fibres, GL $=423.4 \mathrm{~mm}$ & 2.45 & 21.28 \\
\hline 100 fibres, GL $=327.4 \mathrm{~mm}$ & 2.49 & 18.77 \\
\hline
\end{tabular}

Weibull parameters were also obtained for tests carried out to study the scale effect of Kevlar 129. Table 5.6 shows the Weibull parameters for various specimen sizes of Kevlar 129 along with the value of the accuracy of fit.

As can be seen, the scale factor, which is analogous to the average failure strength, decreases with increasing specimen size. The shape factor takes a wide range of values similar to those reported by Amaniampong and Burgoyne [1994]. This variation can be attributed to the variation of the defect population with increasing specimen size as well as the need to perform more repeats to obtain a more accurate shape factor. 
Table 5.6 - Scale and shape factors for Kevlar 129 specimens

\begin{tabular}{|c|c|c|c|}
\hline & a [GPa] & $\mathbf{b}$ & $\mathbf{R}^{\mathbf{2}}$ \\
\hline $\begin{array}{c}\text { Single fibre } \\
\text { GL }=8 \mathrm{~mm}\end{array}$ & 4.08 & 14.19 & 0.93 \\
\hline $\begin{array}{c}\text { Single fibre } \\
\text { GL }=16 \mathrm{~mm}\end{array}$ & 4.01 & 20.75 & 0.86 \\
\hline $\begin{array}{c}\text { Single fibre } \\
\text { GL }=25 \mathrm{~mm}\end{array}$ & 4.04 & 14.65 & 0.97 \\
\hline $\begin{array}{c}\text { Single fibre } \\
\text { GL }=50 \mathrm{~mm}\end{array}$ & 3.80 & 15.81 & 0.91 \\
\hline $\begin{array}{c}\text { Single fibre } \\
\text { GL }=100 \mathrm{~mm}\end{array}$ & 3.77 & 20.27 & 0.96 \\
\hline $\begin{array}{c}1154 \text { fibres } \\
\text { GL }=24 \mathrm{~mm}\end{array}$ & 2.91 & 24.56 & 0.75 \\
\hline $\begin{array}{c}2308 \text { fibres } \\
\text { GL }=24 \mathrm{~mm}\end{array}$ & 2.68 & 15.06 & 0.93 \\
\hline $\begin{array}{c}1154 \text { fibres } \\
\text { GL }=100 \mathrm{~mm}\end{array}$ & 2.42 & 24.50 & 0.88 \\
\hline $\begin{array}{c}1154 \text { fibres } \\
\text { GL }=170 \mathrm{~mm}\end{array}$ & 2.39 & 9.36 & 0.98 \\
\hline
\end{tabular}

Now that all the results have been reported, these finding will be summarised and discussed in the next chapter. In the discussion chapter, an expression relating the average failure stress and the size of the specimen will be proposed. Before this expression is proposed, some theoretical yarn models will be discussed and their applicability to the experimental results obtained considered. 


\subsection{DISCUSSION}

\subsection{Failure Strength Results}

Quasistatic and dynamic tensile strength of various yarns were evaluated which were previously unavailable in the literature. As is visible from the results in Table 5.1 , the Kevlar products showed limited dependence on strain rate while Twaron and Zylon show a more significant dependence on increasing strain rate. Twaron's results shows smaller scatter in comparison to Kevlar yarns while Zylon yarns exhibited some very large variation of tensile strength in the dynamic tests. Half of the dynamic strength data for Zylon are well above the average quasistatic strength and they exhibit a distinct tow region in their stress versus time behaviour. The higher strength values in these tests are in the range of 7 to $9 \mathrm{GPa}$ which is a significant increase from the average quasistatic strength of $4.12 \mathrm{GPa}$. The mechanism of this increase in strength was not explored, however it is only observed in the high strain rate tests.

Attempts were made to make comparisons between the literature and the findings of this study; however there is limited data available as well as the large number of variables that play into the behaviour of the material. The tensile strength for Kevlar 129, Kevlar LT, Twaron and Zylon were not previously available in literature. However, even with the availability of the tensile strength of Kevlar KM2, firm comparisons could not be made since as it is shown the specimen sizing plays a role in the failure strength of the yarn. Other factors that play a role are the inherent variations within the manufacturing 
process as Schwartz et al. [1984] point out when comparing the variation of the diameter of a single fibre of Kevlar between different batches of the same material.

\subsection{Weibull Parameters}

Experimental work by Schwartz et al. [1984] and Amaniampong and Burgoyne [1994] show the dependence of the Weibull parameters on the length of single fibre and bundles, respectively. Results obtained in this study show variation of the Weibull parameters with the size of the specimen and testing method. However, no specific trend was observed in the variation of the shape factor while the scale factor followed the trends observed in the variation of average stress with specimen size. Weibull parameters are dependent on the population that they are representing; therefore their accuracy can be significantly improved by increasing the number of repeats of the experiments.

\subsection{Scale Effect Results}

A number of authors such as Daniels [1945], Coleman [1958], McCartney and Smith [1983], and Watson and Smith [1985] have used analytical models to try to predict the relation between the properties of a single fibre and the properties of a yarn. Although these models are quite involved and well developed, they are based on certain underlying assumptions that make their results not conforming to experimental results as Coleman [1958] pointed out. The lack of interfibre friction and the assumption of equal load sharing between the fibres are important assumptions that need to be addressed. The discussion on the effect of twist in Chapter 2 shows the importance of interfibre interactions. 
Coleman [1958] developed a model for the strength of a single fibre. By application of the weakest-link theory, he showed that for a Weibull type fibre, the average strength of a single fibre at a given length, takes the following form:

$$
\sigma_{\text {fibre,avg }}=\left(l_{f} a\right)^{-1 / b} \cdot \Gamma\left(1+\frac{1}{b}\right)
$$

where $l_{f}$ is the single fibre gage length, $a$ and $b$ are Weibull scale and shape parameter and $\Gamma(x)$ is the statistical gamma function. This model has limited use in the scope of this study, since the variation of the Weibull parameters with the gage length was not considered. Furthermore, the experimental results for the single fibres show a variation of the failure stress over a certain range of gage lengths $(25-50 \mathrm{~mm})$ with constant values of failure stress above and below that range. The model proposed by Coleman exhibits decreasing failure stress with increasing gage length. The failure stress approaches zero as the gage length approaches infinity and as the gage length approaches zero, the strength approaches infinity. The experimental results obtained show two asymptotic values of strength for short and long gage lengths which contradict the model proposed. Therefore, this model was not applied to the single fibre data obtained.

Daniels [1945] used the assumptions of equal loading sharing and no fibre interaction to develop a model for a bundle consisting of a large number of fibres. He states that the variation in the breaking strain of each fibre will result in the decrease in the strength of the bundle in comparison with the strength of a single fibre. According to Daniels, this variation results in a normal distribution of the failure strength of a bundle. Daniels 
stated that the average strength of a bundle takes the following form in term of Weibull parameters and the length of the component fibres:

$$
\sigma_{\text {bundle,avg }}=\left(l_{f} a b\right)^{-1 / b} \cdot \exp \left(-\frac{1}{b}\right)
$$

In the two models introduced above, the Weibull parameters are assumed to be independent of the gage length of the fibres. However, as mentioned previously, the work of Schwartz [1984] shows that the Weibull parameters are dependent on the gage length of a single fibre.

The assumption of equal load sharing, which is the common assumption of the authors above, is one that has significant effect on the sequence of the breakage of the fibres. Equal load sharing assumes that all fibres are of the same length and therefore during deformation are under equal uniaxial stress. Once failure is initiated from the weakest link, the stress is redistributed evenly between the remaining fibres. However, this is not quite realistic since there will always be some deviation between the lengths of the fibres in a yarn even under the most careful specimen preparation. Under the uneven load sharing, the weakest link in the yarn may not be under the same uniaxial stress as the other links; therefore the failure may not be initiated from the weakest link.

Phoenix [1979] proposed a model based on a local-load-sharing rule. The model proposed by Phoenix is not presented, however, some of its findings will be briefly discussed. Phoenix found that the random slack in the fibres leads to a reduction of the 
mean strength of a yarn composed of a large number of fibres. Phoenix stated that this effect becomes quite severe when the standard deviation of the slack variation becomes a significant fraction of the mean failure strain. The model developed by Phoenix also includes the effect of the degree of twist for a yarn consisting of a large number of fibres; it also assumes that there is low friction between the fibres.

Another point worth noting is that the models proposed by Coleman [1958] and Daniels [1945] consider a variation of the of the gage length of a yarn consisting of a large number of fibres. However, experimental results in this study suggest a dependence of the strength of the yarn on the gage length as well as the number of fibres in a bundle. Phoenix's model reports an asymptotic value of the tensile strength of a yarn consisting of a large number of fibres.

Developing a new theoretical model starting from a single fibre to a yarn is beyond the scope of this study. However, by using the form of the proposed literature models and the experimental results obtained in this study, a semi-empirical relation is proposed for the relation between the failure strength of a yarn and the volume of the material under stress. The choice of relating the strength to the volume was made in order to lump the effect of the gage length and cross section into one variable. This choice is considered to be reasonable since the fibres are under uniaxial loading. Although with unequal load sharing in effect, they all may not be under the same stress but the effect of random unequal load sharing will be represented in the average failure strength values obtained as Phoenix [1979] predicted using local-load-sharing modelling. 
The decrease in the strength of the yarns with increasing specimen size can be associated with the increase of the defects in the overall volume of the material tested. Increasing the volume of the material tested will provide for a more diverse defect population. The increase in the defect population can be considered as a growth in the defect population with volume. Hence, a semi-empirical form for the relation of the failure stress to the specimen volume is proposed taking the form of a three-parameter exponential growth model where $m, n$ and $p$ are independent parameters and $V^{*}$ and $\sigma_{f}^{*}$ are the volume and the average failure stress of the material, normalised with the volume and average failure stress of the smallest single fibre specimen. The normalized volume is greater than or equal to 1 since it is normalised by the smallest specimen volume considered while the normalised stress varies between $m$ and 1 .

$$
\begin{aligned}
& \sigma_{f}^{*}=m+n \exp ^{-p V^{*}} \\
& V^{*} \geq 1 \\
& 1 \geq \sigma_{f}^{*} \geq m
\end{aligned}
$$

The parameters $m, n$, and $p$ are evaluated using the curve fitting software CurveExpert v1.3. The parameter, $m$, is the asymptotic value of the tensile strength of the material (as a fraction of the single fibre strength) as volume of the material increases. The parameters $n$ and $p$, incorporate the decrease of the tensile stress as a result of the increase in the defect population. All the parameters are non-dimensional since the independent and the dependent variables are non-dimensional.

An attempt was made to reduce the number of the parameters to two; however this did not prove to be successful, since the two-parameter form did not provide enough 
flexibility. The three parameters were evaluated and are listed in Table 6.1 along with the accuracy of fit parameter. Figure 6.1 shows the plot of the relation with the parameters listed in Table 6.1. The error bars shown are at one standard deviation.

Table 6.1 - Parameter for the relation between failure stress of Kevlar 129 and the specimen volume along with the accuracy of fit parameter

\begin{tabular}{|c|c|}
\hline Parameter & Value \\
\hline$m$ & 0.597 \\
\hline$n$ & 0.373 \\
\hline$p$ & $1.846 \times 10^{-4}$ \\
\hline $\mathrm{R}^{2}$ & 0.994 \\
\hline
\end{tabular}

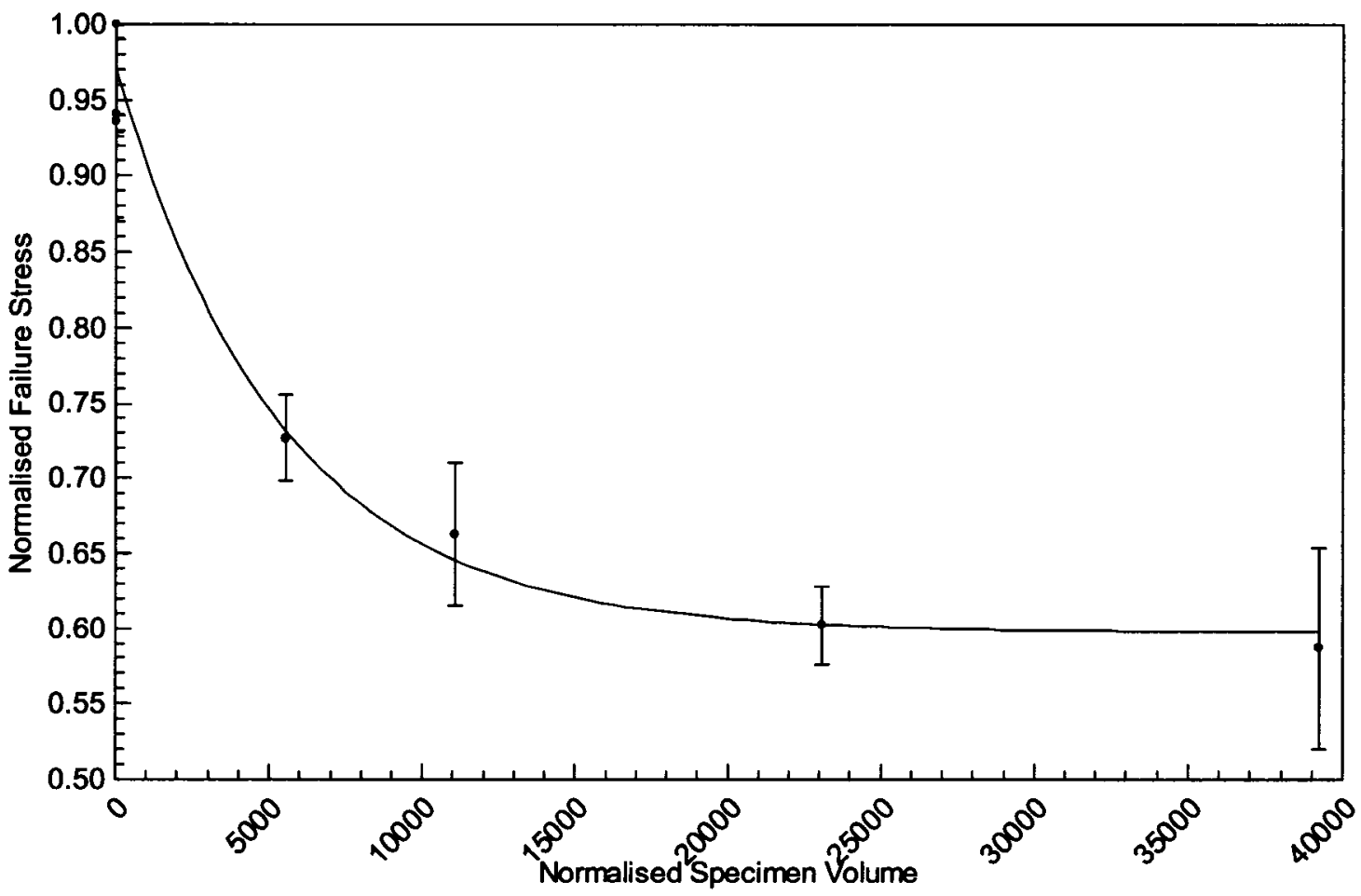

Figure 6.1 - Plot of the relation between the normalized failure stress versus normalised specimen volume along with the error bar (1 STD) 


\subsection{CONCLUSION}

Quasistatic and dynamic tensile strength of yarns previously unavailable in the literature has been evaluated. The tensile strength of some of the yarns such as, Twaron and Zylon, showed a clear response to increasing strain rate while Kevlar yarns showed little response.

The study of the scale effect showed that the strength of untwisted yarn decreases as its specimen size increases. This is in agreement with the behaviour of brittle material. A model is presented that can be used to obtain the strength of a yarn from its single fibre properties using parameters that are obtained experimentally. The information obtained in this study can be implemented into numerical models in the form of an average failure stress for a given yarn or as an average failure stress as a function of the volume of yarn under uniaxial stress.

\subsection{Future Work}

The future work for this project involves areas that require additional attention. This study provides a firm foundation to build on and to further study the variables that play into the material properties of yarns.

A detailed study on a single yarn material should be carried out in order to understand the interactions and trends in the behaviour of the yarn. By studying a single material and 
concentrating the resources, the number of repeats can be increased with a minimum of 20 repeats per parameter studied.

A study of the variation of the single fibre diameter will also provide insight in the validity of the constant circular cross section assumption for the single fibre. This information can be used to obtain more accurate evaluation of the cross sectional area as well as the failure strength. The tensile strength of a yarn can also be studied more systematically by carrying out separate studies which would focus on the effect of cross section, i.e. the number of fibres in a yarn, as well as the effect of the gage length.

A theoretical model can be developed using uneven load sharing between fibre with the introduction of some friction and twist interactions between the fibres. By observing changes in the material properties with the variation of gage length and cross section, the model can be improved and steered in the right direction. 


\subsection{REFERENCES}

Al-Mousawi, M. M., Reid, S. R., Deans, W.F., 1997, “The use of the split Hopkinson pressure bar techniques in high strain rate materials testing", Proceedings Institution of Mechanical Engineers, v. 211 (C), pp. 273-292.

Amaniampong, G., Burgoyne, C. J., 1994, "Statistical variability of the strength and failure strain of aramid and polyester yarns", Journal of Materials Science, v. 29, pp. $5141-5152$

Cheng, M., Chen, W., 2005, "Mechanical properties of Kevlar KM2 single fiber", Journal of Engineering Materials and Technology, v. 127, n. 2, pp. 197-203

Coleman, B. D., 1958, "On the strength of classical fibres and fibre bundles", Journal of the Mechanics and Physics of Solids, v. 7, pp. 60-70

Dai, S. R., Piggott, M. R., 1993, "The strengths of carbon and Kevlar fibres as a function of their length", Composites Science and Technology, v. 49, pp. 81-87

Daniels, H. E., 1945, "The statistical theory of the strength of bundles of threads", Proceedings of Royal Society of London, v. A183, pp. 405

Hertzberg, R. W., 1996, "Deformation and fracture mechanics of engineering materials", John Wiley

Huang, Y. K., Fringes, P. H., Hennes, E., 2002, "Mechanical properties of Zylon/epoxy composite", Composites: Part B, v. 33, pp. 109-115

McCartney, L. N., Smith, R. L., 1983, "Statistical theory of the strength of fiber bundles", Journal of Applied Mechanics, v. 50, pp. 601-608

Mulkern, T. J., Raftenberg, M. N., 2002, "Kevlar KM2 yarn and fabric strength under quasi-static tension", Army Research Laboratory, ARL-TR-2865, AD-A408883

Naik, N. K., Madhavan, V., 2000, "Twisted impregnated yarns: elastic properties", Journal of Strain Analysis, v. 35, n. 2, pp. 83-91

Pan, N., Hua, T., Qiu, Y., 2001, "Relationship between fiber and yarn strength", Journal of Textile Research, v. 71, n. 11, pp. 960-964

Phoenix, S. L., 1979, "Statistical theory for the strength of twisted fiber bundles with application to yarn and cables", Journal of Textile Research, v. 49, pp. 407-423 
Schwartz, P., Wagner, H. D., Phoenix, S. L., 1984, "A study of statistical variability in the strength of single aramid filaments", Journal of Composite Materials, v. 18, pp. 312-338

Shim, V. P. W., Lim, C. T., Foo, K. J., 2001, "Dynamic mechanical properties of fabric armour", International Journal of Impact Engineering, v. 25, pp. 1-15

Wang, B., Jin, Z., Qiu, Z., Liu, M., 2001, "Experimental study of basic properties of PBO organic fiber", Journal of Xi'an Jiaotong University, v. 35, n. 11, pp. 1189-1192

Watson, A. S., Smith, R. L., 1985, "An examination of statistical theories for fibrous materials in the light of experimental data", Journal of Materials Science, v. 20, pp. 3260-3270

Weinberg, A., Schwartz, P., 1987, "Twist effects on the mechanical behaviour of Kevlar 29/epoxy strands", Journal of Materials Science Letters, v. 6, pp. 832-834

Xia, Y., Wang, Y., 1998, "The effect of strain rate on the mechanical behaviour of Kevlar fibre bundles: an experimental and theoretical study", Composites Part $A$, v. 29A, pp. 1411-1415

Yang, H. H., 1993, “Kevlar Aramid Fiber”, Chichester, UK: John Wiley

Yue, C. Y., Sui, G. X., Looi, H. C., 2000, "Effects of heat treatment on the mechanical properties of Kevlar 29 fibre", Composites Science and Technology, v. 60, pp. 421-427 